\title{
Value Relevance of Integrated Reporting using a Novel Approach: Comparative Cross Country Evidence of Mandatory and Voluntary Implementers
}

\author{
Author \\ FJ MOHAIMEN
}

A thesis submitted in fulfillment of the requirements for the degree of Doctor of Philosophy in Accounting at the School of Accounting and Commercial Law of Victoria University of Wellington 


\title{
Thesis Supervisors
}

\author{
Dr. Martien Lubberink
}

Associate Professor

School of Accounting and Commercial Law

Victoria University of Wellington

\section{Dr. Ainul Islam}

Senior Lecturer

School of Accounting and Commercial Law

Victoria University of Wellington 


\section{Acknowledgement}

I express my sincere gratitude to my supervisors Dr. Martien Lubberink and Dr. Ainul Islam for their support, guidance, advice and patience throughout my $\mathrm{PhD}$ without which, I could not have completed this thesis. Their guidance have been invaluable in this journey and I appreciate their support immensely.

I thank the Victoria University of Wellington and especially the School of Accounting and Commercial Law for giving me the opportunity to join this prestigious school as a $\mathrm{PhD}$ student and also for recruiting me as an Assistant Lecturer. I sincerely appreciate the support of the school and the university and am grateful for the trust they have shown in me by appointing me as a member of the staff.

I especially thank Dr. Ian Eggleton and Dr. Carolyn Fowler who as head of schools, have always supported my professional development and provided me every opportunity to develop my skills and knowledge.

I thank the RW Steele Scholarship foundation for providing me their prestigious award which in addition to being a great financial help, was also a great source of motivation.

Finally, I thank my family whose support throughout this time have been absolute. From the bottom of my heart, I thank my wife who has constantly supported me and motivated me. I express my gratitude to my parents who has always been a steadfast pillar on which I can lean on and I thank my siblings who have always motivated me. 


\section{Declaration}

I hereby that declare that this thesis is my own and original work. I affirm that I completed this work during my candidature as a $\mathrm{PhD}$ thesis student at the School of Accounting and Commercial Law of the Victoria University of Wellington. I declare that this thesis, either whole or in part, has not been submitted for consideration of any other degree or award in any other institution. To the best of my knowledge this thesis contains no materials previously published or written by any other person or institutions except where due references have been made.

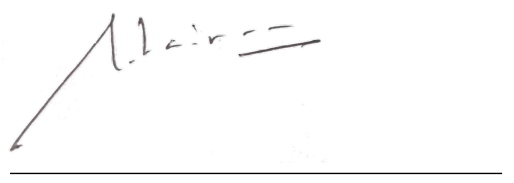

\section{FJ Mohaimen}

PhD Candidate

Victoria University of Wellington 


\title{
Value Relevance of Integrated Reporting using a Novel Approach:
}

\section{Comparative Cross Country Evidence of Mandatory and Voluntary}

\author{
Implementers
}

\begin{abstract}
This thesis examines the value relevance of accounting information under integrated reporting (IR) in a comparative mandatory and voluntary setting. A meta review is conducted of all published work focusing on integrated reporting since 2011, which provides detailed insight into the gaps in the IR literature. Multiplicative log-linear model is used in measurement, which is a novel technique that mitigates the shortcomings of traditional value relevance models. The findings show that value relevance of summary accounting information increases after the implementation of IR in the mandatory setting. In the voluntary setting, market effect and the existing reporting paradigm effect the value relevance of accounting information under IR. If the market is large and existing reporting requirements are robust voluntary adoption of IR has minimal to no effect. However, in smaller markets with less rigorous reporting environment, adoption of IR does result in increased value relevance of accounting information. Compared to traditional models, the multiplicative model provides estimates that are more stable over time and shows better explanatory power. Overall, the findings of this thesis show that capital providers value the information content of IR under specific circumstances. This thesis contributes to the IR and value relevance literature by providing the first comparative cross-country evidence of the effect of IR in the change in value relevance of reported accounting information. It provides policy relevant input to the standard setters of IR by demonstrating the effect of IR in the decision usefulness of summary accounting information. The thesis further provides robust evidence of the efficacy of using the multiplicative log-linear model in measuring value relevance instead of the traditional linear additive models.
\end{abstract}

Keywords: Integrated reporting, value relevance, multiplicative model, log linear analysis 


\section{Table of Contents}

Thesis Supervisors $\quad$ i

Acknowledgement

Declaration $\quad$ iii

$\begin{array}{ll}\text { Abstract } & \text { iv }\end{array}$

$\begin{array}{lll}\text { Chapter } 1 & \text { Introduction } & 1\end{array}$

1.1 General Introduction $\ldots \ldots \ldots \ldots \ldots$

1.2 Research motivation . . . . . . . . . . . . . . . . . 2

1.3 Research question . . . . . . . . . . . . . . . . . 4

1.4 Multiplicative model . . . . . . . . . . . . . . . 5

1.5 Research setting . . . . . . . . . . . . . . . . . 8

1.6 Summary of key findings . . . . . . . . . . . . . . . 10

1.7 Contribution of the research . . . . . . . . . . . . . . . . . . 10

1.8 Overview of the remaining chapters $\ldots \ldots \ldots \ldots \ldots$

$\begin{array}{lll}\text { Chapter } 2 & \text { Integrated Reporting } & 14\end{array}$

2.1 Introduction . . . . . . . . . . . . . . . . . . . . . 14

2.2 History of IR . . . . . . . . . . . . . . . . . . . . . . . 14

2.3 IR Framework . . . . . . . . . . . . . . . . . . . . . . . . . 19

2.3.1 Fundamental Concepts . . . . . . . . . . . . . . . . 20

2.3.2 Guiding Principles . . . . . . . . . . . . . . . 22

2.3.3 Content Elements . . . . . . . . . . . . . . . . . . . 23

2.4 Chapter summary . . . . . . . . . . . . . . . . 23

2.5 Appendix for Chapter $2 \ldots \ldots \ldots \ldots \ldots$

Chapter 3 Literature on IR: A meta review 29

3.1 Introduction . . . . . . . . . . . . . . . . . . . . . . . . 29

3.2 SLR framework . . . . . . . . . . . . . . . . . . . 30

3.3 Analysis of literature . . . . . . . . . . . . . . 34

3.3 .1 Jurisdiction . . . . . . . . . . . . . . . . . 34 
3.3.2 Country of research . . . . . . . . . . . . . . 35

3.3 .3 Organization focus . . . . . . . . . . . . 35

3.3.4 Focus of Integrated Reporting (IR) literature . . . . . . . . . . . . . . 36

3.3.5 IR Framework and models . . . . . . . . . . . . . . . . 36

3.3.6 Professional background . . . . . . . . . . . . . . . 37

3.3 .7 Theory distribution $\ldots \ldots \ldots$. . . . . . . . . . . . . . 37

3.3 .8 Methodology . . . . . . . . . . . . . . . 38

3.3 .9 Research method . . . . . . . . . . . . . . . . . 38

3.3 .10 Research with most impact . . . . . . . . . . . . . . . . . . . 39

3.4 Summary of meta review findings . . . . . . . . . . . . . . 40

3.5 Appendix for Chapter $3 \ldots \ldots \ldots$. . . . . . . . . . . . . 43

Chapter 4 Value relevance of accounting information $\quad 57$

4.1 Introduction . . . . . . . . . . . . . . . . 57

4.2 Value relevance of accounting information: Proponents and Critiques . . . . . . 58

4.3 Value relevance of IR . . . . . . . . . . . . . . . . . . . . . . . . 59

4.4 Chapter summary . . . . . . . . . . . . . . . . . . . . 61

Chapter 5 Research framework and hypotheses development 62

5.1 Introduction . . . . . . . . . . . . . . . . . . 62

5.2 Theoretical framework . . . . . . . . . . . . . . . 63

5.3 Hypotheses development . . . . . . . . . . . . . . 66

5.3 .1 Mandatory setting . . . . . . . . . . . . . . . . 67

5.3 .2 Voluntary setting . . . . . . . . . . . . . . . 68

5.4 Chapter summary . . . . . . . . . . . . . . . . . . . . . . 69

$\begin{array}{lll}\text { Chapter } 6 & \text { Research design and data } & 71\end{array}$

6.1 Introduction . . . . . . . . . . . . . . . . . . . 71

6.2 Research design . . . . . . . . . . . . . . . . . . . . 72

6.3 Sample and Data . . . . . . . . . . . . . . . . . 74

6.3 .1 Mandatory setting . . . . . . . . . . . . . . . . . 74

6.3 .2 Voluntary Setting . . . . . . . . . . . . . . . . 75

$6.3 .2 .1 \quad$ Japan . . . . . . . . . . . . . . 76

6.3 .2 .2 Europe ..................... 77

6.4 Chapter summary . . . . . . . . . . . . . . . . . . . . 78

6.5 Appendix for Chapter $6 \ldots \ldots \ldots \ldots$

$\begin{array}{lll}\text { Chapter } 7 & \text { Discussion of results - Mandatory setting } & 88\end{array}$

7.1 Introduction . . . . . . . . . . . . . . . . . . . 88

7.2 Main results . . . . . . . . . . . . . . . . 88 
7.2.1 Variation in type of industry $\ldots \ldots \ldots 90$

7.2.2 Effect of reporting quality . . . . . . . . . . . . . 91

7.2 .3 Chow Test . . . . . . . . . . . . . . . . . 92

7.2.4 Difference-in-difference analysis . . . . . . . . . . . . . . 92

7.3 Sensitivity Analysis . . . . . . . . . . . . . . . . . . 93

7.4 Summary of findings . . . . . . . . . . . . . . . . . . 94

7.5 Appendix for Chapter $7 \ldots \ldots \ldots \ldots$

$\begin{array}{lll}\text { Chapter } 8 & \text { Discussion of results - Voluntary setting } & 108\end{array}$

8.1 Introduction . . . . . . . . . . . . . . . . . . . 108

8.2 Main results - Japan . . . . . . . . . . . . . . . . . . 108

8.2 .1 Chow test . . . . . . . . . . . . . . . . . . . 109

8.2.2 Difference-in-difference analysis . . . . . . . . . . . . . . 110

8.2 .3 Sensitivity analysis . . . . . . . . . . . . . . . . . 110

8.3 Main results - Europe . . . . . . . . . . . . . . . . . . 111

8.3.1 Results for Europe including UK . . . . . . . . . . . . . . . . . . 111

8.3.1.1 Chow test . . . . . . . . . . . . . . 111

8.3.1.2 Difference-in-difference analysis . . . . . . . . . . 112

8.3 .2 Sensitivity analysis . . . . . . . . . . . . . . . . 112

8.3.3 Results for Europe excluding UK . . . . . . . . . . . . . . . . . . 112

8.3.3.1 Chow test . . . . . . . . . . . . . . 113

8.3.3.2 Difference-in-difference analysis . . . . . . . . . . 114

8.3.4 Sensitivity analysis . . . . . . . . . . . . . . . . . . . 114

8.4 Summary of findings . . . . . . . . . . . . . . . . . 115

8.5 Appendix for Chapter $8 \ldots \ldots \ldots \ldots$. . . . . . . . . . . . . . . . . .

$\begin{array}{lll}\text { Chapter } 9 & \text { Conclusion of thesis } & 137\end{array}$

9.1 Introduction . . . . . . . . . . . . . . . . . . . 137

9.2 Summary of findings . . . . . . . . . . . . . . . . . . 138

9.3 Research contributions . . . . . . . . . . . . . . . . . . . . . 139

9.4 Research limitations . . . . . . . . . . . . . . . . . . . . . . . . . 140

9.5 Future research opportunities . . . . . . . . . . . . . . . . 141

$\begin{array}{lr}\text { Appendices } & 149\end{array}$ 


\section{List of Tables}

3 Literature on IR: A meta review 29

3.1 Theory Distribution . . . . . . . . . . . . . . . . . . . . 49

3.2 Most Total Citations . . . . . . . . . . . . . . . . . . . 53

3.3 Most Total Citations - Continued . . . . . . . . . . . . . . . . . . 54

3.4 Most Citations per Annum . . . . . . . . . . . . . . . 55

3.5 Most Citations per Annum - Continued . . . . . . . . . . . . . 56

6 Sample and Data $\quad \mathbf{7 4}$

6.1 Descriptive Statistics. - South Africa (Unlogged data) . . . . . . . . . . . . . 80

6.2 Descriptive Statistics. - South Africa (Logged data) . . . . . . . . . . . . . . 81

6.3 Descriptive Statistics. - Japan (Unlogged Data) . . . . . . . . . . . . . . 82

6.4 Descriptive Statistics. - Japan (Logged Data) . . . . . . . . . . . . . . . . . 83

6.5 Descriptive Statistics. - Europe Combined (Unlogged data) . . . . . . . . . . . 84

6.6 Descriptive Statistics. - Europe Combined (Logged data) . . . . . . . . . . . 85

6.7 Descriptive Statistics. - Europe excluding UK (Unlogged data) . . . . . . . . . 86

6.8 Descriptive Statistics. - Europe excluding UK (Logged data) . . . . . . . . . . 87

7 Discussion of results - Mandatory setting $\quad 88$

7.1 Overall Regression Results. - South Africa . . . . . . . . . . . . . . . . . . 95

7.2 Regression Results - Financial Firms - South Africa . . . . . . . . . . . . . . 97

7.3 Regression Results - Non-Financial Firms - South Africa . . . . . . . . . . . . 99

7.4 Regression Results - Top 2012 - South Africa . . . . . . . . . . . . . . . 101

7.5 Chow Test - South Africa . . . . . . . . . . . . . . . . . . . . 103

7.6 Regression Results - Difference in Difference - South Africa . . . . . . . . . 104

7.7 Regression Results - Traditional - South Africa . . . . . . . . . . . . . 105

8 Discussion of results - Voluntary setting $\quad 108$

8.1 Overall Regression Results - Japan . . . . . . . . . . . . . . . . . . . 116

8.2 Chow Test - Japan . . . . . . . . . . . . . . . . . . . . . . . . . 118

8.3 Regression Results - Difference-in-Difference - Japan . . . . . . . . . . . . . 119 
8.4 Regression Results - Traditional - Japan . . . . . . . . . . . . . . . . . 120

8.5 Overall Regression Results - Europe Combined . . . . . . . . . . . . . . . . 123

8.6 Chow Test - Europe Combined . . . . . . . . . . . . . . . . . . . 125

8.7 Regression Results - Difference in Difference - Europe Combined . . . . . . . 126

8.8 Regression Results - Traditional - Europe Combined . . . . . . . . . . . . . . . 127

8.9 Overall Regression Results - Europe excluding UK . . . . . . . . . . . . . 130

8.10 Chow Test - Europe excluding UK . . . . . . . . . . . . . . . 132

8.11 Regression Results - Difference in Difference - Europe excluding UK . . . . . 133

8.12 Regression Results - Traditional - Europe excluding UK . . . . . . . . . . . . . 134 


\section{List of Figures}

2 Integrated Reporting $\quad 14$

2.1 Value created by $I R \ldots \ldots \ldots \ldots \ldots$. . . . . . . . . . . . . . 24

2.2 Capitals in IR . . . . . . . . . . . . . . . . 25

2.3 Value creation process in IR . . . . . . . . . . . . . . . . . 26

2.4 IR Guiding Principles . . . . . . . . . . . . . . . . . . . . . . . . 27

2.5 IR Content Elements . . . . . . . . . . . . . . . . . . . . . . 28

3 Literature on IR: A meta review 29

3.1 Jurisdiction - IR Literature . . . . . . . . . . . . . . . . . . . . . . . 43

3.2 Country of Research - IR Literature . . . . . . . . . . . . . . . . . . . . . 44

3.3 Organization Focus - IR Literature . . . . . . . . . . . . . . . . . . . . . . 45

3.4 Focus of IR Literature . . . . . . . . . . . . . . . . . . . . . . . . . 46

3.5 IR Framework and Models . . . . . . . . . . . . . . . . . . . . . . . . 47

3.6 Professional Background . . . . . . . . . . . . . . . . . . . . . 48

3.7 Theory Distribution . . . . . . . . . . . . . . . . . . . 50

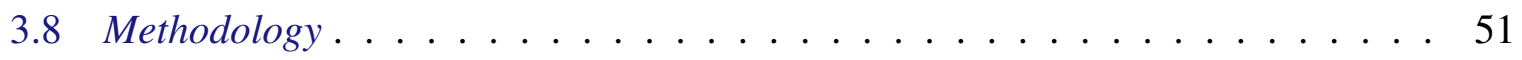

3.9 Research Method . . . . . . . . . . . . . . . . . . . . 52

7 Discussion of results - Mandatory setting $\quad \mathbf{8 8}$

7.1 Market elasticities using full sample - South Africa . . . . . . . . . . . . . . 96

7.2 Market elasticities for Financial Firms - South Africa . . . . . . . . . . . . . 98

7.3 Market elasticities for Non-Financial Firms - South Africa . . . . . . . . . . 100

7.4 Market elasticities for Firms with Recognized Reports - South Africa . . . . . . 102

7.5 Regression coefficients using traditional linear model - South Africa . . . . . . 106

7.6 Comparison of Adj.R-squared values - South Africa . . . . . . . . . . . . . . . 107

8 Discussion of results - Voluntary setting $\quad 108$

8.1 Market elasticities - Japan . . . . . . . . . . . . . . . . . 117

8.2 Regression coefficients using traditional linear model - Japan . . . . . . . . . . 121

8.3 Comparison of Adj.R-squared values - Japan . . . . . . . . . . . . . . . . . . 122 
8.4 Market elasticities - Europe Combined . . . . . . . . . . . . . . . . . . 124

8.5 Regression coefficients using traditional linear model-Europe Combined . . . 128

8.6 Comparison of Adj.R-squared values - Europe Combined . . . . . . . . . . . 129

8.7 Market elasticities - Europe excluding UK . . . . . . . . . . . . . . . . . . 131

8.8 Regression coefficients using traditional linear model-Europe excluding UK . 135

8.9 Comparison of Adj.R-squared values - Europe excluding UK . . . . . . . . . 136 


\section{List of Abbreviations}

A4S Accounting for Sustainability

GDP Gross Domestic Product

GRI Global Reporting Initiative

IFRS International Financial Reporting Standards

IIRC International Integrated Reporting Council

IR Integrated Reporting

JSE Johannesburg Stock Exchange

OLS Ordinary least squares

SLR Structured Literature Review

TSE Tokyo Stock Exchange

UK United Kingdom 


\section{Chapter 1}

\section{Introduction}

\subsection{General Introduction}

The aim of this thesis is to address the question whether implementation of Integrated Reporting (IR) results in increased value relevance of reported accounting information. Empirical analysis, through a novel modelling technique is used to analyze whether or not the implementation of IR has an impact in the value relevance of the reported accounting information. The key idea being, if IR is value relevant, then it is contributing towards increasing the usefulness of reported accounting information.

IR is a new trend in financial reporting, which promotes the idea of integrating financial and non-financial information in the company's report with the intended purpose of providing the providers of financial capital with more relevant and useful information about the performance and prospects of the organization (IIRC, 2013). The International Integrated Reporting Council (IIRC), key standard setter of IR, outlined the aim of IR in the Integrated Reporting Framework as to improve the quality of information available to providers of financial capital 
to enable a more efficient and productive allocation of capital (IIRC, 2013). The IIRC promotes the idea of integrated thinking and suggests reporting on six different capitals such as financial, manufactured, intellectual, human, social and relationship, and natural capital and their interdependencies (IIRC, 2013). Integrated reporting has gained traction in the global corporate reporting community in the past decade and the IIRC have undertaken significant efforts to implement integrated reporting worldwide.

However, before switching to such a different reporting system, which can be a costly and resource-consuming endeavour, it is important to understand how value relevant integrated reporting is to investors and capital markets. That is what is being tested empirically in this thesis. If integrated reporting is providing useful additional information to the providers of the financial capital, not provided by existing reporting practices, then the information presented under the IR approach should be more value relevant.

\subsection{Research motivation}

Examining the value relevance of IR and comparing between mandatory and voluntary implementers is important for multiple reasons. First, research into value relevance provides useful insights to the standard setters about the reliability and relevance of presented accounting information. It operationalizes key dimensions of the underlying theory as adopted by the standard setters when setting the reporting rules in order to assess the relevance of reported accounting amounts (Barth, Beaver, and Landsman, 2001). IR was established with the idea of providing information to the investors and stakeholders in an integrated form, which will provide additional value and thus make information more decision useful when compared to traditional financial reporting. However, to this date there is very little empirical evidence, 
which establishes the decision usefulness of accounting information under IR. There are some papers that has looked into the value of implementing IR (Barth, Cahan, Chen, and Venter, 2017, Baboukardos and Rimmel, 2016, etc.), but the evidence to this date is sparse. Without empirical evidence to establish otherwise, IIRC's claim that IR adds additional value and decision usefulness cannot be substantiated. This thesis, by looking into the value relevance of IR, provides valuable insights to the IIRC about the enhancement or lack thereof of accounting information under IR. This can help identify the possible strengths and weaknesses of IR, which will help in determining the strategic position of IR and IIRC going forward.

Second, there is considerable disagreement between IIRC and other academics and interested bodies regarding the actual value of implementing IR (Elkington, 2009, Milne and Gray, 2013, Flower, 2015, etc.). Such differences are difficult to mitigate without proper evidence. This value relevance research, by showing the change in the decision usefulness of accounting information before and after implementation of IR, can help mitigate some of those differences by providing actual documented evidence of the effect of implementing IR. Analysis of the value relevance of IR will demonstrate how implementation of IR has effected the usefulness of reported information and thus establish a defendable case for one side or other.

Last, existing literature shows that in implementing new accounting and reporting rules, there is a difference in derived results between voluntary and mandatory adopters. Most of these however focus on implementation of International Financial Reporting Standards (IFRS). Daske, Hail, Leuz, and Verdi (2008) show that capital market effects are most pronounced for firms that voluntarily switched to IFRS when compared to those that were mandated. Horton, Serafeim, and Serafeim (2013) on the other hand, document larger improvement in the information environment for mandatory adopters of IFRS relative to voluntary adopters and 
non-adopters. Byard, Li, and Yu (2011) find results, which suggest that mandatory IFRS adoption improves analysts' information environment only when the changes mandated by IFRS are substantial and rigorously enforced. To this date, there is no research that looks into the difference in derived benefits between voluntary and mandatory implementers of IR. This thesis addresses this issue and analyzes the value relevance of IR for a sample of mandatory and voluntary implementers. This will provide further insight for the standard setters as well as regulatory bodies when deciding whether to mandate IR or not.

\subsection{Research question}

The key question this thesis aims to address is: what is the actual value of implementing IR and is it relevant for capital providers? IR, since its introduction, have received mixed responses from the corporate and the academic community. IIRC have taken an aggressive stance in popularizing IR worldwide and have been received positively in many countries. Johannesburg Stock Exchange (JSE) have mandated the use of IR and big four audit firms such as EY and $\mathrm{PwC}$ have supported its implementation. The voluntary implementation of IR have also been on the rise over the past few years (IIRC, 2014). However, for all the support IR has garnered, it has received significant criticisms from many authors and critical theorists. The critics have argued that IR have veered away from its original goal of ensuring sustainable accounting practices (Brown and Dillard, 2014) and some have marked IR as a complete failure (Flower, 2015). These mixed responses surrounding IR is suggestive of uncertainties surrounding the value of actually implementing IR. This prompts the question about whether IR is actually value relevant to the capital providers and subsequently other stakeholders. This thesis focuses on this question and analyzes the value relevance of IR on a sample of mandatory and voluntary implementers. 


\subsection{Multiplicative model}

This research uses a novel multiplicative modelling technique developed by Lubberink and Willett (2020) which proposes to mitigate the shortcomings of existing linear additive models used in the value relevance literature. The use of this novel model is based on two assumptions. First assumption being that market values and accounting values are measured on ratio scales and market-accounting relations is invariant to changes in these scales. Second assumption being that accounting values are generated by proportional growth and decay processes (Lubberink and Willett, 2020). By using Cauchy's mathematical theory of functionals (Cauchy, 1821), Lubberink and Willett demonstrate that under the first assumption, it is implied that the relationship between market values and fundamental accounting variables follow the power law and it is multiplicative. Using Gibrat's law (Gibrat, 1931) the author's demonstrate that the second assumption implies that accounting variables are approximately distributed according to log-normal law. (Lubberink and Willett, 2020).

Given the log-normal distribution, under the multiplicative model the variables are transformed by taking the logs of their absolute values. By comparing the Ordinary least squares (OLS) estimated coefficients from the regression between market values and fundamental accounting values for both multiplicative and linear models, Lubberink and Willett demonstrate that the market-accounting relation has the form of multiplicative power law. By comparing the histograms and P-P plots of both unlogged and logged data and by using the Lilliefors statistic to measure the maximum distance that the estimated cumulative function of the data reaches from the Gaussian distribution function, the authors demonstrate that the distribution of market values and accounting variables are log-normal (Lubberink and Willett, 2020). 
Comparison of distributional properties of unlogged accounting variables show that the variables over time are often not normally distributed and thereby does not meet the requirements of Gauss-Markov theorem and thus does not satisfy the criteria of applying OLS. This results in coefficients derived under traditional additive linear models to be misspecified. Wheres the logged variables used in the multiplicative models are almost always normally distributed and thereby satisfies the criteria of Gauss-Markov theorem and allows for use of OLS. Since the model is not additive, the coefficient estimates derived from the model are interpreted as elasticities on a scale of one. The closer the coefficients to one in the multiplicative model, the more they explain the changes in the dependent variables.

Taken together, the findings of Lubberink and Willett (2020) demonstrate that it is valid to assume to the linear statistical model when the variables are transformed into logs and Gauss-Markov assumptions can be reliably applied in the multiplicative model. Further, the multiplicative model provides estimates that are scale free and provides results that are easier to interpret and exhibit much less volatility compared to traditional additive linear models. Comparison of regression results by Lubberink and Willett show that the multiplicative model provides estimates that are significantly more consistent and show greater explanatory power when compared to traditional linear models.

In analysing the relationship between market values and book values, existing research show that book values can be considered unbiased estimators of market value (Ohlson, 1995, Penman, 1992). Disintegrating the ending book value into its essential components provides the beginning book value, earnings and dividends (Lubberink and Willett, 2020). The argument here is that if accounting information is value relevant and book value is an unbiased estimator of market value then the summed coefficients of the book value components from the regression 
with market value should be close to 1 . This is consistent with the findings of Penman (1992), Ohlson (1995), that book value contributes unit to unit to market value. This would indicate that book value and its components are value relevant when determining market value.

However, contrary to the notion put forward by Penman (1992), Ohlson (1995), existing literature does not demonstrate that the market to book ratios are exactly one (Lubberink and Willett, 2020). Lubberink and Willett explain this by showing that the intercept of book value in the regression of market value to book value components tracks the market to book ratio almost perfectly. This explain why market to book ratios are not exactly one in all circumstances. An argument made in this thesis is that value relevance of accounting information can be effected by exogenous factors. In theory, if implementation of IR contributes to the greater reliability of accounting information for the purpose of decision making for the capital providers, then it can be argued that after implementation of IR value relevance of accounting information would increase and as per the multiplicative model, will be closer to one in the after IR period. This can be another explanation of the fact that why market to book ratios do not exactly equal to one in all circumstances and why exogenous factors play a role.

The multiplicative model as demonstrated by Lubberink and Willett (2020) and in this research show this by showing the summed coefficients of the book value components in the regression with market value. The multiplicative model show that when accounting information is value relevant, the summed coefficients of the book value components approach one. Which indicates that book value can explain almost all the movements in market value if accounting information is value relevant. 
This research uses this multiplicative model and demonstrates the efficacy of the notion that book value coefficients will explain the movements in market value. The multiplicative model demonstrates that implementation of IR results in increased value relevance of accounting information as the summed coefficients of book value, earnings and dividends are higher and approach closer to one under specific circumstances where implementation of IR increases the value relevance of accounting information.

\subsection{Research setting}

Previous studies have been done to determine the value of IR to the capital market and financial capital providers (Baboukardos and Rimmel, 2016, Barth, Cahan, Chen, and Venter, 2016, etc.). Baboukardos and Rimmel (2016) examine South African companies and using a linear price level model, find a sharp increase in the earnings valuation coefficient and a decline in the value relevance of net assets. Barth et al. (2016) also examine South African companies and show that IR quality is connected with lower bid-ask spreads, higher Tobin's Q and higher expected cash flows. Some other papers have looked into the market effects of IR.

This thesis contributes to this existing literature by using a new modelling technique that has not been used in the related literature to test the value relevance of IR and by providing a comparative cross evidence between mandatory and voluntary settings.

Mandatory setting refers to the case where implementation of IR have been mandated through regulation. Data from listed companies in the JSE of South Africa is used for the mandatory setting, which is as of yet, the only exchange to mandate IR for all listed companies. This provides a unique opportunity to measure the value relevance of IR in a mandatory setting because all companies listed in the JSE were required to implement IR in the same year. 
Voluntary setting is used for the case where implementation of IR has not been mandated but organizations have voluntary chosen to implement IR. For the voluntary setting, data of the listed companies in Tokyo Stock Exchange (TSE) from Japan and relevant stock exchanges in Europe are used. Japan is chosen as TSE has a high volume of early voluntary implementers of IR with about 140 listed companies implementing IR in the year after the IR framework was officially issued. TSE thus provides a good spread of source of information. Europe is considered as one uniform block and data of voluntary implementers spread across Europe are collected and combined together.

The tests for measurement of value relevance are conducted empirically by determining the relationship between reported information under IR and stock market prices. Traditionally, value relevance has been measured in the literature using linear scaled models (Barth, Li, and McClure, 2017, Barth, Beaver, and Landsman, 2001, etc.). However, as Lubberink and Willett (2020) shows, the market-book relation takes the form of power law ${ }^{1}$ and the distributions of fundamental accounting variables such as earnings are close to being jointly log normal. ${ }^{2}$ Therefore, following Lubberink and Willett (2020), a multiplicative log-normal transformation model is used to determine the value relevance of reported accounting information under IR. The analysis is conducted by using the Fama and MacBeth (1973) yearly regression and tracing the change in the regression coefficients. As multiplicative regression models are used, the elasticities of the accounting variables in the models are used as measure for value relevance. A Chow test Chow (1960) is also applied to determine structural break within our data. Addi-

\footnotetext{
${ }^{1}$ The relationship between the variables is multiplicative instead of being linearly additive

${ }^{2}$ Continuous probability distribution of the logarithm of the variables are normally distributed
} 
tionally, difference in difference analysis is done to further provide evidence of robustness of the findings.

\subsection{Summary of key findings}

The findings of this thesis show that the overall value relevance of accounting information increases after the implementation of IR mandatory setting. This suggests that investors and capital providers consider the information content of IR to be relevant when implementation is mandated. The results are similar for both financial and non-financial firms and also robust in terms of the quality of the integrated report as prepared by different corporations. The Chow test shows a significant structural break in the value of the coefficients of different accounting variables between before and after IR implementation periods. This provides additional evidence towards the validity of the findings.

In the voluntary setting, the findings show mixed results. Evidence suggest that in the voluntary setting market effects and existing reporting regime plays a moderating role. If the market is large and existing reporting environment is well developed, then implementation of IR has a negligible effect as evidenced by the results from Japan. However, in smaller markets with less rigorous reporting regime, implementation of IR results in increased value relevance of accounting information, as evidenced by the findings from Europe excluding United Kingdom (UK).

\subsection{Contribution of the research}

Implementation of IR is a complex process, which requires compound interactions between many related parties, such as the government, securities exchanges, organizations and many other related institutions. It is an effort that consumes significant amount of resources in the 
form of time and money. Before deciding to undertake this, it is important to understand the multifaceted implications of implementing IR. Pertaining to this issue, the contribution of this thesis is that it provides valuable insight to standard setters and interested parties by empirically demonstrating the impact of IR in enhancing the decision usefulness of accounting information in both mandatory and voluntary settings. The use of multiplicative models in this thesis mitigates the shortcomings of traditional research designs in value relevance and provides further insight into the relevance of IR to the investors and other stakeholders. The cross-country sample of this thesis provides wide generalizability and applicability. Overall, this thesis provides empirical evidence of value relevance of IR across multiple countries in both voluntary and mandatory settings using multiplicative log-linear models. The result of this thesis can be beneficial to standard setters, academics, stock exchanges, countries and companies that are deciding whether to implement IR or not.

\subsection{Overview of the remaining chapters}

\section{Chapter 2: Integrated Reporting}

Chapter 2 presents a discussion on IR and the history of its development along with a summary of the IR framework which guides all IR practices.

Chapter 3: Literature on IR - A meta review

Chapter 3 presents a meta review of all published research on IR from 2011 to 2019. Using a structured literature review framework, all existing work on IR in analyzed which provides insights into the current research practices and the gaps that remain to be analyzed. 
Chapter 4: Value relevance of accounting information

Chapter 4 presents a summary of the proponents and critiques of value relevance research and looks into research with a specific focus on value relevance of IR.

Chapter 5: Research framework and hypotheses development

Chapter 5 discusses the theoretical framework underpinning this thesis and develops the hypotheses. Separate hypotheses are developed for the mandatory and voluntary settings through the theoretical framework.

Chapter 6: Research design and data

Chapter 6 discusses the novel research design employed in this thesis, which is the multiplicative modelling technique. It further presents the sample and data for the mandatory and voluntary setting that is used in this thesis.

Chapter 7: Discussion of results - Mandatory setting

Chapter 7 presents the findings of this thesis in the mandatory of setting of JSE. The finding confirm the hypothesis that mandatory implementation of IR results in increased value relevance of accounting information.

Chapter 8: Discussion of results - Voluntary setting

Chapter 8 presents the findings of the this in the voluntary settings of TSE and Europe. The findings demonstrate that voluntary implementation of IR and its effect on the value relevance of accounting information is moderated by market effects and existing reporting environment. 
Chapter 9: Conclusion of thesis

Chapter 9 concludes this thesis and presents a summary of its finding and research contribution. This chapter also presents a discussion on the future research opportunities in IR. 


\section{Chapter 2}

\section{Integrated Reporting}

\subsection{Introduction}

This chapter provides a historical background of IR and summary of the IR framework which governs all IR practices. Before analyzing the effects of IR it is important understand how IR as a reporting paradigm developed and the key aspects of the framework that now governs. A brief historical analysis of the development of IR is provided first. That is followed by a discussion of the IR framework and the associated fundamental concepts, content elements and guiding principles.

\subsection{History of IR}

Social, environmental and sustainability reporting has a long history (Guthrie and Parker, 1989, Buhr, 2007). In the past few decades there has been considerable development and evolution in the field of financial and non-financial performance management and reporting (De Villiers, Unerman, and Rinaldi, 2014). Different systems, methods and paradigms have been proposed in the academic literature that can provide insights about management, gover- 
nance and reporting of financial and non-financial information by organizations. In this process of development of new systems of reporting and evolution of existing ones, four distinct reporting paradigms emerged, which are the balanced scorecard, the tripe bottom line reporting, sustainability reporting and most recently integrated reporting (Giovannoni and Maraghini, 2013, De Villiers et al., 2014).

Kaplan and Norton introduced the concept of balanced scorecard in 1992 with the notion that exclusive reliance on financial measurements for the purpose of organization management is insufficient (Kaplan and Norton, 1996). Kaplan and Norton argue that relying solely on financial measures, which are a lagging indicator of firm performance, sacrifices long term value creation for short term positive outcomes. The balanced scorecard was developed with the idea that it will retain the measures of the lagging indicators of financial performance and supplement those with additional measures focused on the drivers and lead indicators of future firm performance (Kaplan and Norton, 2001).

The system of balanced scorecard relies on management judgment about which financial and non-financial measures are to be included in the report (Kaplan and Norton, 1996). The novelty of balanced scorecard was in the notion of including non-financial and forward looking measures in performance reports which were not done in the then traditional financial reporting. While balanced scorecard brought in the concept of non-financial and forward looking measures of performance, it had very little to do with social, environmental and sustainability reporting. Thus it is highly unlikely that balanced scorecard can or will be used to achieve any form of integration among different reporting paradigms (De Villiers et al., 2014). 
In the attempt to include the concept of social and environmental reporting in corporate reports, in his 1997 paper, Elkington coined the term triple bottom line, which refers to a company reporting on their economic, social and environmental performance (Elkington, 1997). The triple bottom line provided a novel method of reporting on the concept of social and environmental reporting along with financial performance (Elkington, 1997). This form of reporting gained prominence in the late 1990's with the notion that it can provide valuable information about non-financial social and environmental indicators in addition to the information pertaining to the indicators of financial performance of firms (De Villiers et al., 2014).

The concept of social and environmental reporting evolved into what is now known as sustainability reporting. The idea is that by reporting on the financial, social, environmental and governance performance of an organization, sustainability reports can help organizations measure, understand and communicate their economic, social and environmental impact to the relevant stakeholders (GRI, 2017).

However, this concept of sustainability as well as the idea of triple bottom line reporting has been widely criticised in the literature. Critics have argued that sustainability reporting as it is practiced now has little to do with any actual sustainability information but rather is an attempt by organizations to validate the usual business practices (Milne, Tregidga, and Walton, 2009). The argument has been that the sustainability portion under triple bottom line is largely symbolic and has been heavily criticized in the literature (Brown, Dillard, and Marshall, 2006). Drawing from this strand of environmental and sustainability reporting and building on the criticism of the previous reporting regimes, the concept of IR developed with the promise of effectively integrating financial and non-financial information together (IIRC, 2013). 
In the early days of development of non-financial reporting, these reports tended to be addenda or disclosures attached to the periodic financial reports presented by the organizations (De Villiers et al., 2014). The presentation of the social and environmental information evolved over the past few decades. Instead of including non-financial information as addenda or disclosures, more organizations started to prepare stand alone reports geared towards providing social, environmental and sustainability related information (Warren, Davison, Cho, Phillips, Hageman, and Patten, 2009). However, these stand alone reports tended to become increasingly lengthy and complex in nature as a plethora of stakeholder information requirements needed to be satisfied (De Villiers et al., 2014). In response to deal with this complexity, there has been a call to action in the past decade to combine the financial and non-financial reporting together to present a more holistic picture of different aspects of the reporting organization (Hopwood, Unerman, and Fries, 2010, De Villiers et al., 2014). Breaking away from the practice of issuing stand alone social and environmental reports, the movement has been to integrate social, environmental and financial information together in one report, which will present an overall snapshot of the reporting entity (De Villiers et al., 2014). This resulted in the development of IR with the goal of achieving integration among different aspects of information presented by reporting entities.

As more organizations started reporting on sustainability matters, the need arose for voluntary reporting standards to guide the practices of such reporting. To serve the purpose of preparing specific standards and guidelines for sustainability reporting, the Global Reporting Initiative (GRI) was founded. The GRI was formulated in 1997 with the mission to develop standards of sustainability reporting which will guide organizations in preparing effective sustainability reports and enhance the credibility and comparability of sustainability reports across 
different organizations (GRI, 2017). At present, GRI continues to issue standards on sustainability reporting and provide guidance to organizations with the goal of ensuring effective communication of the organization's performance and its impact on society and environment. While the idea was GRI was to create harmony and uniformity in the social and sustainability reporting sector, in practice, the GRI guidelines tended to become increasing complex and difficult to follow uniformly. With increasing complexity in the GRI reports, the value added tended to decline from this reports for all but most technical and thorough readers of these reports (Fries, McCulloch, and Webster, 2010). This created a disconnect between the readers of these sustainability reports and the information presented in the said reports.

In 2004, the Prince of Wales established the Accounting for Sustainability (A4S) project (A4S, 2020) with the specific aim of reducing this disconnect that is experienced by the readers of sustainability reports (De Villiers et al., 2014). The project coined the term 'connected reporting' where it was expected that reporting organizations will draw the readers attention about the connectivity between financial, social and environmental information contained within the reports and developed guidelines to help organizations achieve this goal (Hopwood et al., 2010).

Over the next few years, the idea of connected and integrated reports continued to evolve and many organizations began to play a pioneering role in adopting this concept. The first noted company to issue an integrated report was Novozymes from Denmark. They issued their first report in 2002. Following them, slowly other companies started voluntarily publishing integrated reports. In 2009, the King III Code of Governance Principles was released in South Africa and it recommended that companies listed in South Africa prepare and publish integrated reports. In 2010, following the principles out lined in King III, the JSE mandated that all listed companies must issue integrated reports and thus South Africa became the first and to this 
date the only country to make integrated reporting mandatory. Following this, the Integrated Reporting Committee of South Africa was formed in May of 2010 with the aim to improve IR practices (GRI, 2017).

In August of 2010, the A4S project and GRI joined together and submitted a press release which announced the formation of the IIRC the mission of which is to "... establish integrated reporting and thinking within mainstream business practice as the norm in the public and private sectors" (A4S-GRI, 2010). IIRC defines itself as "a global coalition of regulators, investors, companies, standard setters, the accounting profession, and NGOs. The coalition is promoting communication about value creation as the next step in the evolution of corporate reporting" (IIRC, 2017). In 2011, IIRC started its two-year pilot program with a group of volunteering companies to use and exchange ideas about integrated reporting. In 2012, IIRC released its first draft outline of the Integrated Reporting Framework. And in December of 2013 IIRC published the International IR Framework which guides the integrated reporting practices today (IASPLUS, 2017).

\subsection{IR Framework}

The purpose of the IR framework is ".. to establish Guiding Principles and Content Elements that govern the overall content of an integrated report, and to explain the fundamental concepts that underpin them (IIRC, 2013). The framework defines IR as a "...a concise communication about how an organization's strategy, governance, performance and prospects, in the context of its external environment, lead to the creation of value over the short, medium and long term" (IIRC, 2013). The framework is prepared to be used by for-profit, private companies with the aim of explaining to the providers of the financial capital how the organization 
creates value for them over time (IIRC, 2013). This is suggestive of the fact that IR primarily has a investor focus and seeks to aid their decision making. Although the primary purpose of IR is to benefit the providers of the financial capital, the framework notes that it benefits other stakeholders such as employees, customers, suppliers, business partners, local communities, legislators, regulators and policy-makers who may have an interest in the organization's ability to create value over time (IIRC, 2013).

Instead of being rigid, the IR framework takes a principles based approach in establishing its policies with the aim of establishing a balance between flexibility and prescription that recognizes the wide variation in individual circumstances of different organizations while enabling a sufficient degree of comparability across organizations to meet relevant information needs (IIRC, 2013). The framework provides the fundamental concepts, guiding principles and content elements of IR but, does not prescribe specific key performance indicators, measurement methods or the disclosure of individual matters (IIRC, 2013). This passes the responsibility of exercising judgment to the prepares of the integrated report in determining what to include or not include in the report.

\subsubsection{Fundamental Concepts}

The fundamental concepts underpin and reinforce the requirements and guidance of the IR framework (IIRC, 2013). The key idea behind IR is that an integrated report needs to explain how an organization creates value over time (IIRC, 2013). The framework recognizes that value is not created by or within an organization alone. It is influenced by the external environment, created through relationships with stakeholders and is dependent on various resources (IIRC, 2013). The value that an organization creates over time in measured by the increases, decreases 
or transformations of the capitals caused by the activities and outputs of the organization (IIRC, 2013). The organization creates value for itself, which manifests in the form of return for the providers of the financial capital. It also creates value for for the other stakeholders and society at large. The capacity of an organization to create value for itself, which is the primary interest of the providers of the financial capital, is linked to the capacity to create value for other stakeholders (IIRC, 2013). This link is established by a range of activities, interactions and relationships in addition to those that are directly associated with changes in financial capital (IIRC, 2013).

[Figure 2.1 about here]

The framework notes that since value is created for different stakeholders over different time horizons and from different perspectives, it is unlikely that reporting on only one capital will satisfy the needs of all stakeholders. To address this issue, the framework identifies six different capitals that organizations depend upon to create value for their financial capital providers and for others. They are financial, manufactured, intellectual, human, social and relationship, and natural capitals. These capitals are stocks of value that are increased, decreased or transformed through the activities and outputs of the organization (IIRC, 2013).

[Figure 2.2 about here]

Central to the idea of IR is how organizations use these capitals in their business model to create value in the short, medium and long term. The framework identifies the business model as a system of transforming inputs, through its business activities, into outputs and outcomes that aims to fulfill the organization's strategic purposes and create value over the short, medium 
and long term (IIRC, 2013). The business model of an organization takes input from the various capitals, processes them through their business activities and creates outputs over short, medium and long term, that benefits the financial capital providers, other stakeholders and the environment and society at large. IR recognizes the importance of reporting on these different capitals and a thorough understanding of the business model through which the organization creates value.

[Figure 2.3 about here]

It is important to note that the framework, while highlighting the importance of reporting on different capitals, also recognizes that not all capitals are equally important for all organizations. Thus, the framework provides room for exceptions. If a capital is considered immaterial by an organization, it is not required to report it (IIRC, 2013).

\subsubsection{Guiding Principles}

The Guiding Principles underpin the preparation and presentation of an integrated report, informing the content of the report and how information is presented. These principles are applied individually and collectively for the purpose of preparing an integrated report and judgment is required from the preparer when using these Guiding Principles to prepare an integrated report (IIRC, 2013). The framework presents seven such principles that are to be adhered to in preparation of an integrated report. They are outlined in Figure 2.4.

[Figure 2.4 about here] 


\subsubsection{Content Elements}

An integrated report includes eight content elements that are fundamentally linked to each other and are not mutually exclusive (IIRC, 2013). These content elements represent information that should be included in an integrated report. However, they should not be considered as an example of the structure of the report. The framework allows for individual organizations to develop their own structure as the purpose of the report is for them to demonstrate their own value creation process.

[Figure 2.5 about here]

\subsection{Chapter summary}

Overall, IR is a new reporting paradigm that promotes the idea of reporting on six different capitals and their interdependencies and presenting the story of how an organization creates value for its financial capital providers as well as other stakeholders in the short, medium and long term. In this section, a history of the development of IR is outlined and a summary of the framework for preparing an integrated report is provided. It is important to note that IR promotes a principle based system of reporting with the primary aim of creating value for the providers of the financial capital. This thesis focuses on determining the value relevance of IR to examine if investors consider IR information to be relevant for their purposes. 


\subsection{Appendix for Chapter 2}

Figure 2.1: Value created by IR

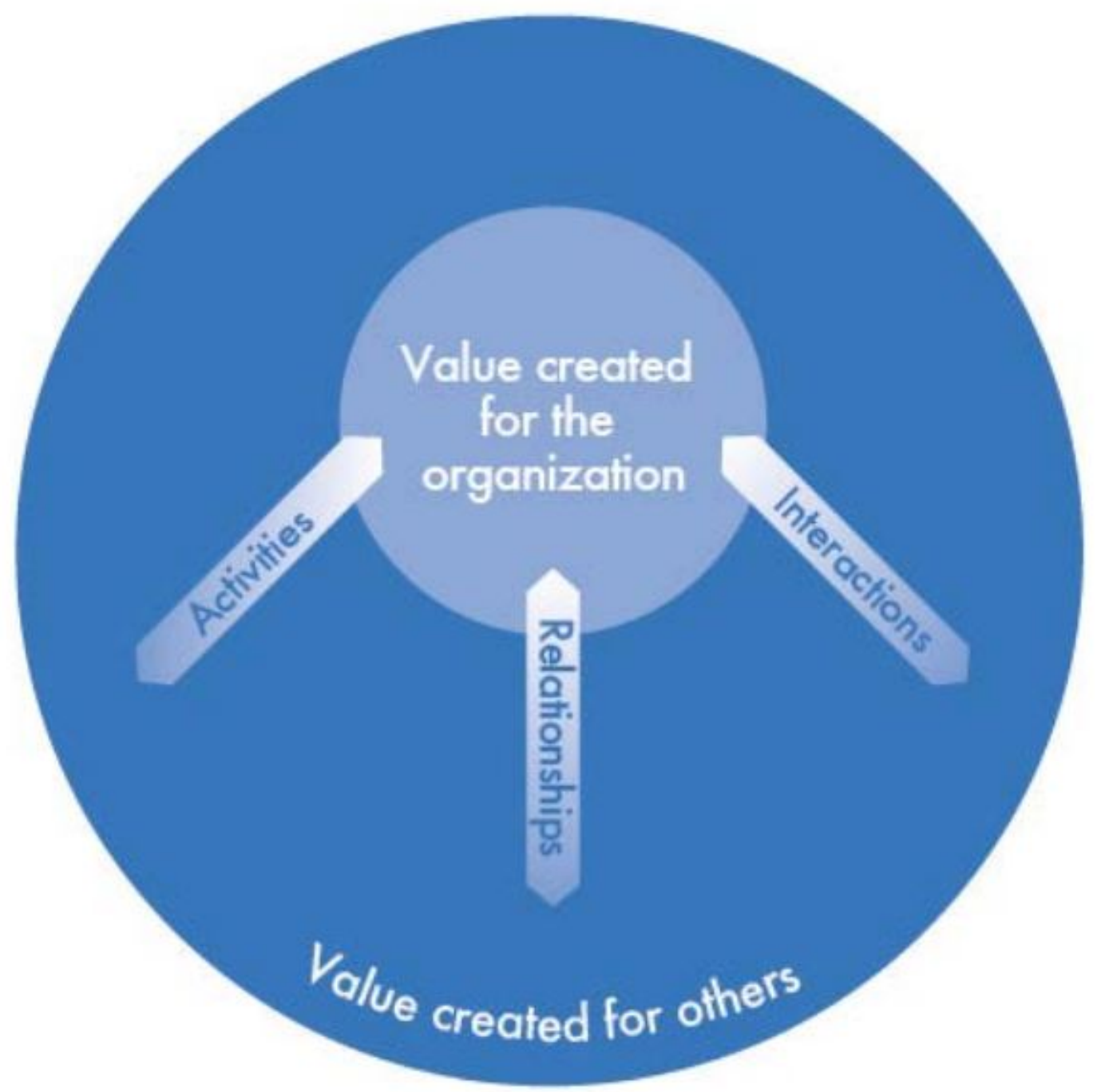

Value created for the organization and for others. source: International IR Framework 2013 (IIRC, 2013) 
Figure 2.2: Capitals in IR

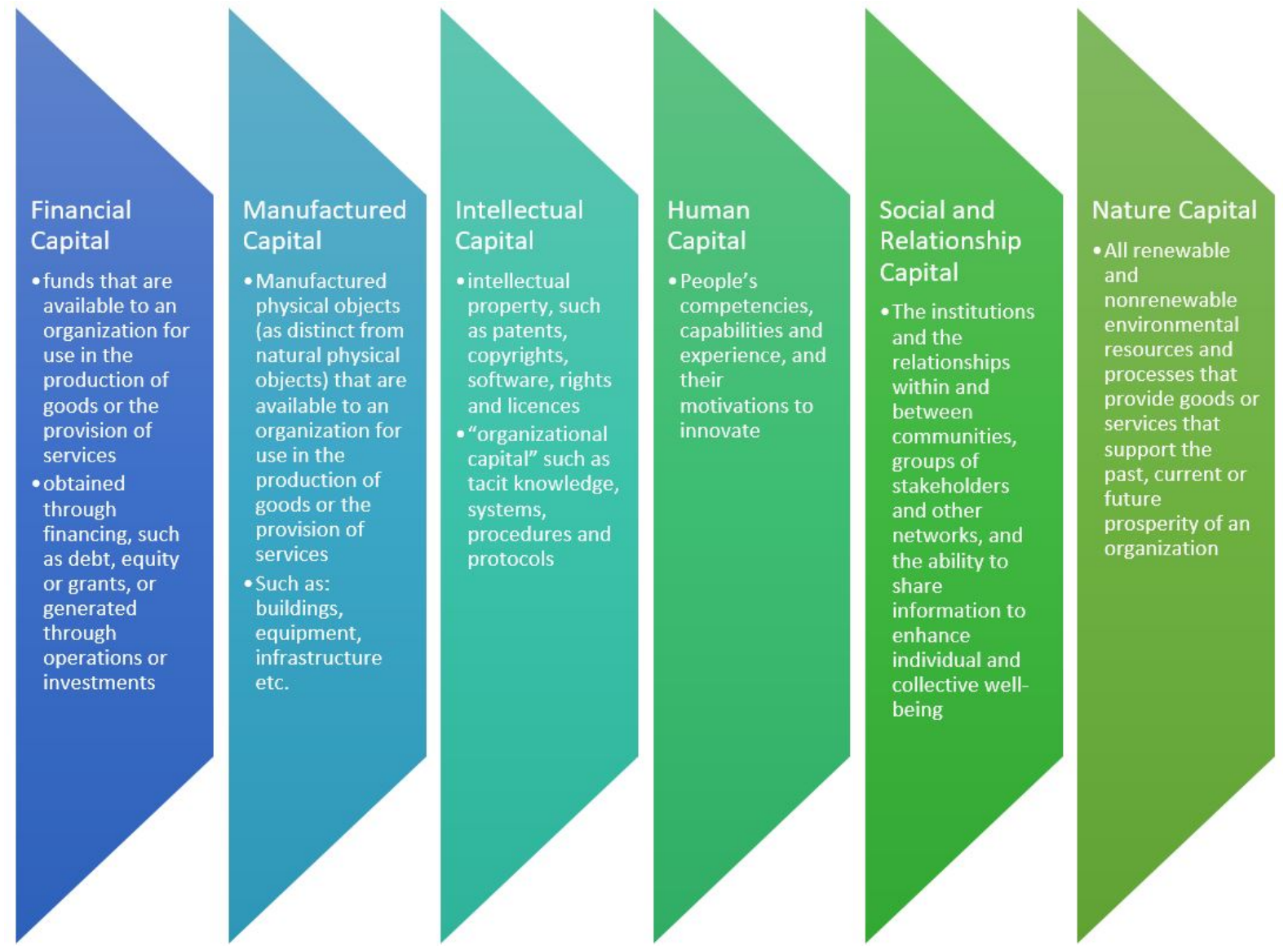

Capitals in IR. source: adapted from International IR Framework 2013 (IIRC, 2013) 
Figure 2.3: Value creation process in IR

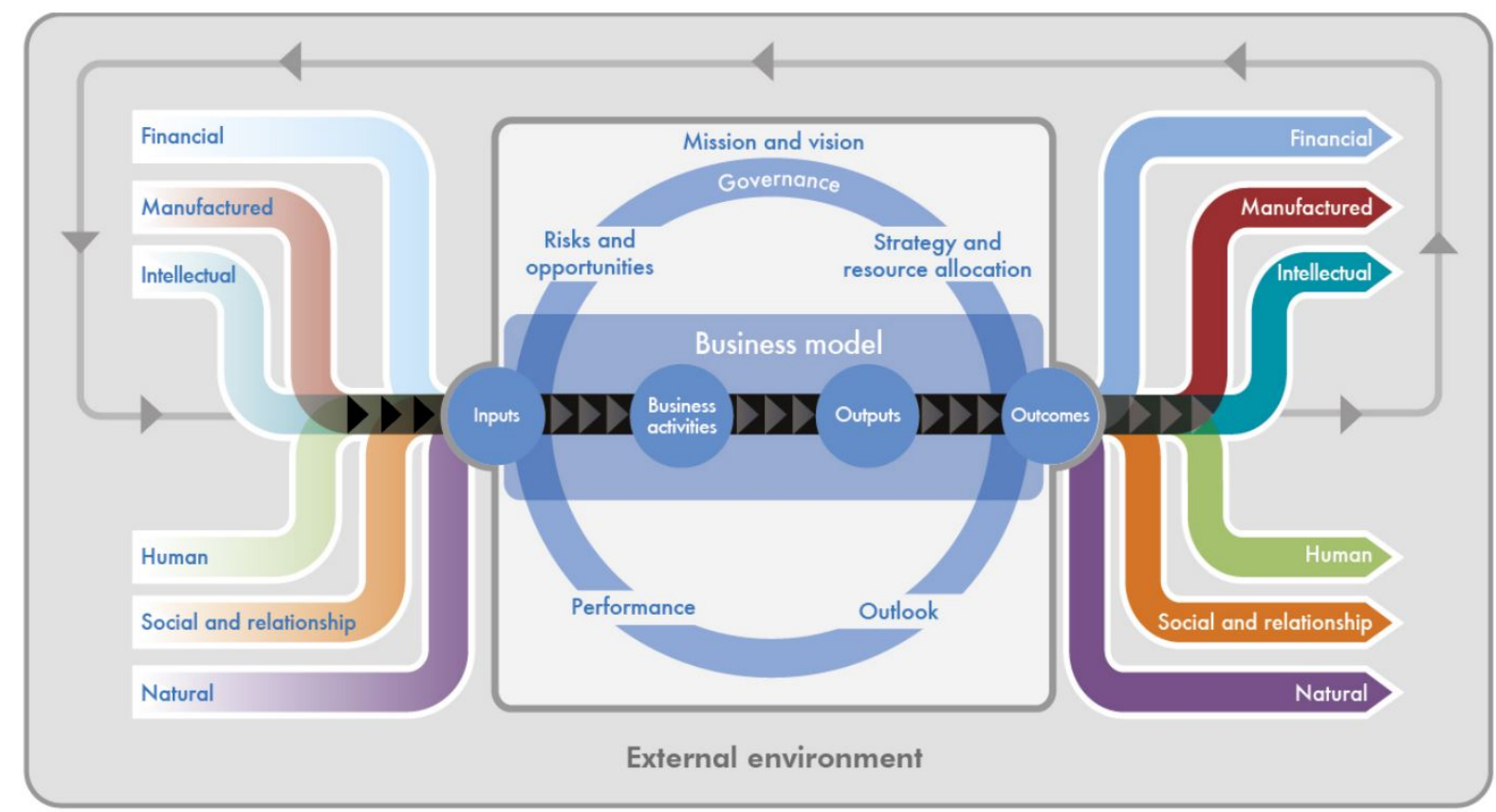

Value creation (preservation, diminution) over time

Value creation process in IR. source: International IR Framework 2013 (IIRC, 2013) 
Figure 2.4: IR Guiding Principles

\section{GUIDING PRINCIPLES}

The following Guiding Principles underpin the preparation of an integrated report, informing the content of the report and how information is presented:

- Strategic focus and future orientation: An integrated report should provide insight into the organization's strategy, and how it relates to the organization's ability to create value in the short, medium and long term, and to its use of and effects on the capitals

- Connectivity of information: An integrated report should show a holistic picture of the combination, interrelatedness and dependencies between the factors that affect the organization's ability to create value over time

- Stakeholder relationships: An integrated report should provide insight into the nature and quality of the organization's relationships with its key stakeholders, including how and to what extent the organization understands, takes into account and responds to their legitimate needs and interests

- Materiality. An integrated report should disclose information about matters that substantively affect the organization's ability to create value over the short, medium and long term

- Conciseness. An integrated report should be concise

- Reliability and completeness. An integrated report should include all material matters, both positive and negative, in a balanced way and without material error

- Consistency and comparability: The information in an integrated report should be presented: (a) on a basis that is consistent over time; and (b) in a way that enables comparison with other organizations to the extent it is material to the organization's own ability to create value over time.

Guiding Principles of IR. source: International IR Framework 2013 (IIRC, 2013) 
Figure 2.5: IR Content Elements

\section{CONTENT ELEMENTS}

An integrated report includes eight Content Elements that are fundamentally linked to each other and are not mutually exclusive:

- Organizational overview and external environment: What does the organization do and what are the circumstances under which it operates?

- Governance: How does the organization's governance structure support its ability to create value in the short, medium and long term?

- Business modet. What is the organization's business model?

- Risks and opportunities: What are the specific risks and opportunities that affect the organization's ability to create value over the short, medium and long term, and how is the organization dealing with them?

- Strategy and resource allocation: Where does the organization want to go and how does it intend to get there?

- Performance: To what extent has the organization achieved its strategic objectives for the period and what are its outcomes in terms of effects on the capitals?

- Outlook. What challenges and uncertainties is the organization likely to encounter in pursuing its strategy, and what are the potential implications for its business model and future performance?

- Basis of presentation: How does the organization determine what matters to include in the integrated report and how are such matters quantified or evaluated?

Content Elements of IR. source: International IR Framework 2013 (IIRC, 2013) 


\section{Chapter 3}

\section{Literature on IR: A meta review}

\subsection{Introduction}

In order to understand the current state of research surrounding IR and identify possible gaps, a meta review is conducted of all published work about IR from 2011 to 2019 (see Appendices for the references of all reviewed papers). The year range of 2011 to 2019 is selected because IR first became mandated in South Africa in 2010 and it is unlikely for there to be any major academic work about IR before this date. The papers are identified through Google Scholar and following literature (Massaro, Dumay, and Guthrie, 2016, Dumay, Bernardi, Guthrie, and Demartini, 2016), a Structured Literature Review (SLR) is conducted. Meta review is used because it provides the capacity to analyze the entire literature surrounding IR as a whole and understand the holistic picture (Moses, Mohaimen, and Emmanuel, 2020). A SLR technique is useful here as it assists in understanding the underlying themes and offers insights into a 
research genre (Dumay et al., 2016) which can be used to identify possible research gaps and future research agendas. ${ }^{1}$

\subsection{SLR framework}

In order to conduct a SLR, a framework is developed, which is inspired by literature (Guthrie and Parker, 2012, Dumay et al., 2016, Moses et al., 2020) and modified to fit the purpose of this research. In this research, each identified paper is coded in multiple categories, which provide different insights. The categories that are used are described below.

Jurisdiction: This category identifies the jurisdiction focus of the paper and is divided in four sub-categories. The International category identifies papers that have focused on multiple countries (i.e. Jensen and Berg, 2012, Frias-Aceituno, Rodriguez-Ariza, and Garcia-Sanchez, 2013). The National category refers to papers that focused on one nation (i.e. Stubbs and Higgins, 2014, Adams and Simnett, 2011). The One organization category refers to papers that have focused on one particular organization (i.e. Lodhia, 2015, Beck, Dumay, and Frost, 2017). The General category identifies papers that have no jurisdictional focus but present a general discussion on IR issues (i.e. Flower, 2015, De Villiers, Rinaldi, and Unerman, 2014). This categorisation is important because it provides insights about what jurisdictions have primarily been focused on IR research and what have been not paid enough attention to.

Country of research: This category divides the papers in terms of their country focus. If the paper on focused on one particular nation then it is coded as that nation (i.e. Stubbs and Higgins, 2014, Adams and Simnett, 2011). If the authors focused on multiple countries the

\footnotetext{
${ }^{1}$ Dumay et al. presented a SLR of IR literature in 2016. However, given that their analysis included only 31 journal articles from the years 2011 to 2015 and a significant number of articles focusing on IR have been published after that, a new analysis is necessary in order to understand current state of IR literature
} 
paper is coded as Multiple (i.e. Jensen and Berg, 2012, Frias-Aceituno et al., 2013). If there is no country focus then it is coded as General (i.e. De Villiers et al., 2014, Flower, 2015). If the authors focused on a continent or a specific group such as European Union, then they are coded as the continent or the group (i.e. Reimsbach, Hahn, and Gürtürk, 2018, Sofian and Dumitru, 2017). This category helps identify which countries or continents have received particular attention in IR research.

Organizational focus: Here the papers are categorized based on the type of organization they primarily focus on. The categories used are Not for profit (i.e. Adams and Simnett, 2011), Private (i.e. Del Baldo, 2015), Public Sector (i.e. Guthrie, Manes-Rossi, and Orelli, 2017, Guthrie, Dumay, Veltri, and Silvestri, 2015), Publicly Listed (i.e. Stubbs and Higgins, 2014, Frias-Aceituno, Rodríguez-Ariza, and Garcia-Sánchez, 2014), Private-Publicly Listed where both private and publicly listed organizations are used (i.e. Laine, 2014, Fasan and Mio, 2017), Private-Publicly Listed-Public Sector where private, publicly listed and public sector entities are used (i.e. Feng, Cummings, and Tweedie, 2017) and for papers that do not focus on any particular organization are categorized as General (i.e. Eccles and Serafeim, 2011, Adams, 2015). This category sheds light on what kind of organization has been the focus on attention for IR academia.

Focus of IR literature: Following Dumay et al., the papers are categorized based on the aspect of IR literature they primarily focused on. The sub-categories here are External Reporting (i.e. Zhou, Simnett, and Green, 2017, Laine, 2014), Auditing and Assurance (i.e. Reimsbach et al., 2018, Briem and Wald, 2018), Accountability and Governance (i.e. Frias-Aceituno et al., 2013, Adams, Potter, Singh, and York, 2016), Management Control/Strategy (i.e. Dumay and Dai, 2017, Guthrie et al., 2017), Performance Measurement (i.e. Churet and Eccles, 2014) and 
if any of the prevailing categories do not apply, the papers are coded as General (i.e. Stubbs and Higgins, 2018, Gibassier, Rodrigue, and Arjaliès, 2018). This analysis shows the aspects of IR literature that has been the primary focus in IR academia.

IR Framework and models: This category identifies if the papers have used the current IR Framework or proposed changes to it. This is insightful as it shows the amount of academic work that has called for possible improvement to the current IR practices based on the framework. The categories used here are Applies Current (i.e. Cheng, Green, Conradie, Konishi, and Romi, 2014, Stubbs and Higgins, 2014), Proposes New (i.e. Abeysekera, 2013, de Villiers, Unerman, Rinaldi, Haller, and van Staden, 2014) and if none of the above applies then Other (i.e. Kannenberg and Schreck, 2019).

Professional background: This category identifies the professional background of the researchers. The three sub-categories used here are Academic (i.e. Eccles and Serafeim, 2011, Flower, 2015), Practitioner (i.e. Owen, 2013) and Academic-Practitioner (i.e. Churet and Eccles, 2014, Kılıç and Kuzey, 2018). This is useful to show if the practitioner are actively interested in IR research or is it the domain of academics only.

Theory distribution: This category is used to understand the different theories that have been applied by authors in the IR literature. If the authors have used particular theories in their analysis they are coded as such. For instance, Lai, Melloni, and Stacchezzini (2016), Haji and Anifowose (2016) use legitimacy theory and Frias-Aceituno, Rodríguez-Ariza, and García-Sánchez (2013), Jensen and Berg (2012) use institutional theory in their research. If no particular theory have been used then they are coded as None (i.e. Flower, 2015, Abeysekera, 2013). Some papers have used multiple theories (i.e. Wang, Zhou, and Wang, 2019) in which 
case each theory has been counted separately. Understanding the theories that have been applied by the authors is important as it provides valuable insights about the different theoretical analytical tools that have been used in IR research.

Methodology: This is a broad category which differentiates the papers as either Quantitative (i.e. Lee and Yeo, 2016, Maniora, 2017) or Qualitative (i.e. Brown and Dillard, 2014, Flower, 2015). As different types of research leads to different types of knowledge, it is important to understand what type of research have received priority in IR and perhaps what is lacking.

Research method: Here the categorization goes more deep than Methodology and the papers are sub-categorized in terms of specific characteristics. If the paper used case study or interview or performs some form of content analysis, it is categorized as Case Study/Interview/Content Analysis (i.e. Laine, 2014, Stent and Dowler, 2015). If it is critique or commentary or a normative discussion then it is categorized as Commentary/Critique/Normative (i.e. Flower, 2015, Brown and Dillard, 2014). Literature reviews are categorized as Literature Review (i.e. Dumay et al., 2016). If the authors use an experimental technique then the paper is coded as Experiment (i.e. Green and Cheng, 2019). If is used statistical or empirical analysis such as regression, analysis of variance etc. then it is categorized as Statistical/Empirical Analysis (i.e. Frias-Aceituno et al., 2013, 2014). For papers that utilized surveys or questionnaires, Survey/Questionnaire (i.e. Rensburg and Botha, 2014) is used.

Research with most impact: Through the review, papers that have made the most impact in the literature are identified and analyzed in order to provide insights about their characteristics. Impact is determined through two measures: most total citations and citations per annum, which are derived from Google Scholar as of 30 March 2020. Citations per annum is used 
as using only total citations count can be misleading as it provides an advantage to older papers (Moses et al., 2020, Dumay et al., 2016).

\subsection{Analysis of literature}

The coded papers are analyzed from both quantitative and qualitative perspectives. The purpose behind this exercise is to unveil the underlying themes and patterns in the IR literature and identify potential gaps in the knowledge base. This is done by looking at the results both at points in time and through time to understand the evolution of IR research and develop knowledge about what more needs to be addressed. The analysis of the results based on each categories of coding are presented below.

\subsubsection{Jurisdiction}

The jurisdictional analysis presented in Figure 3.1 shows that most of the papers have focused on a national jurisdiction. Which is understandable as it provides more focus to a particular research work. It can be noted here that a high number of papers are in General category (49 out of 197) which have not focused on any particular jurisdiction but rather presented a general or open discussion on IR.

[Figure 3.1 about here]

The findings show that IR literature has been diverse in terms of jurisdictions covered which speaks to the broadening nature of research in this emerging area. However, it is also apparent that IR research is lacking in developing and emerging economies as very few research work has been done in that area. 


\subsubsection{Country of research}

Going more in depth from jurisdictions, the country of research analysis presented in Figure 3.2 show that most of the papers do not focus on any particular country but rather presented a general discussion on IR. Of papers that do focus on countries, most focus on multiple countries. For the papers that focus on particular nations, most focus on South Africa. This is understandable as South Africa is the first and only nation to mandate IR. After South Africa, Italy has received the second most attention from IR literature. Considering that IR is not mandated in Italy, this can indicate a heightened interest of the academia in the voluntary adoption of IR.

[Figure 3.2 about here]

Also of interest is to note that their is a broad spectrum of nations that has one or more papers on IR which again speaks to the notion that perhaps IR is generating more global interest and is broadening out.

\subsubsection{Organization focus}

Looking into organizational focus demonstrates the type of organizations that have been the focus of attention in IR literature. As Figure 3.3 shows, the primary focus has been on publicly listed organizations. This is expected as the IR framework is primarily developed for for-profit organizations (IIRC, 2013). There is also a high volume of papers that do not focus on any particular organizational structure but rather presented discussion on IR from a organization neutral point of view.

[Figure 3.3 about here] 
The findings point to the fact that IR is still focused on publicly listed for-profit entities and very little attention has been paid to the public sector or the not-for-profit sector.

\subsubsection{Focus of IR literature}

Figure 3.4 shows that most papers have focused on External Reporting. This is consistent with the IR framework's claim that the purpose of IR is to explain to the providers of financial capital how an organization creates value (IIRC, 2013).

[Figure 3.4 about here]

It can be noted that very little focus have been given to Auditing and Assurance, Accountability and Governance or Performance Measurement. Considering that one of the aims of IR is to facilitate integrated thinking and explain how organization creates value over time (IIRC, 2013), it should be noted that to this date very little has been done to address this issue in the IR literature.

\subsubsection{IR Framework and models}

The illustration in Figure 3.5 shows that majority of the papers, 186 out of 197, applied the current IR framework and 9 papers proposed an improvement to it. This demonstrates a possible gap in the literature which does not focus on further developing the current IR framework but rather conformed to it.

[Figure 3.5 about here]

This thesis, by looking at the change in value relevance of accounting information under IR, can contribute to this, by demonstrating if IR indeed is adding value for capital providers and decision makers. 


\subsubsection{Professional background}

This category provides insight about the source of contribution in IR literature. Figure 3.6 shows that majority of the papers in IR literature, 184 out of 197, have been published by academics. There are only 2 papers exclusively from practitioners and 11 papers from academicpractitioner collaboration.

[Figure 3.6 about here]

Similar to what Dumay et al. (2016) find, this shows that IR research has primarily been the domain of the academics with very little participation from the practitioners. It further highlights the importance of involving more practitioners in the IR research field in order to make IR research policy relevant.

\subsubsection{Theory distribution}

Table 3.1 shows that of the 197 papers that are part of this meta review, 119 papers do not apply any theories in their analysis and 78 papers applied one or more theories. This shows that most papers do not focus on any theoretical underpinnings. Figure 3.7 illustrates that of the applied theories, legitimacy, stakeholder and institutional theory have been used by the authors the most with agency theory also in the mix. As these are mainstream economics related theories and IR is primarily focused on serving the needs of capital providers, it makes sense that these theories have received precedence over others.

[Table $3.1 \&$ Figure 3.7 about here]

Theories such as signalling, diffusion of innovation and impression management have also been applied a significant times. This can be associated with the explained by the fact that IR is still 
relatively new and literature have focused on its aspects that can evolve. There has been a wide range of theories that have been applied in the IR literature however, it can be seen that mainstream economics theories have been favored.

\subsubsection{Methodology}

This broad categorization shows a simple classification based on the research methodology applied. As Figure 3.8 shows, most authors have focused on a qualitative methodology with 121 papers out of 197 preferring this.

[Figure 3.8 about here]

The trend shows that over time more quantitative papers have come in to the mix. This can be explained by the fact that as more and more companies are adopting an IR approach, more empirical data are becoming available. This perhaps speaks to the growing importance of focusing on more empirical data to find new insights about IR.

\subsubsection{Research method}

This is a further sub-categorization of the Methodology discussed above where the papers are divided in terms of their specific characteristics of their research method. As Figure 3.9 demonstrates, over time, Case Study/Interview/Content Analysis have been applied the most in IR literature. In recent years, the focus on Statistical/Empirical Analysis which as discussed in the Methodology subsection, can be attributed to more availability of empirical data.

[Figure 3.9 about here] 
Literature reviews, research using surveys and questionnaires and experimental designs have not been widely used. This indicates a growing interest in using empirical methods to analyze IR issues, which is the focus of this thesis.

\subsubsection{Research with most impact}

Analyzing the papers that have created the most impact provides valuable insights about the characteristics that have received the most attention in the IR literature. Table 3.2 and Table 3.3 shows the papers with the most total citations and their categorized characteristics. De Villiers et al. (2014) discussion on the insights, gaps and agenda for future research on IR is the most cited paper with the Flower (2015) critique on IR being a close second.

[Table 3.2 and Table 3.3 about here]

Look into the characteristics of the most cited papers show that 8 out of the 10 are qualitative discussion based papers, with no specific jurisdictional or IR literature focus. This can be associated with the notion that these are early papers on the early stages of IR and have thus have primarily adopted a discussion based approach. It also provides further credence to the notion that quality impact work on IR focusing on empirical methods is lacking on the literature, which is a gap this thesis aims to contribute towards.

Table 3.4 and Table 3.5 demonstrates the papers and their characteristics that have received the most citations per annum. Comparing this list to the papers with most total citations show that there are 5 papers in common. The characteristics of these high impact works demonstrate that 4 out of the 5 are qualitative discussion based papers with a general focus on jurisdiction and IR literature. This further conveys that so far the works that have created the most impact in IR have not utilized quantitative, empirical methodologies. 
Thus far the most impactful works on IR have primarily provided critiques (Flower, 2015), developed suggestions for future research (De Villiers et al., 2014, Cheng et al., 2014) and called for further developments in IR (Adams, 2015). As IR is now being applied globally in mandatory and voluntary settings, it is important to look into the actual impact of IR and take the discussion from a theoretical space to a practical one. This thesis attempts to do this by providing an analysis about the value relevance of accounting information under IR approach, which has the potential to assist capital providers and standard setter in their decision making.

\subsection{Summary of meta review findings}

The meta review highlights that IR research so far has a narrow focus with most attention given to issues surrounding external reporting. Not a lot of research has been conducted to look into issues around accountability, assurance or performance management under IR. In addition to focusing on external reporting, this thesis contributes towards addressing the issue of performance measurement of IR by looking at the value relevance of accounting information under an IR approach.

In terms of jurisdiction and country of research, a large number of authors have not focused on any jurisdiction but rather presented a general discussion on IR. As IR is still a developing field, this is expected. A significant number of papers have also looked into multiple countries in their analysis. This can be associated with the IR pilot program which included multiple nations and made data available from them. Most research that has looked at individual nations have focused on South Africa. This is also understandable as South Africa so far in the only nation to mandate IR. This is thesis contributes to this existing literature of IR by taking a com- 
parative cross country analysis approach involving both voluntary and mandatory implementers of IR.

Consistent with the findings of Dumay et al. (2016), this meta review also finds that IR research to this date has primarily been the domain of academics. If IR research is to be policy relevant and make an impact in the professional world, it is important to take note of this and include more practitioner perspectives.

From a theoretical perspective, mainstream business or economics theories such as legitimacy, stakeholder, institutional and agency theory have been more widely used in the IR literature. Though it is convivial to note that other than the mainstream theories a wide range of theories such as signalling, diffusion of innovation, impression management and others have also been used to analyze IR and related issues.

In terms of research methodology, qualitative methods have so far been favored by the academics. Research using case studies, interviews or content analysis have been the prevalent method over the years for discussing IR issues. There has been very little use of surveys, questionnaires or experimental designs. This can be due a lack of usable data in order to apply these methods. It should be noted that over the past few years research using quantitative statistical and empirical methods have increased. This can be associated with the fact that more companies are using IR and more empirical data are becoming available. As data becomes more available, it calls for more research that will look into IR issues through quantitative empirical methods.

The most impactful works in IR so far have been qualitative and discussion based with little attention given to empirical quantitative methods. This shows a research gap in literature 
which calls from more work in this area that makes use of empirical quantitative methods to generate new insights about IR. This thesis contributes to this growing field by adopting a novel multiplicative modelling technique in its analysis. 


\subsection{Appendix for Chapter 3}

Figure 3.1: Jurisdiction - IR Literature

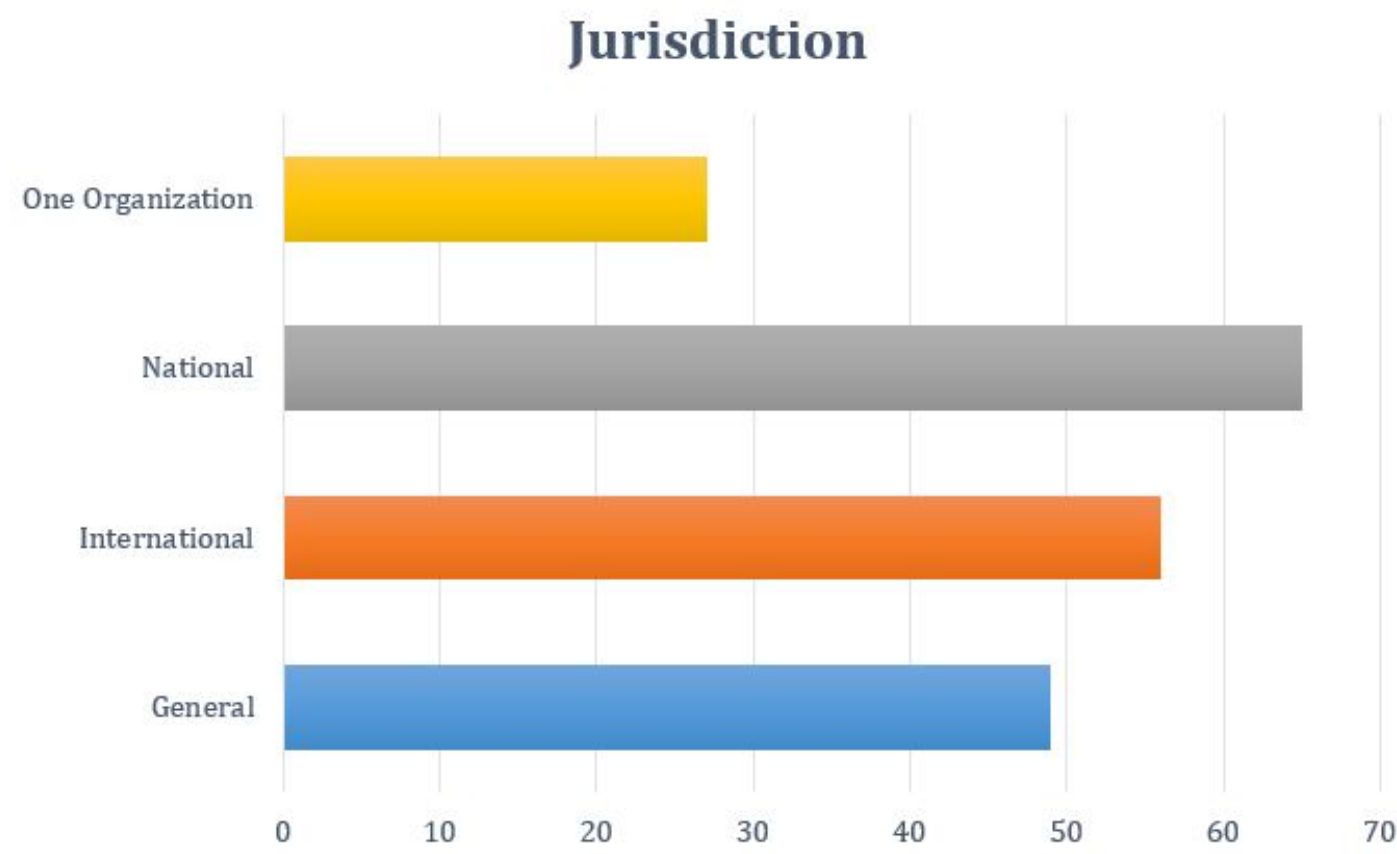

Jurisdictions in IR Literature 
Figure 3.2: Country of Research - IR Literature

\section{Country of Research}

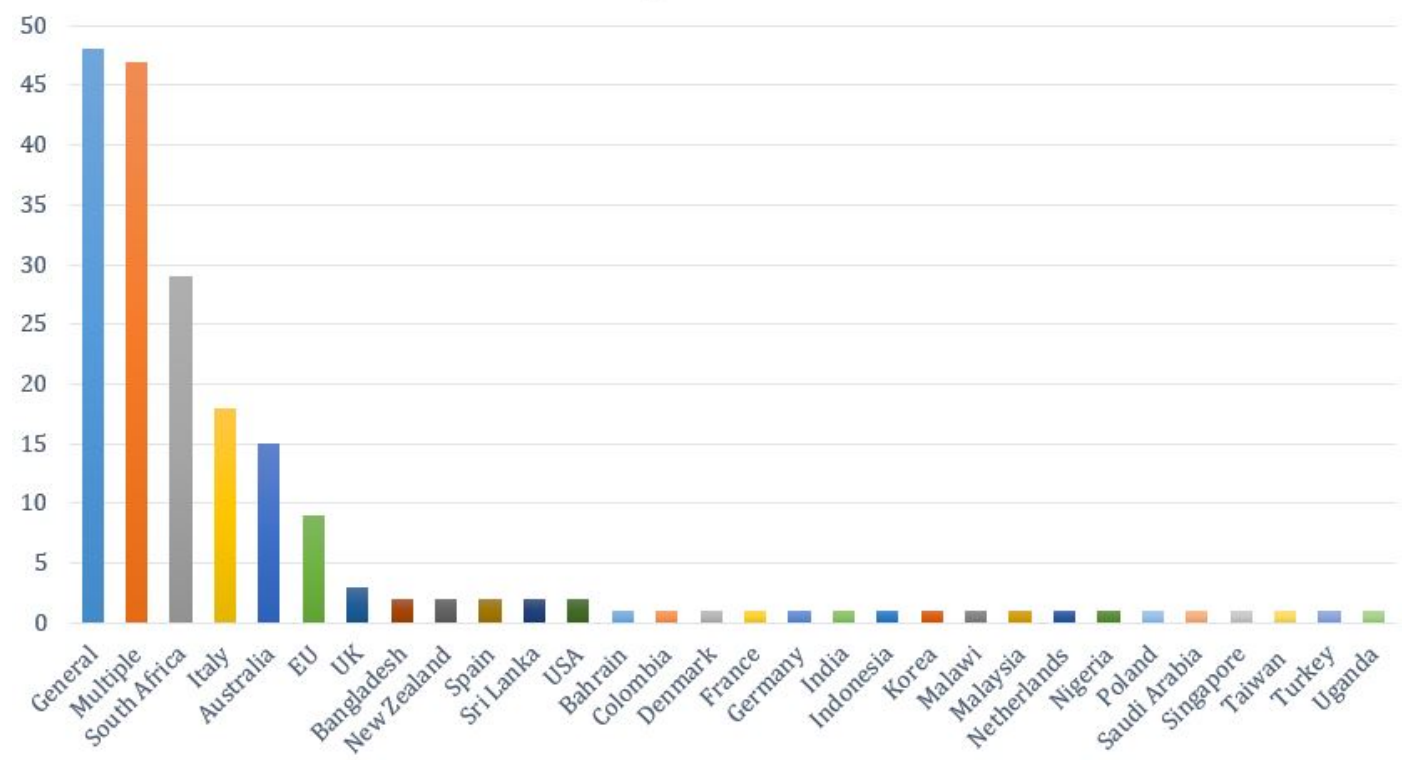

Country of Research in IR Literature 
Figure 3.3: Organization Focus - IR Literature

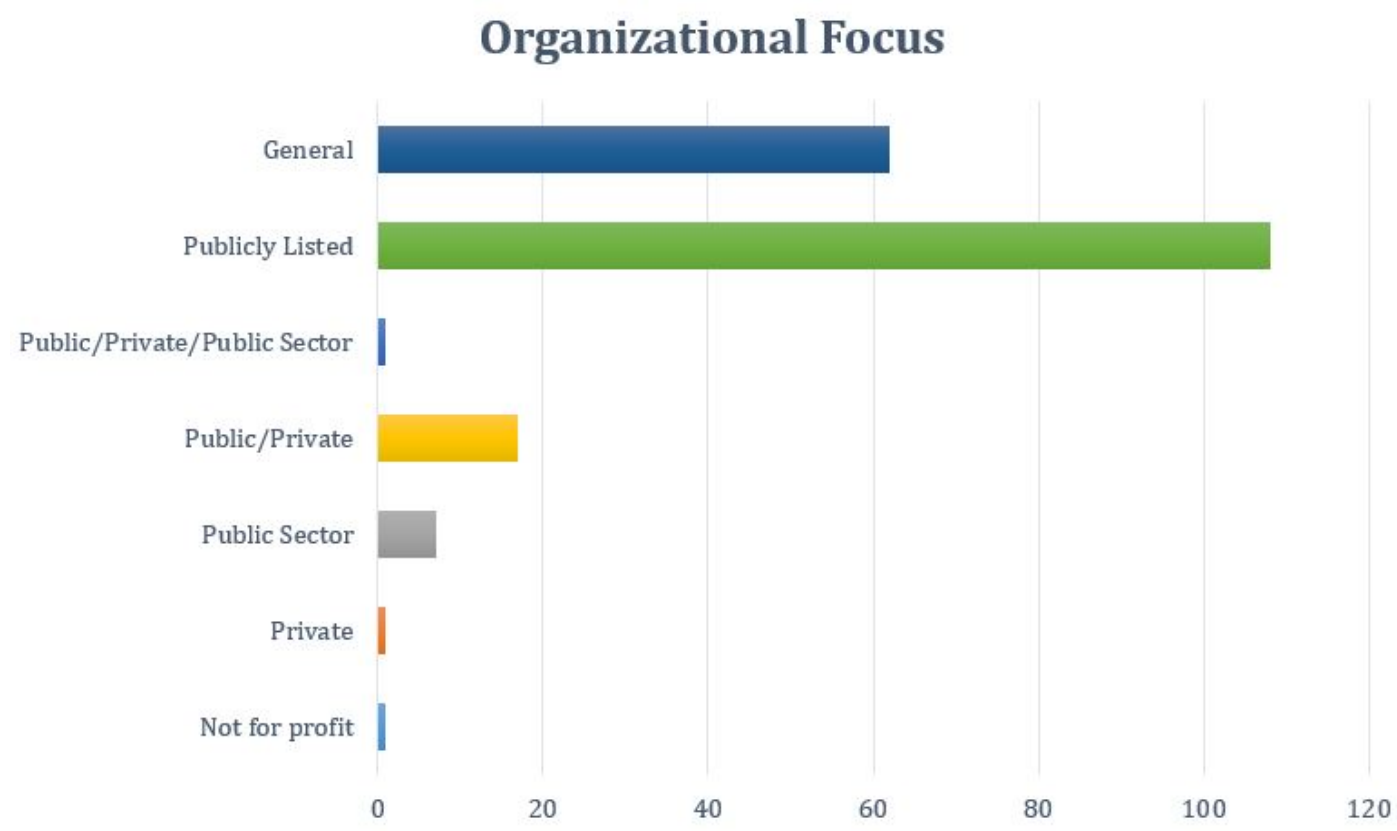

Organizational Focus in IR Literature 
Figure 3.4: Focus of IR Literature

\section{Focus of IR Literature}

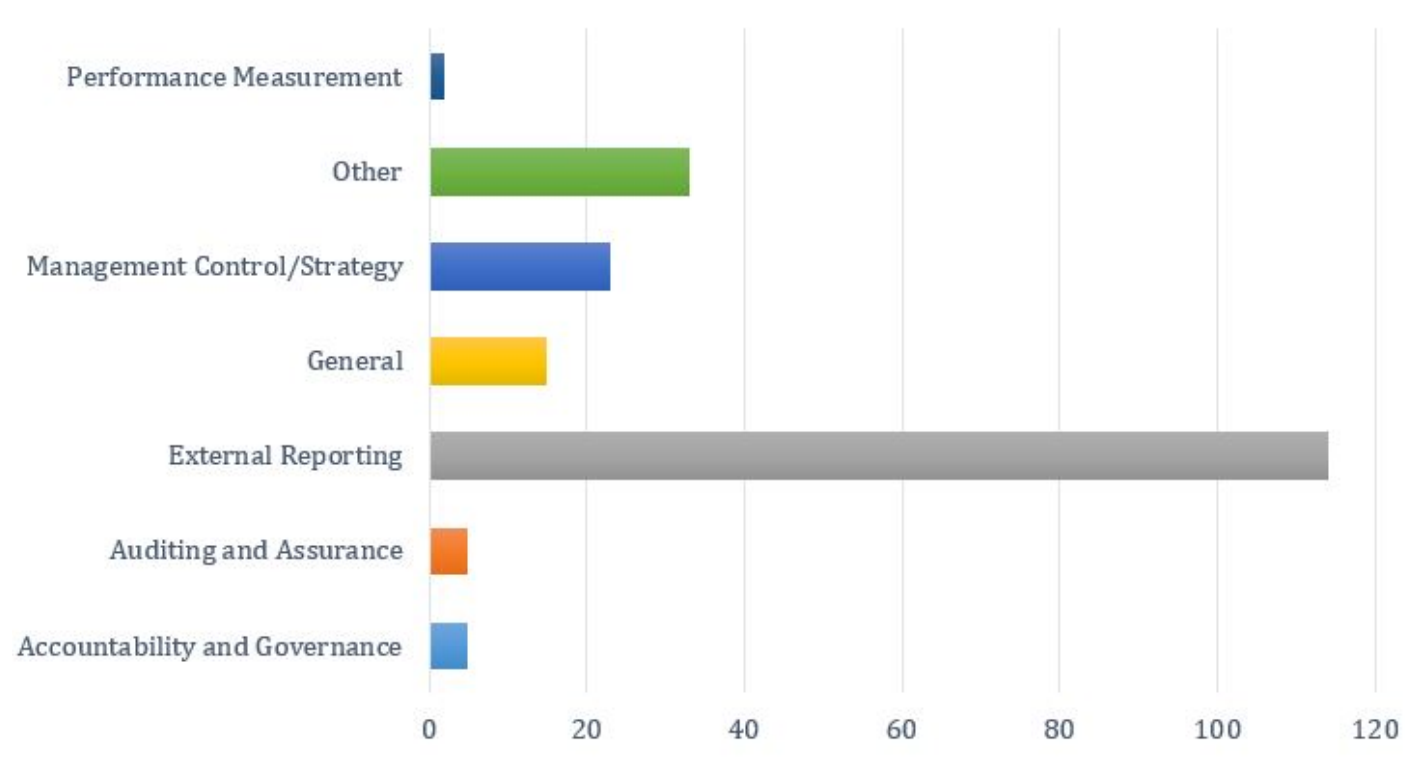

Focus of IR Literature 
Figure 3.5: IR Framework and Models

\section{IR Framework \& Models}

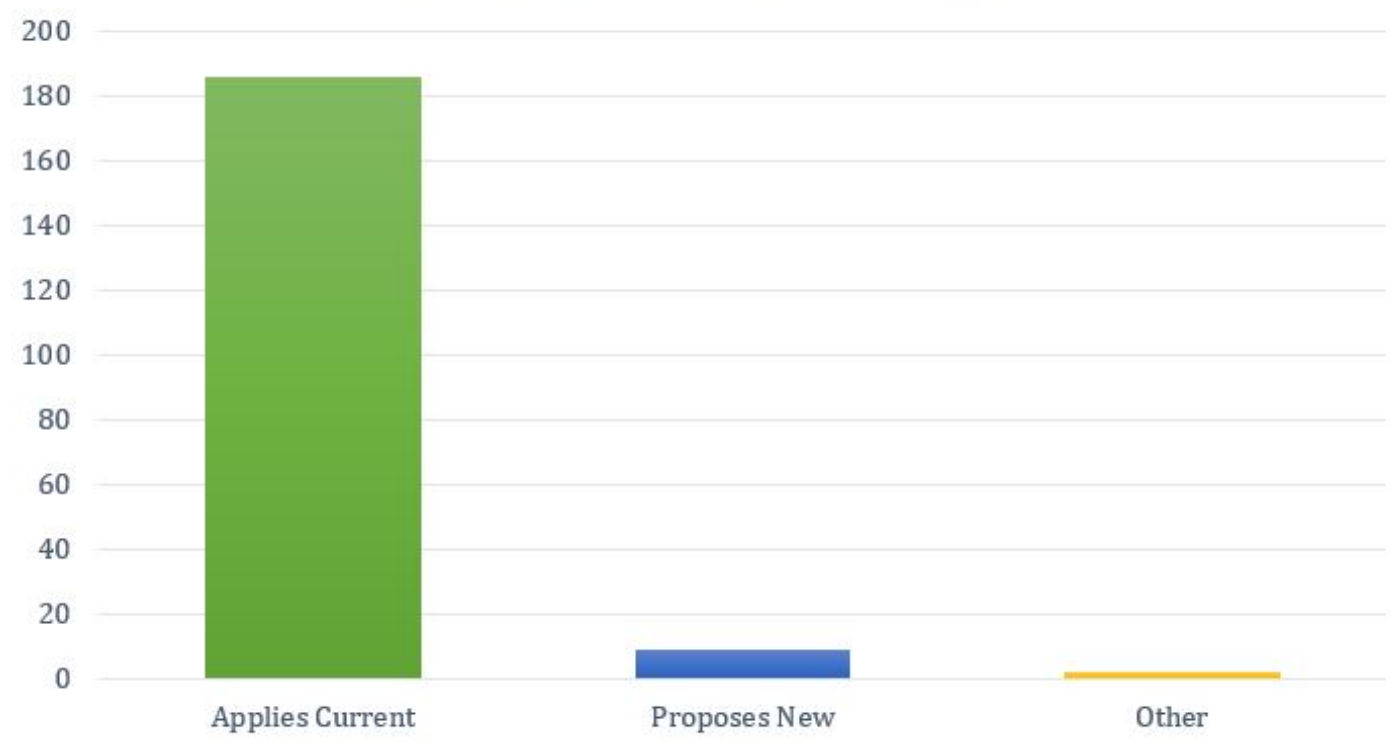

IR Framework and Models - IR Literature 
Figure 3.6: Professional Background

\section{Professional Background}

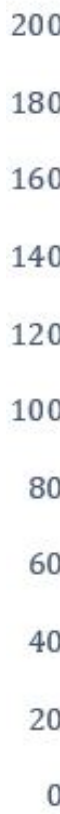

180

160

140

120

100

80

60

40

0

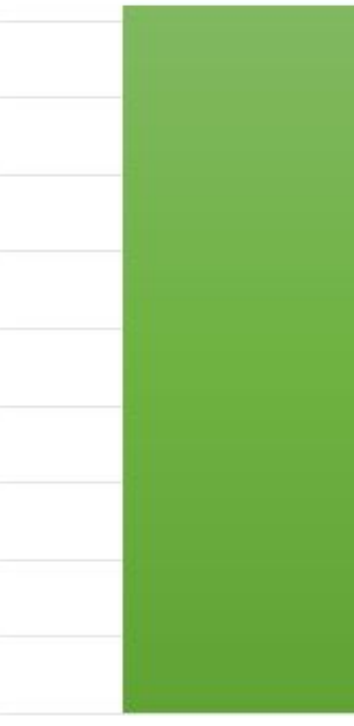

Academic

Academic-Practitioner

Practitioner

Professional Background - IR Literature 


\begin{tabular}{ll}
\hline Applied Theory & Did not Apply Theory \\
\hline \multicolumn{1}{c}{78} & 119 \\
& \\
Theory Applied & $\#$ \\
\hline Actor Network & 1 \\
Agency & 9 \\
Bourdieu's theory of practice & 1 \\
Cognitive Cost & 1 \\
Decision Usefulness & 1 \\
Diffusion of Innovation & 4 \\
Economies of Worth & 1 \\
Equilibrium & 1 \\
Game & 1 \\
Impression Management & 3 \\
Information Asymmetry & 2 \\
Institutional & 14 \\
Legitimacy & 18 \\
Luhmann's Complex Systems Theory & 1 \\
Management Fashion & 1 \\
Media Richness & 1 \\
Organisational Learning & 1 \\
Porter's Diamond & 1 \\
Practice & 2 \\
Proprietary cost & 1 \\
Reputation Risk Management & 1 \\
Searle's theory of institutional reality & 1 \\
Signaling & 5 \\
Slack Resource & 1 \\
Social Ontology & 1 \\
Stakeholder & 1 \\
Stakeholder Salience & 1 \\
The triple bottom dispersal of actions & 1 \\
Theory of Metaphors & \\
Trust in Social Relationship & Voluntary Disclosure \\
\hline
\end{tabular}


Figure 3.7: Theory Distribution

\section{Theories in IR Literature}

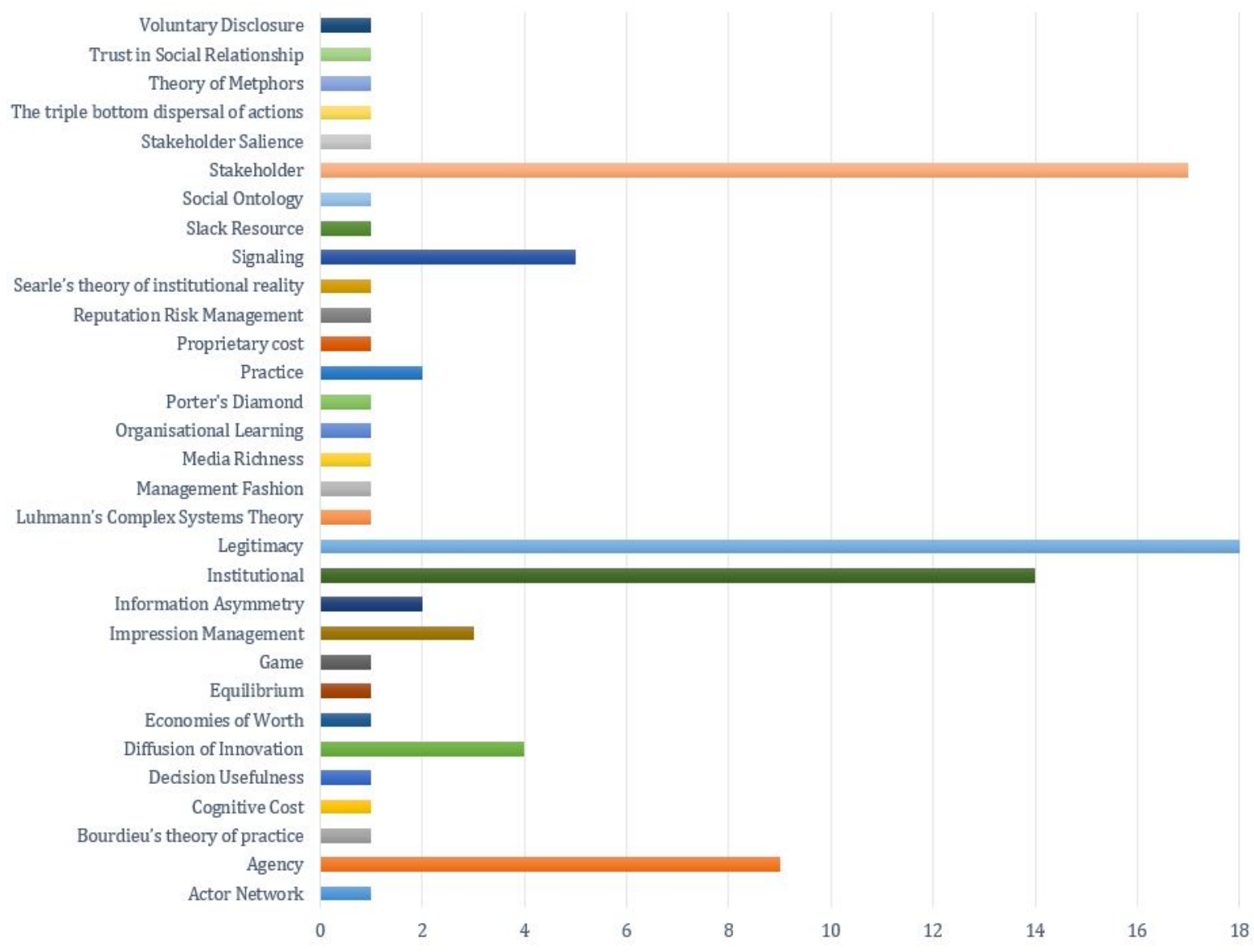

Theory Distribution - IR Literature 
Figure 3.8: Methodology

\section{Methodology}

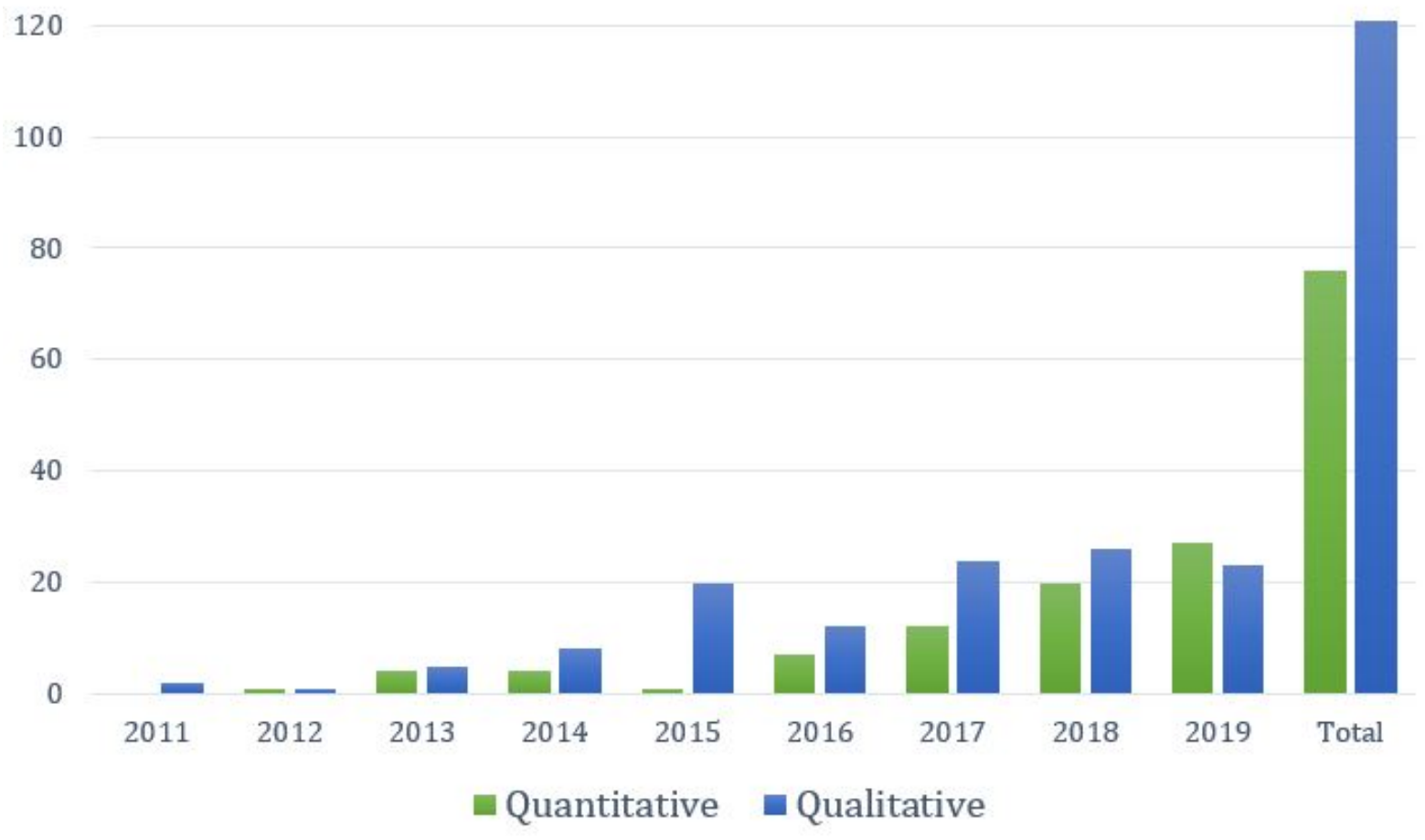

Methodology - IR Literature 
Figure 3.9: Research Method

\section{Research Method}

30

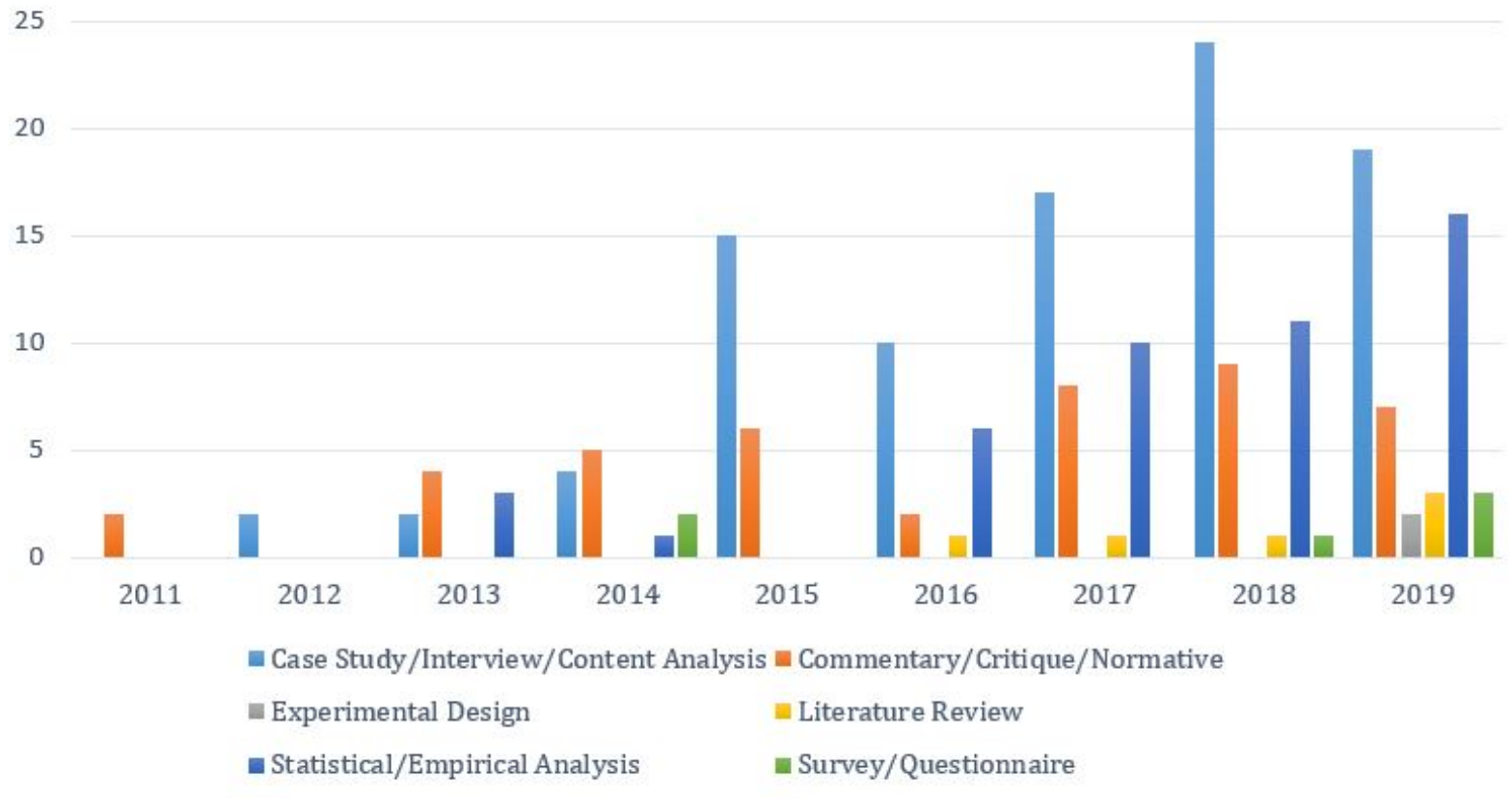

Research Method - IR Literature 
Table 3.2 Most Total Citations

\begin{tabular}{|c|c|c|c|c|}
\hline Serial & Title of Article & Reference & Year & Citations \\
\hline 1 & $\begin{array}{l}\text { Integrated Reporting: Insights, gaps and an agenda for future } \\
\text { research }\end{array}$ & De Villiers et al. (2014) & 2014 & 470 \\
\hline 2 & $\begin{array}{l}\text { The International Integrated Reporting Council: A story of } \\
\text { failure }\end{array}$ & Flower (2015) & 2015 & 440 \\
\hline 3 & $\begin{array}{l}\text { Determinants of Traditional Sustainability Reporting Versus } \\
\text { Integrated Reporting. An Institutionalist Approach }\end{array}$ & Jensen and Berg (2012) & 2012 & 365 \\
\hline 4 & $\begin{array}{l}\text { The Role of the Board in the Dissemination of Integrated } \\
\text { Corporate Social Reporting }\end{array}$ & Frias-Aceituno et al. (2013) & 2013 & 363 \\
\hline 5 & $\begin{array}{l}\text { The International Integrated Reporting Council: A call to } \\
\text { action }\end{array}$ & Adams (2015) & 2015 & 351 \\
\hline 6 & Achieving Sustainability Through Integrated Reporting & Eccles and Saltzman (2011) & 2011 & 310 \\
\hline 7 & A template for integrated reporting & Abeysekera (2013) & 2013 & 304 \\
\hline 8 & $\begin{array}{l}\text { The International Integrated Reporting Framework: Key Issues } \\
\text { and Future Research Opportunities }\end{array}$ & Cheng et al. (2014) & 2014 & 294 \\
\hline 9 & Integrated Reporting and internal mechanisms of change & Stubbs and Higgins (2014) & 2014 & 292 \\
\hline 10 & $\begin{array}{l}\text { Integrated reporting: On the need for broadening out and } \\
\text { opening up }\end{array}$ & Brown and Dillard (2014) & 2014 & 280 \\
\hline
\end{tabular}


Table 3.3 Most Total Citations - Continued

\begin{tabular}{|c|c|c|c|c|c|c|c|c|c|}
\hline Serial & Jurisdiction & Country of Research & Organisational Focus & Focus of IR Literature & IR Framework and models & Academic/Practitioner & Theory & Methodology & Research method \\
\hline 1 & General & General & General & Other & Applies current & Academic & none & Qualitative & Commentary/Critique/Normative \\
\hline 2 & General & General & General & Other & Applies current & Academic & none & Qualitative & Commentary/Critique/Normative \\
\hline 3 & International & Multiple & Publicly Listed & External Reporting & Applies current & Academic & Institutional & Quantitative & Case Study/Interview/Content Analysis \\
\hline 4 & International & Multiple & Publicly Listed & Accountability and Governance & Applies current & Academic & Agency/Stakeholder & Quantitative & Statistical/Empirical Analysis \\
\hline 5 & General & General & General & & Applies current & Academic & & Qualitative & Commentary/Critique/Normative \\
\hline 6 & General & General & General & Other & Applies current & Academic & none & Qualitative & Commentary/Critique/Normative \\
\hline 7 & General & General & General & External Reporting & Proposes New & Academic & none & Qualitative & Commentary/Critique/Normative \\
\hline 8 & General & General & General & Other & Applies current & Academic & none & Qualitative & Commentary/Critique/Normative \\
\hline 9 & National & Australia & Publicly Listed & Management Control/Strategy & $\begin{array}{l}\text { Applies current } \\
\text { Propsec New }\end{array}$ & Academic & none & $\begin{array}{l}\text { Qualitative } \\
\text { Qunlitive }\end{array}$ & Case Study/Interview/Content Analysis \\
\hline 10 & General & General & General & & & & & & Commentary/Critique/Normative \\
\hline
\end{tabular}


Table 3.4 Most Citations per Annum

\begin{tabular}{|c|c|c|c|c|}
\hline Serial & Title of Article & Reference & Year & Citations Per Annum \\
\hline 1 & The International Integrated Reporting Council: A story of failure & Flower (2015) & 2015 & 110 \\
\hline 2 & $\begin{array}{l}\text { Environmental, social and governance disclosure, integrated reporting, } \\
\text { and the accuracy of analyst forecasts }\end{array}$ & Bernardi and Stark (2018) & 2018 & 110 \\
\hline 3 & Integrated Reporting: Insights, gaps and an agenda for future research & De Villiers et al. (2014) & 2014 & 94 \\
\hline 4 & Integrated reporting: A structured literature review & Dumay et al. (2016) & 2016 & 91 \\
\hline 5 & The International Integrated Reporting Council: A call to action & Adams (2015) & 2015 & 88 \\
\hline 6 & Does Integrated Reporting Matter to the Capital Market? & Zhou et al. (2017) & 2017 & 80 \\
\hline 7 & $\begin{array}{l}\text { Integrated Reporting and Assurance of Sustainability Information: An } \\
\text { Experimental Study on Professional Investors' Information Processing }\end{array}$ & Reimsbach et al. (2018) & 2018 & 68 \\
\hline 8 & $\begin{array}{l}\text { Stakeholders' Perspectives on the Role of Regulatory Reform in Integrated } \\
\text { Reporting }\end{array}$ & Stubbs and Higgins (2018) & 2018 & 61 \\
\hline 9 & $\begin{array}{l}\text { The Role of the Board in the Dissemination of Integrated Corporate Social } \\
\text { Reporting }\end{array}$ & Frias-Aceituno et al. (2013) & 2013 & 61 \\
\hline 10 & $\begin{array}{l}\text { The International Integrated Reporting Framework: Key Issues and Future } \\
\text { Research Opportunities }\end{array}$ & Cheng et al. (2014) & 2014 & 59 \\
\hline
\end{tabular}


Table 3.5 Most Citations per Annum - Continued

\begin{tabular}{|c|c|c|c|c|c|c|c|c|c|}
\hline Serial & Jurisdiction & Country of Research & Organisational Focus & Focus of IR Literature & IR Framework and models & Academic/Practioner & Theory & Methodology & Research method \\
\hline & General & General & General & & Applies current & Academic & none & Qualitative & Commentary/Critique/Normative \\
\hline 2 & National & South Africa & Publicly Listed & External Reporting & Applies current & Academic & none & Quantitative & Statistical/Empirical Analysis \\
\hline & General & General & General & Other & Applies current & Academic & none & Qualitative & Commentary/Critique/Normative \\
\hline 4 & General & General & General & Other & Applies current & Academic & none & Qualitative & Literature Review \\
\hline & General & General & General & Other & Applies current & Academic & none & Qualitative & Commentary/Critique/Normative \\
\hline & International & South Africa & Publicly Listed & External Reporting & Applies current & Academic & Voluntary Disclosure & Quantitative & Statistical/Empirical Analysis \\
\hline & International & European Union & General & Auditing and Assurance & Applies current & Academic & Cognitive Cost & Quantitative & Survey/Questionnaire \\
\hline & National & Australia & General & General & Applies current & Academic & & Qualitative & Case Study/Interview/Content Analysis \\
\hline & International & Multiple & Publicly Listed & Accountability and Governance & Applies current & Academic & Agency/Stakeholder & Quantitative & Statistical/Empirical Analysis \\
\hline
\end{tabular}




\section{Chapter 4}

\section{Value relevance of accounting information}

\subsection{Introduction}

This chapter presents the concept of value relevance of accounting information, discusses its principal proponents and critiques and presents a summary of value relevance literature focused on IR. Accounting information is value relevant if there is a predictive association between accounting numbers and share market prices (Ali and Hwang, 2000). The relationship between accounting figures and share values are well documented in the literature with varying degrees of reported association. For instance, Lev and Sougiannis (1996) document a positive association between research and development capitalization and share price. Amir and Lev (1996) find that non-financial information such as growth proxy and market penetration are highly value relevant. Barth, Beaver, and Landsman (1996) show that fair value disclosures of banks are value relevant. Hassel, Nilsson, and Nyquist (2005) find that environmental performance along with financial information is associated with changes in share prices. Aboody and Lev (1998) look into the relationship between share prices and intangibles and find reported 
intangibles to be value relevant. In looking at the change in value relevance of accounting information both Collins, Maydew, and Weiss (1997) and Barth et al. (2017) find that value relevance of accounting information has increased over time.

The diversity in value relevance literature demonstrates the importance of different accounting figures under different circumstances in explaining movement in share market prices. This literature however, is not without its critiques. The most significant criticism comes from Holthausen and Watts (2001) who argue that value relevance research is not useful for standard setting. Barth et al. (2001) provide a counter argument to this and present the case for the importance of value relevance literature in standard setting and other decision making. A discussion on these proponents and critiques is provided below.

\subsection{Value relevance of accounting information: Proponents and Critiques}

Research focusing on value relevance of accounting information in general has both its proponents and critiques. In advocating for the efficacy of value relevance research, Barth et al. (2001) opine that research into value relevance of accounting information provide useful insights to the equity investors, policy makers and standard setters. Barth et al. argue that one of the primary focus of financial statements is to provide input for equity investors and hence the relationship that value relevance research draws between equity and other accounting variables is of great value. They assert that research on value relevance assess how accounting figures reflect the information usage by equity investors and thus provides useful insights to standard setters regarding developing future standards. While the authors note that value relevance may not have a big role to play regarding the stewardship or contracting role of accounting information, it in no way diminishes the importance of such research. 
In critiquing value relevance research, Holthausen and Watts (2001) argue that the association that value relevance research draws between accounting numbers and equity valuations do not have a descriptive underlying theory and hence, can hardly be used for drawing standard setting inferences. Holthausen and Watts argue that value relevance research may inform the readers about the role of accounting information in providing input to equity investors valuation, but largely ignores the other roles of accounting and other things standard setters have to consider. The authors essentially draw distinction between the valuation and stewardship roles of accounting and connote that value relevance research focuses only on the valuation perspective while ignoring the others and thus is not significantly relevant for standard setting.

Despite the notions put forth by Holthausen and Watts (2001), value relevance research have continued to gain prominence (see Beisland, 2009, for a literature review). While this line of research may not directly provide inputs pertaining to the stewardship role of accounting, the literature documents the role of value relevance in assisting with the valuation role of accounting information. Consistent with the opinion of Barth et al., this thesis notes that value relevance of accounting information provides useful information to the capital providers and standard setters for their decision making. This thesis, by looking at the change in the value relevance of accounting information under IR in different settings, provides robust decision useful evidence to the capital providers and standard setters.

\subsection{Value relevance of IR}

Research focusing on the value relevance of accounting information under IR so far has been very limited. Cortesi and Vena (2019) look into a sample of voluntary adopters of IR and find that IR enhances corporate disclosure and reduces information asymmetries. Cortesi 
and Vena also document increase in the quality of reported earnings under IR. They use the traditional linear model to lead to their findings. Baboukardos and Rimmel (2016) look into whether the value relevance of summary accounting information such as book value per share of equity and earnings, of firms listed in the JSE, enhance after the mandatory adoption of integrated reporting in 2010. Baboukardos and Rimmel document change in the value relevance of IR before and after implementation using linear models and three-year before and after implementation window. Their findings show that value relevance of earnings has increased but the value relevance of net assets have decreased. However, their limitation is that the time window used is very narrow and they used traditional linear models (Barth, Li, and McClure, 2017) to show the relationship between market price per share and book value per share and other accounting variables.

Following similar linear model, Landau, Rochell, Klein, and Zwergel (2020) look into the change in the value relevance of accounting information under IR for firms in the STOXX Europe 50 index (STOXX, 2020), which is an index of firms that represent around $50 \%$ of market capitalization of the European stock market. Landau et al. use data from 2010 to 2016 and find that IR can have a negative influence of market value which they associate with the cost concerned school that suggests that implementation of IR results in increased costs and thus is associated with a reduction in firm value. The authors further demonstrate that quality of report can be a relevant factor and present evidence that higher quality reports can mitigate the negative effects of voluntarily implementing IR.

' Considering that the market to book relation usually takes the form of the power law and distributions of fundamental accounting variables such as earnings are log-normal (Lubberink and Willett, 2020), then the implication is that the relationship between market and fundamental 
accounting values in multiplicative instead of being additive. Therefore, use of a multiplicative model to measure value relevance could provide better and more representative results, which is the focus of this thesis.

\subsection{Chapter summary}

The research focusing on the value relevance of accounting information in diverse. As discussed above, different accounting figures under different circumstances have been documented to be value relevant. While there are critiques such as Holthausen and Watts who argue that value relevance is not important for important decision such as standard setting, there are also proponents such as Barth et al. who present the case for the importance of value relevance literature. This thesis focuses on the later school of thought and recognizes the importance of value relevance research for making important assessments about standard setting. To this date, research focusing on the value relevance of IR has been sparse. The few work that has been done in this area have used the linear modelling technique. This thesis by using a multiplicative modelling technique which overcomes the issues with traditional linear models, analyzes the value relevance of accounting information under IR. This has the potential to provide important insights about the actual value of implementing IR for the capital providers. 


\section{Chapter 5}

\section{Research framework and hypotheses}

\section{development}

\subsection{Introduction}

This chapter presents the theoretical framework underpinning this thesis and discusses the development of the hypotheses. In the literature different theories have been used to analyze and discuss issues pertaining to IR (see Chapter 3 for a meta review of these papers). This thesis takes a theoretically diverse approach in analyzing the value relevance of accounting information under IR. Agency theory suggests that managers have a fiduciary responsibility to increase shareholder wealth (Meckling and Jensen, 1976). Since implementation of IR is a resource consuming process, it follows from agency theory that managers have the responsibility to use IR as a way to directly or indirectly increase shareholder wealth. Signalling theory establishes that information disclosed to the market is a way of reducing information asymmetries, providing better decision making capacity to the investors and increasing the value of the firm (Baiman 
and Verrecchia, 1996). IR presents additional information to the market which then should decrease information asymmetries and lead to better value for capital providers. Impression management theory shows that information is used to control or modify the impression one party has of another (Leary and Kowalski, 1990). Since the key purpose of IR is to provide additional information to capital providers, it can be argued that it is used as a mechanism to create better impression about the presented information in the eyes of the capital providers and hence should increase the presented information's value relevance.

Considering that managers have a responsibility to use company resources to maximize shareholder wealth (agency theory); additional information disclosed to the market is a mechanism for reducing information asymmetries and provide better decision making capacity to the capital providers (signalling theory); and information is used by the managers to control or modify the impressions of capital providers about the organization (impression management theory), it can be argued that presented information after implementation of IR should be more value relevant to the capital providers when compared to before IR periods. This is the central hypotheses of this thesis and is discussed in more detail below.

\subsection{Theoretical framework}

The theoretical framework of this thesis is developed using three individual theories. According to agency theory, managers have a fiduciary responsibility to take actions that maximizes shareholder wealth (Meckling and Jensen, 1976). Implementation of IR requires managers to divert organization resources from other areas and use that to present additional information as required by the IR framework. Considering that it is the responsibility of the managers to take actions so that it directly or indirectly maximizes shareholder wealth, it fol- 
lows that presented information under IR should have a positive effect on shareholders decision making. If presented information under IR is more value relevant for capital providers then it can be argued that IR is adding value for the shareholders. The principal aim of this thesis is to test whether presented information under IR is more value relevant to the capital providers as it should be as posited by agency theory.

Signalling theory posits that information disclosed to the market is used to reduce existing information asymmetries, increase market efficiency, assist parties in making more informed decisions and overall increasing the value of the firm (Baiman and Verrecchia, 1996). Key purpose of IR is to provide information to capital providers which is not provided by traditional financial reporting and thereby leading to better decision making (IIRC, 2013). IR provides information in an integrated form which should lead to integrated thinking and better decision making by the capital providers (IIRC, 2013). If presentation of information under an IR approach is to aid in better decision making on the part of the capital providers, then it follows that the presented information should be more value relevant. This thesis measures if the presented information under IR is indeed more value relevant or not.

The purpose of IR is to provide integrated information, which should lead to integrated thinking and better decision-making. The argument in this thesis is that use of IR can signal to the market that since the presented information under IR is integrated, it should lead to better quality information and thus lead to better decision making by the capital providers. The key signal here is the integration of information.

Impression management theory states that information is used as a way of changing or modifying the impression one party has over another (Leary and Kowalski, 1990). In the context 
of corporate reporting, impression management is a method for managers to use information to manipulate capital provider's perception about the activities of the organization (Clatworthy and Jones, 2006). IR combines the concepts of financial and non-financial reporting together, provides information with focus on short, medium and long terms and aims to provide more integrated information which should lead to integrated thinking and better decision making on the part of shareholders (IIRC, 2013). If IR achieves this goal and capital providers have a better impression of the information presented in an IR approach compared to non IR approach, then it follows that presented information under IR should be more relevant to the capital providers. This thesis aims to address this claim by looking at the change in value relevance of accounting information from before IR implementation to after IR implementation.

This thesis is not arguing whether IR is increasing or decreasing impression management. Impression management theory is used here to provide a possible explanation of why managers use IR and how it could lead to greater value relevance of accounting information under IR. The attempt here is not so much to quantify impression management but rather explain how use of IR as a qualitative tool to moderate the impression of capital providers about the reported accounting information can possibly lead to greater value relevance of accounting information under IR. The effect argued here is indirect not direct. No attempt is made in this thesis to associate impression management with concepts such as earnings management neither is there any goal to quantify impression management directly. The argument is that if managers can use IR as a tool to qualitatively create a better impression in the eyes of the readers of IR that information presented under IR is more value relevant then that should have an effect in the value relevance of accounting information. The effect being argued here is linked between IR 
and value relevance of accounting information. No attempt is being made to quantitatively measure whether impression management is increasing or decreasing under IR.

\subsection{Hypotheses development}

The key aim of this thesis is to address the question, what is the value of implementing IR and is it relevant for capital providers? The discussion on the theoretical framework shows that effectiveness of adopting IR can be measured by enhancements to the relevance of reported information as a result of the adoption of IR. This thesis specifically tests whether adopting IR results in the said enhancement and determines the value relevance of implementing IR.

The central idea behind this thesis is that if IR is associated with higher value relevance, then it is contributing towards increased usefulness of reported accounting information to the capital providers and other stakeholders. If IR is to be decision useful for the capital providers, then implementation of IR should increase the value relevance of reported accounting information under IR in comparison to what was there before.

Based on Lubberink and Willett (2017), multiplicative regression models are used in this thesis to analyze the value relevance of accounting information under IR. The use of multiplicative models in this thesis mitigates the shortcomings of existing additive-linear models. As shown by Lubberink and Willett (2020), the commonly used additive-linear form of the relationship between accounting values and market are logically incorrect and empirically inaccurate. Existing additive linear models fails to measure for scale and distributional form of accounting numbers are often not normal. This leads to misunderstanding and confusion regarding the interpretation of the decision usefulness of accounting values when examined using traditional linear models. To mitigate this logarithmic transformation is used in the analysis and 
log-linear multiplicative models are used to determine the value relevance of accounting information under IR. The log-linear transformation mitigates the scale problem of existing linear models by providing a scale free model that shows the relationship between different variables in the form of elasticities. This demonstrates the change in value relevance of accounting information under IR in a more accurate and representative manner and provides valuable insights as to their decision usefulness.

Consequently, the coefficient estimates of market elasticities of different accounting numbers are used as the measure for value relevance. If these estimates are positive and closer to one after implementation of IR than it was before, then it will signify that IR increases the relevance of reported accounting information.

Initially, the market elasticities of book value per share, earnings per share and dividend per share are measured, all of which has been predominantly used in the literature as the summary measure for value relevance (see Barth et al., 2017). The idea being, if IR does indeed enhance the relevance of reported accounting information, then the elasticities of these accounting numbers should improve and be closer to one after the implementation of IR than it was before.

As this thesis focuses on two different settings, mandatory and voluntary, of IR adoption, separate hypotheses are developed for both settings.

\subsubsection{Mandatory setting}

In the mandatory setting of JSE, if IR is to be useful for capital providers decision making purposes, then it is expected that implementation of IR will increase the value relevance of reported accounting information. As elasticities are used in thesis to measure value relevance, the central hypothesis for the mandatory setting is as follows: 
Hypothesis 1 The sum of market price elasticities of summary accounting information is higher and closer to one after the implementation of IR than it was before.

\subsubsection{Voluntary setting}

Under the voluntary setting, two different markets are used: the TSE of Japan and the European markets. Under different scenarios, different results are expected. In large well developed markets with rigorous reporting regimes (i.e. Japan, United Kingdom, United Sates of America etc.) information asymmetry can be considered minimal and the market is close to being efficient. In that situation, voluntary adoption of IR should not result in any significant change to the information environment in the market and thus should have minimal effect. The effect is measured using the same method as for the mandatory setting using market elasticities. The hypothesis derived from this is as follows:

Hypothesis 2 In large well developed markets with rigorous reporting environment voluntary adoption of IR should have minimal to no effect on the change in value relevance of accounting information.

However, in smaller markets with less rigorous reporting regimes (i.e. European markets excluding UK), implementation of IR should result in increased benefit as IR purports to provide additional information not provided by the existing reporting paradigm. The argument here is that IR would reduce information asymmetry by providing a common framework for presentation of IR information. If all prepares of IR use a common framework and that framework is designed to provide additional value-added information, then it can be argued that the result that comes from this process will reduce information asymmetry. Of course as is true 
for any argument, it can also be argued here that more information can lead to greater information asymmetry. However, since the purpose of IR is to provide more integrated information with the specific aim of addressing the decision-making capacity of the capital providers, the argument made here is that IR should reduce information asymmetry in such a setting.

If the specific market characteristics and existing reporting paradigm moderates the effect of IR then it can be ascertained that IR will have a better effect in situations where the markets are smaller and existing reporting paradigm is less rigorous. The hypothesis is thus:

Hypothesis 3 Effect of IR in the value relevance of accounting information is moderated by the markets effects and rigorousness of existing reporting paradigm.

\subsection{Chapter summary}

This chapter presented a discussion on the theoretical framework underpinning this thesis and developed the hypotheses. Using the concepts of agency theory, signalling theory, and impression management theory, it is ascertained that if IR is relevant for decision making by the capital providers, then value relevance of reported accounting information should increase after the implementation IR when compared to before IR periods. However, it is expected that this effect on value relevance will be moderated by whether the implementation is mandatory or voluntary and by the market characteristics. In the mandatory setting it is expected that implementation of IR will add additional value to the existing reporting framework and thus it is hypothesized that value relevance of accounting information will increase after the implementation of IR.

In the voluntary setting this effect will be moderated by the exiting market characteristics. In large well developed markets with rigorous reporting environment, voluntary implementa- 
tion of IR should not provide any additional benefits in terms of shareholder decision making. However, in smaller markets, voluntary implementation of IR should provide additional useful information to the capital providers for the purpose of decision making and therefore value relevance of reported accounting information should increase after implementation of IR. 


\section{Chapter 6}

\section{Research design and data}

\subsection{Introduction}

This chapter presents an overview of the research design of this thesis and the data. Based on Lubberink and Willett (2020), multiplicative log-linear modelling technique is used which mitigates the shortcomings of existing linear modelling and provides more useful results. For the mandatory setting, the data is collected from JSE of South Africa which, as of yet is the only exchange to mandate IR. For the voluntary setting data is collected from two sources: from the TSE in Japan and the European markets. These markets are chosen as they have a large volume of voluntary implementers of IR and provide a differentiated sample for comparative analysis. Comparison between the Japanese and European markets provides the opportunity to analyze the effects of voluntary implementation of IR under different settings. The European market is diverse and excluding UK, is a collection of smaller markets in similar geographical position. Whereas the Japanese market is large and significantly more developed. Comparative analysis between these two settings provides the opportunity to identify the possible scenarios in which 
implementation of IR can be useful for capital providers. The research design and associated data is discussed in detail below.

\subsection{Research design}

Accounting information is value relevant if it has predictive association with equity market prices. Value relevance research has a broad literature with different value relevance metrics being used (see Core, Guay, and Van Buskirk, 2003, Lang, Raedy, and Yetman, 2003, Lang, Smith Raedy, and Wilson, 2006, Barth, Li, and McClure, 2017, etc.). Despite the wide breadth of value relevance research, the field is not without its controversies. As noted in the Chapter 4 of this thesis, there are dissenting views about the efficacy of research focusing on the value relevance of accounting information. Lubberink and Willett argue that a key factor contributing to the differentiated opinions regarding the research value of value relevance of accounting information is the functional forms of the mathematical models that are used to measure the relationship between market values and summary accounting variables. Value relevance research to this date has almost exclusively focused on traditional linear models, which provide estimates that are highly volatile over time and are thus very difficult to interpret with any degree of certainty. For instance, Barth (1994), Francis and Schipper (1999), Barth et al. (2001), Song, Thomas, and Yi (2010), Zeng, Lee, and Zhang (2016) all use similar linear models to look into the relationship between market value, book value and earnings and report significantly different coefficients and results.

To explain and mitigate this issue, by analyzing Compustat data from 1971 to 2016 of firms in United States of America, Lubberink and Willett show that the traditional linear models used in the value relevance research is logically flawed and empirically inaccurate. The authors 
demonstrate this by replicating the coefficient patterns of the value relevance research using the traditional linear additive models. They subsequently run the analysis using the same data but applying the multiplicative model. The results show that the coefficient estimates of the multiplicative model are more consistent and superior than the coefficients produced by the traditional linear models. Lubberink and Willett demonstrate that the distributional of accounting variables under the linear additive approach do not remotely approach normal distribution and thus are subject to flawed estimations. Instead the authors show that the market to book relation takes the form of the power law and distributions of fundamental accounting variables such as earnings and dividends are log-normal. This implies that the relationship between market and fundamental accounting values is multiplicative instead of being additive and takes the following form:

$$
M_{i}=e^{k} \Pi_{n}\left|X_{i, n}\right|^{\beta n}+\varepsilon_{i}
$$

In which, $M_{i}=$ the market price; $X_{i, n}=$ a set of fundamental values; $\varepsilon_{i}=$ error term

In order to estimate this model, following Lubberink and Willett (2017), the model is converted to a linear version where the variables are the logs of the absolute values of $X_{i, n}$ :

$$
m_{i, t}=\beta_{0}+\sum_{n=1}^{N} \beta_{j} \cdot X_{n, i, t}+\varepsilon_{(i, t)}
$$

where $m_{i, t}$ is the market price and $X_{n, i, t}$ a list of $n$ accounting variables for the $i^{t h}$ firm all at time $t$. The intercept term, $\beta_{0}$, and the slope coefficients, $\beta_{n}$, are assumed constant, with the error term, $\varepsilon_{(i, t)}$, assumed to be approximately normally distributed. The explanatory variables are earnings per share, book value per share and dividend per share. 
The logs of absolute values are used because as shown by Lubberink and Willett, their elasticities are close to averages of the elasticities of the positive and negative values by the relative number of observations of each. This provides evidence that there is no information loss in taking the logs of absolute values of accounting variables when analysing elasticities (Lubberink and Willett, 2020).

\subsection{Sample and Data}

\subsubsection{Mandatory setting}

For the mandatory setting, accounting data are used from companies listed in the JSE of South Africa from 2003-2017. Book value per share, earnings per share and dividend per share are the key variables of interest because these are found to be most relevant and contains the most explanatory power when compared to price movements (Barth et al., 2017, Barth, Landsman, and Lang, 2008, Lubberink and Willett, 2017). This data is further divided in two parts: before-integrated reporting and after-integrated reporting periods. Since JSE mandated integrated reporting from the year 2010, the years between 2003 and 2009 are considered before $I R$ period and the following years as after IR period. In choosing the sample, first all companies listed in the JSE are selected. From the full sample, only the companies that issued integrated reports since 2010 regularly are picked. This selection is made by manually checking the annual reports of the organizations.

Descriptive Statistics - South Africa: Table 6.1 and Table 6.2 reports the descriptive statistics of key variables of interest in the sample from JSE in unlogged and logged format respectively. The sample firms are JSE listed firms with observations reported from 2003 to 2017 on a per share basis. 
The unlogged mean market value per share is 40.4 , mean book value per share 17.4 , mean earnings per share is 2.58 and mean dividend per share is 1.24 . Most of the variables in the sample have a wide range which suggests that there is variability in terms of size of the companies in the sample. However, since the multiplicative model is scale free, this is not considered to be an issue. In terms of spread of the data, the standard deviation naturally varies across variables with higher standard deviations observed in market values and book values. There are companies that have paid no dividends and it is adjusted for in the regression. Both profit and loss making companies are in the sample but, since logs of absolute values are used in the models, no further adjustments are necessary for them. Skewness and kurtosis figures reduce significantly under the logged data which further provides evidence of the multiplicative model better satisfying the Gauss-Markov assumptions and thereby providing better estimates under OLS. Number of observations varies across years which is due to data availability.

\subsubsection{Voluntary Setting}

For the voluntary setting, data is used from Japan and Europe as these two jurisdictions have the highest number of voluntary implementers of IR. For Europe, the countries included in the sample are Austria, Belgium, Denmark, England, Finland, France, Germany, Italy, Luxembourg, Netherlands, Poland, Russian, Spain, Sweden, Switzerland and Turkey. These countries were chosen due data availability. The same data that is collected for the mandatory setting is also collected for the voluntary settings. However, for the voluntary setting, since the official framework of IR was released on 2013, the period on or after 2013 is considered after 
IR period. Matching the number of years after IR, the before IR period data is collected from 2008.

\subsubsection{Japan}

In the case of Japan, a list of all companies in Asia that issued integrated reports are downloaded from the official IIRC database (IIRC, 2020). From this full sample only publicly listed companies belonging to Japan are extracted. From this sub-sample, a manual check is done to identify all voluntary implementers from TSE who published integrated reports in 2013 and on-wards.

Descriptive Statistics - Japan: Table 6.3 and Table 6.4 show the descriptive statistics of unlogged and logged data respectively for companies registered in the TSE of Japan who voluntary issued integrated reports in the year 2013 and on-wards. The data is reported from 2008 to 2018 in Japanese Yen on a per share basis.

[Table $6.3 \&$ Table 6.4 about here]

The unlogged mean market value per share is observed to be 1,994 , mean book value per share is 1,574 , mean earnings per share is 114 and mean dividend per share is 39.5 . The sample is diverse with a wide range in all of the variables. The difference between the 5 th percentile and the 75th percentile is large for all variables is the sample. In terms of spread of the data, the standard deviation of the variables are close to their mean values. As the multiplicative modelling technique is used in this thesis, which provides a scale free environment, the range of difference and standard deviation of the values does not present any significant issue. The reduction in skewness and kurtosis of the data from the unlogged to logged format further show 
that the data under the multiplicative model better satisfies the Gauss-Markov assumption when compared to the traditional additive models.

\subsubsection{Europe}

For Europe primarily data is collected from the IIRC database (IIRC, 2020) for all companies who issued integrated reports. From this sample, the publicly listed entities are manually selected and only companies that issued integrated reports in 2013 and on-wards are kept. A manual check is done to identify the companies that issued integrated reports since 2013.

Descriptive Statistics - Europe: Table 6.5 and Table 6.6 show the descriptive statistics in unlogged and logged format respectively of all firms in Europe who issued integrated reports from year 2013 and on-wards. The data is reported on Euros and is on a per share basis.

\section{[Table $6.5 \&$ Table 6.6 about here]}

The European market is comprised of some smaller similar markets and some larger one like the UK. The data demonstrates that with some obvious large outliers which explains the large standard deviations. As expected the sample is diverse with a wide range on all variables. This is consistent with the diversity noted in the European markets in terms of their sizes. Similar to previous findings, significant reduction is observed in the skewness and kurtosis of the data under the logged format providing further evidence of the efficacy of the multiplicative model better satisfying the Gauss-Markov criteria.

\section{Europe excluding $U K$}


Since the UK is the outlier as the largest market in Europe and is not part of the same reporting regime as the rest of Europe, separate analysis is done by excluding UK. For this, from the Europe sample data for all companies belonging to the UK are excluded.

Descriptive Statistics - Europe excluding UK: The descriptive statistics of the sample excluding UK is demonstrated in Table 6.7 and Table 6.8 in unlogged and logged form respectively. The data is reported in Euros, on a per share basis and covers the period 2008 to 2018.

[Table 6.7 about here]

The data is widely spread with a high range for all the variables. The sample excluding UK shows much lower standard deviation for earnings per share, book value per share and dividend per share when compared to the sample including UK. This is expected as UK is the largest market in Europe and removing it changes the sample characteristics. This is useful for this thesis because it allows for a differentiated sample which provides additional useful insights about change in value relevance of accounting information under different circumstances. The mean values of all variables also lowers significantly in the sample excluding UK. This can be explained by the fact that UK has the largest firms and removing it from the sample reduced the average values across the sample. Similar to previous finding, taking logs of the variables significantly reduces the skewness and kurtosis demonstrating the data is more normally distributed under the multiplicative method.

\subsection{Chapter summary}

This chapter presented the research design of this thesis and discussed the data that are used. This thesis uses a novel multiplicative modelling technique in its analysis. This multiplicative 
modelling technique based on Lubberink and Willett, presents significant advantages over the traditional linear modelling techniques used in the literature. The modelling technique is scale free and provides better estimates when compared to the previous techniques. Taking logs of the variables significantly reduces their skewness and kurtosis which provides evidence that the multiplicative model better satisfies the Gauss-Markov assumptions for application of OLS and thus is the superior method for regression based analysis.

For the mandatory setting data on market values and different accounting variables are collected from the JSE of South Africa. For the voluntary setting, the TSE from Japan and the European markets are used. The European data is further subdivided by including and excluding the UK, which provides a differentiated sample. Analysis of the descriptive statistics show that the data is well balanced and diverse for both settings. 


\subsection{Appendix for Chapter 6}

Table 6.1 Descriptive Statistics. - South Africa (Unlogged data)

\begin{tabular}{|c|c|c|c|c|c|c|c|c|c|c|}
\hline$n=3,251$ & Mean & Min & $\mathrm{p} 5$ & $\mathrm{p} 25$ & p50 & p75 & Max & StDev & Skewness & Kurtosis \\
\hline $\mathrm{M}$ & 40.4 & 0.00 & 0.26 & 2.70 & 12.5 & 40.7 & 2,540 & 93.7 & 10.8 & 213 \\
\hline BV & 17.4 & -115 & 0.08 & 1.37 & 5.92 & 18.6 & 1,388 & 41.3 & 17.0 & 492 \\
\hline NI & 2.58 & -95.5 & -0.61 & 0.10 & 0.79 & 2.97 & 94.5 & 6.93 & 1.94 & 55.2 \\
\hline DIV & 1.24 & 0.00 & 0.00 & 0.00 & 0.31 & 1.29 & 56.4 & 2.85 & 8.28 & 114 \\
\hline Year & & & & & & M & BV & NI & DIV & \# of Obs. \\
\hline 2003 & & & & & & 13.2 & 9.6 & 1.13 & 0.67 & 158 \\
\hline 2004 & & & & & & 16.9 & 8.83 & 1.45 & 0.54 & 160 \\
\hline 2005 & & & & & & 19.8 & 9.5 & 2.49 & 0.63 & 163 \\
\hline 2006 & & & & & & 31.3 & 13.0 & 3.38 & 0.77 & 171 \\
\hline 2007 & & & & & & 41.6 & 14.8 & 3.60 & 1.07 & 185 \\
\hline 2008 & & & & & & 40.1 & 16.2 & 3.76 & 1.27 & 207 \\
\hline 2009 & & & & & & 26.5 & 20.2 & 2.39 & 1.27 & 213 \\
\hline 2010 & & & & & & 35.7 & 20.0 & 2.51 & 0.89 & 219 \\
\hline 2011 & & & & & & 39.4 & 20.5 & 3.15 & 1.11 & 224 \\
\hline 2012 & & & & & & 41.8 & 26.5 & 3.14 & 1.32 & 233 \\
\hline 2013 & & & & & & 44.1 & 28.6 & 2.84 & 1.32 & 242 \\
\hline 2014 & & & & & & 50.6 & 24.9 & 3.20 & 1.43 & 248 \\
\hline 2015 & & & & & & 55.2 & 28.2 & 3.03 & 1.39 & 264 \\
\hline 2016 & & & & & & 52.3 & 29.6 & -1.33 & 1.44 & 276 \\
\hline 2017 & & & & & & 54.7 & 26.9 & 0.77 & 1.47 & 288 \\
\hline
\end{tabular}

This table presents descriptive statistics of variables from companies registered in the Johannesburg Stock Exchange over the 2003 to 2017 period. The variables are not logged and are in their original format. $M$ is market price per share. $B V$ is book value per share. $N I$ is earnings per share. DIV is dividend per share. Yearly values presented are means of the variables. All data have been collected from EIKON Datastream. Both financial and non-financial firms are included. 
Table 6.2 Descriptive Statistics. - South Africa (Logged data)

\begin{tabular}{|c|c|c|c|c|c|c|c|c|c|c|}
\hline$n=3,251$ & Mean & Min & p5 & $\mathrm{p} 25$ & $\mathrm{p} 50$ & p75 & Max & StDev & Skewness & Kurtosis \\
\hline $\mathrm{M}$ & 2.26 & -4.61 & -1.27 & 1.00 & 2.53 & 3.71 & 7.84 & 2.01 & -0.56 & 3.13 \\
\hline BV & 1.53 & -6.91 & -2.15 & 0.35 & 1.80 & 2.93 & 7.24 & 2.00 & -0.83 & 4.00 \\
\hline NI & -0.25 & -11.6 & -3.69 & -1.54 & 0.00 & 1.21 & 4.56 & 2.01 & -0.66 & 3.73 \\
\hline DIV & -0.43 & -4.61 & -3.22 & -1.39 & -0.24 & 0.69 & 4.03 & 1.55 & -0.38 & 2.77 \\
\hline Year & & & & & & M & BV & NI & DIV & \# of Obs. \\
\hline 2003 & & & & & & 1.60 & 1.21 & -0.53 & -0.98 & 158 \\
\hline 2004 & & & & & & 1.88 & 1.11 & -0.60 & -0.90 & 160 \\
\hline 2005 & & & & & & 2.17 & 0.99 & -0.55 & -0.61 & 163 \\
\hline 2006 & & & & & & 2.41 & 0.92 & -0.28 & -0.41 & 171 \\
\hline 2007 & & & & & & 2.54 & 1.10 & -0.26 & -0.37 & 185 \\
\hline 2008 & & & & & & 1.91 & 1.26 & -0.08 & -0.45 & 207 \\
\hline 2009 & & & & & & 2.02 & 1.54 & -0.28 & -0.47 & 213 \\
\hline 2010 & & & & & & 2.19 & 1.59 & -0.29 & -0.56 & 219 \\
\hline 2011 & & & & & & 2.20 & 1.63 & -0.31 & -0.37 & 224 \\
\hline 2012 & & & & & & 2.32 & 1.65 & -0.27 & -0.22 & 233 \\
\hline 2013 & & & & & & 2.50 & 1.69 & -0.25 & -0.22 & 242 \\
\hline 2014 & & & & & & 2.50 & 1.69 & -0.20 & -0.27 & 248 \\
\hline 2015 & & & & & & 2.40 & 1.75 & -0.05 & -0.29 & 264 \\
\hline 2016 & & & & & & 2.45 & 1.95 & -0.08 & -0.33 & 276 \\
\hline 2017 & & & & & & 2.39 & 2.03 & -0.10 & -0.32 & 288 \\
\hline
\end{tabular}

This table presents descriptive statistics of variables from companies registered in the Johannesburg Stock Exchange over the 2003 to 2017 period. The variables are logs of absolute values. $M$ is market price per share. $B V$ is book value per share. $N I$ is earnings per share. $D I V$ is dividend per share. Yearly values presented are means of the variables. All data have been collected from EIKON Datastream. Both financial and non-financial firms are included. 
Table 6.3 Descriptive Statistics. - Japan (Unlogged Data)

\begin{tabular}{|c|c|c|c|c|c|c|c|c|c|c|}
\hline$n=1,483$ & Mean & Min & $\mathrm{p} 5$ & $\mathrm{p} 25$ & $\mathrm{p} 50$ & $\mathrm{p} 75$ & Max & StDev & Skewness & Kurtosis \\
\hline M & 1,994 & 119 & 369 & 831 & 1,488 & 2,527 & 18,295 & 1,801 & 2.69 & 15.0 \\
\hline BV & 1,574 & $-1,306$ & 376 & 729 & 1,276 & 2,048 & 7,500 & 1,166 & 1.63 & 6.48 \\
\hline NI & 114 & 0.00 & 0.00 & 31.8 & 77.8 & 160 & 1,314 & 130 & 2.76 & 16.2 \\
\hline DIV & 39.5 & 0.00 & 0.00 & 14.0 & 28.0 & 50.0 & 583 & 45.2 & 4.42 & 37.2 \\
\hline Year & & & & & & M & BV & NI & DIV & \# of Obs. \\
\hline 2008 & & & & & & 2,138 & 1,586 & 141 & 39.1 & 128 \\
\hline 2009 & & & & & & 1,381 & 1,555 & 67.2 & 35.9 & 130 \\
\hline 2010 & & & & & & 1,542 & 1,351 & 55.0 & 27.2 & 133 \\
\hline 2011 & & & & & & 1,450 & 1,373 & 94.5 & 31.5 & 134 \\
\hline 2012 & & & & & & 1,303 & 1,397 & 75.4 & 33.5 & 135 \\
\hline 2013 & & & & & & 1,904 & 1,391 & 94.2 & 34.3 & 136 \\
\hline 2014 & & & & & & 1,831 & 1,524 & 123 & 37.1 & 136 \\
\hline 2015 & & & & & & 2,463 & 1,650 & 126 & 42.4 & 136 \\
\hline 2016 & & & & & & 2,121 & 1,837 & 131 & 45.9 & 136 \\
\hline 2017 & & & & & & 2,690 & 1,772 & 151 & 48.9 & 136 \\
\hline 2018 & & & & & & 3,065 & 1,874 & 193 & 57.7 & 136 \\
\hline
\end{tabular}

This table presents descriptive statistics of variables from companies registered in the Tokyo Stock Exchange over the 2008 to 2018 period. Variables are not logged and are in their original format. $M$ is market price per share. $B V$ is book value per share. $N I$ is earnings per share. $D I V$ is dividend per share. Yearly values presented are means of the variables. All data have been collected from EIKON Datastream. Both financial and non-financial firms are included. 
Table 6.4 Descriptive Statistics. - Japan (Logged Data)

\begin{tabular}{|c|c|c|c|c|c|c|c|c|c|c|}
\hline$n=1,483$ & Mean & Min & p5 & $\mathrm{p} 25$ & p50 & p75 & Max & StDev & Skewness & Kurtosis \\
\hline M & 7.30 & 4.78 & 5.93 & 6.76 & 7.33 & 7.87 & 9.8 & 0.82 & -0.09 & 2.80 \\
\hline BV & 7.11 & 1.35 & 5.93 & 6.59 & 7.15 & 7.62 & 8.92 & 0.75 & -0.56 & 5.23 \\
\hline NI & 4.43 & -1.39 & 2.46 & 3.88 & 4.52 & 5.16 & 7.18 & 1.08 & -1.03 & 5.46 \\
\hline DIV & 3.34 & 0.69 & 1.95 & 2.77 & 3.40 & 3.91 & 6.37 & 0.86 & -0.02 & 3.19 \\
\hline Year & & & & & & M & BV & NI & DIV & \# of Obs. \\
\hline 2008 & & & & & & 7.63 & 7.04 & 4.66 & 3.19 & 128 \\
\hline 2009 & & & & & & 7.34 & 7.06 & 4.56 & 3.35 & 130 \\
\hline 2010 & & & & & & 6.94 & 7.06 & 3.84 & 3.29 & 132 \\
\hline 2011 & & & & & & 7.06 & 6.93 & 3.82 & 3.04 & 133 \\
\hline 2012 & & & & & & 7.01 & 6.97 & 4.14 & 3.14 & 134 \\
\hline 2013 & & & & & & 7.29 & 7.00 & 4.20 & 3.21 & 136 \\
\hline 2014 & & & & & & 7.25 & 7.09 & 4.60 & 3.32 & 136 \\
\hline 2015 & & & & & & 7.52 & 7.18 & 4.55 & 3.43 & 136 \\
\hline 2016 & & & & & & 7.35 & 7.29 & 4.62 & 3.51 & 136 \\
\hline 2017 & & & & & & 7.60 & 7.26 & 4.74 & 3.61 & 136 \\
\hline 2018 & & & & & & 7.73 & 7.32 & 4.92 & 3.78 & 136 \\
\hline
\end{tabular}

This table presents descriptive statistics of variables from companies registered in the Tokyo Stock Exchange over the 2008 to 2018 period. Variables are logs of absolute values. $M$ is market price per share. $B V$ is book value per share. $N I$ is earnings per share. $D I V$ is dividend per share. Yearly values presented are means of the variables. All data have been collected from EIKON Datastream. Both financial and non-financial firms are included. 
Table 6.5 Descriptive Statistics. - Europe Combined (Unlogged data)

\begin{tabular}{|c|c|c|c|c|c|c|c|c|c|c|}
\hline$n=1,333$ & Mean & Min & $\mathrm{p} 5$ & $\mathrm{p} 25$ & p50 & p75 & Max & StDev & Skewness & Kurtosis \\
\hline $\mathrm{M}$ & 446 & 0.01 & 2.96 & 15.9 & 65.2 & 456 & 5,975 & 831 & 2.76 & 11.5 \\
\hline BV & 10.1 & $-9,900$ & 0.83 & 3.34 & 8.16 & 21.7 & 520 & 379 & -235 & 573 \\
\hline NI & -3.25 & $-5,050$ & -0.44 & 0.29 & 0.94 & 2.40 & 92.6 & 171 & -26.3 & 725 \\
\hline DIV & 13.3 & 0.00 & 0.00 & 0.38 & 1.30 & 10.2 & 226 & 29.6 & 3.70 & 19.2 \\
\hline Year & & & & & & M & $\mathrm{BV}$ & NI & DIV & \# of Obs. \\
\hline 2008 & & & & & & 247 & 22.0 & 2.62 & 9.9 & 97 \\
\hline 2009 & & & & & & 337 & 21.4 & -48.0 & 9.8 & 98 \\
\hline 2010 & & & & & & 415 & -54.5 & -23.5 & 10.3 & 98 \\
\hline 2011 & & & & & & 395 & -72.8 & 3.59 & 11.4 & 98 \\
\hline 2012 & & & & & & 439 & 26.4 & 3.40 & 12.8 & 99 \\
\hline 2013 & & & & & & 472 & 26.3 & 3.77 & 13.0 & 101 \\
\hline 2014 & & & & & & 469 & 30.5 & 3.20 & 14.4 & 102 \\
\hline 2015 & & & & & & 468 & 26.3 & 3.45 & 14.7 & 102 \\
\hline 2016 & & & & & & 528 & 26.0 & 3.98 & 15.2 & 103 \\
\hline 2017 & & & & & & 572 & 27.6 & 5.12 & 16.1 & 105 \\
\hline 2018 & & & & & & 542 & 29.5 & 4.60 & 17.8 & 105 \\
\hline
\end{tabular}

This table presents descriptive statistics of variables from companies registered in the European Stock Exchanges over the 2008 to 2018 period. The variables are unlogged and are in their original format. $M$ is market price per share. $B V$ is book value per share. $N I$ is earnings per share. DIV is dividend per share. Yearly values presented are means of the variables. All data have been collected from EIKON Datastream. Both financial and non-financial firms are included. 
Table 6.6 Descriptive Statistics. - Europe Combined (Logged data)

\begin{tabular}{|c|c|c|c|c|c|c|c|c|c|c|}
\hline$n=1,333$ & Mean & Min & p5 & $\mathrm{p} 25$ & $\mathrm{p} 50$ & p75 & Max & StDev & Skewness & Kurtosis \\
\hline M & 4.33 & -4.49 & 1.09 & 2.76 & 4.18 & 6.12 & 8.70 & 2.12 & 0.00 & 2.41 \\
\hline BV & 2.20 & -3.82 & -0.13 & 1.25 & 2.13 & 3.11 & 9.20 & 1.49 & 0.25 & 3.66 \\
\hline NI & 0.08 & -5.73 & -2.63 & -0.94 & 0.06 & 1.06 & 8.53 & 1.66 & 0.15 & 4.36 \\
\hline DIV & 0.82 & -4.61 & -2.41 & -0.54 & 0.41 & 2.52 & 5.42 & 2.08 & 0.16 & 2.30 \\
\hline Year & & & & & & M & BV & NI & DIV & \# of Obs. \\
\hline 2008 & & & & & & 3.91 & 2.01 & 0.08 & 0.85 & 97 \\
\hline 2009 & & & & & & 4.19 & 2.12 & -0.16 & 0.78 & 98 \\
\hline 2010 & & & & & & 4.31 & 2.21 & 0.18 & 0.72 & 98 \\
\hline 2011 & & & & & & 4.16 & 2.24 & 0.25 & 0.77 & 99 \\
\hline 2012 & & & & & & 4.22 & 2.22 & 0.00 & 0.83 & 101 \\
\hline 2013 & & & & & & 4.42 & 2.18 & -0.11 & 0.77 & 102 \\
\hline 2014 & & & & & & 4.40 & 2.18 & -0.03 & 0.72 & 102 \\
\hline 2015 & & & & & & 4.49 & 2.16 & 0.11 & 0.77 & 103 \\
\hline 2016 & & & & & & 4.49 & 2.26 & 0.13 & 0.87 & 105 \\
\hline 2017 & & & & & & 4.54 & 2.28 & 0.26 & 0.96 & 105 \\
\hline 2018 & & & & & & 4.40 & 2.31 & 0.14 & 0.99 & 105 \\
\hline
\end{tabular}

This table presents descriptive statistics of variables from companies registered in the European Stock Exchanges over the 2008 to 2018 period. The variables are logs of absolute values. $M$ is market price per share. $B V$ is book value per share. $N I$ is earnings per share. $D I V$ is dividend per share. Yearly values presented are means of the variables. All data have been collected from EIKON Datastream. Both financial and non-financial firms are included. 
Table 6.7 Descriptive Statistics. - Europe excluding UK (Unlogged data)

\begin{tabular}{|c|c|c|c|c|c|c|c|c|c|c|}
\hline$n=756$ & Mean & Min & p5 & $\mathrm{p} 25$ & p50 & p75 & Max & StDev & Skewness & Kurtosis \\
\hline M & 93.7 & 0.01 & 2.45 & 10.7 & 21.8 & 66.8 & 2,336 & 289 & 5.85 & 38.8 \\
\hline BV & 36.0 & -30.2 & 1.14 & 6.30 & 14.0 & 32.4 & 520 & 64.8 & 3.70 & 18.3 \\
\hline NI & 4.97 & -34.5 & -0.67 & 0.41 & 1.30 & 3.77 & 92.6 & 13.2 & 4.09 & 21.06 \\
\hline DIV & 2.60 & 0.00 & 0.00 & 0.21 & 0.80 & 1.81 & 75.0 & 7.96 & 6.34 & 47.1 \\
\hline Year & & & & & & M & BV & NI & DIV & \# of Obs. \\
\hline 2008 & & & & & & 53.1 & 31.0 & 3.65 & 2.04 & 65 \\
\hline 2009 & & & & & & 66.6 & 29.8 & 3.49 & 1.66 & 66 \\
\hline 2010 & & & & & & 77.3 & 31.8 & 4.78 & 1.65 & 66 \\
\hline 2011 & & & & & & 68.7 & 34.4 & 4.68 & 2.07 & 66 \\
\hline 2012 & & & & & & 84.0 & 36.8 & 4.53 & 2.43 & 66 \\
\hline 2013 & & & & & & 97.0 & 36.5 & 5.32 & 2.31 & 66 \\
\hline 2014 & & & & & & 98.0 & 43.4 & 4.46 & 2.99 & 67 \\
\hline 2015 & & & & & & 108 & 36.8 & 4.86 & 3.11 & 67 \\
\hline 2016 & & & & & & 116 & 36.2 & 5.55 & 3.26 & 68 \\
\hline 2017 & & & & & & 130 & 38.1 & 6.92 & 3.22 & 70 \\
\hline 2018 & & & & & & 127 & 40.4 & 6.31 & 3.74 & 70 \\
\hline
\end{tabular}

This table presents descriptive statistics of variables from companies registered in the European Stock Exchanges excluding United Kingdom over the 2008 to 2018 period. Variables are not logged and are in their original format. $M$ is market price per share. $B V$ is book value per share. $N I$ is earnings per share. DIV is dividend per share. Yearly values presented are means of the variables. All data have been collected from EIKON Datastream. Both financial and non-financial firms are included. 
Table 6.8 Descriptive Statistics. - Europe excluding UK (Logged data)

\begin{tabular}{|c|c|c|c|c|c|c|c|c|c|c|}
\hline$n=756$ & Mean & Min & p5 & $\mathrm{p} 25$ & p50 & $\mathrm{p} 75$ & Max & StDev & Skewness & Kurtosis \\
\hline M & 3.19 & -4.49 & 0.90 & 2.37 & 3.08 & 4.20 & 7.76 & 1.53 & 0.05 & 4.51 \\
\hline BV & 2.67 & -2.70 & 0.16 & 1.86 & 2.65 & 3.52 & 6.25 & 1.42 & -0.18 & 3.38 \\
\hline NI & 0.45 & -5.73 & -2.20 & -0.50 & 0.39 & 1.48 & 4.53 & 1.63 & -0.06 & 3.39 \\
\hline DIV & -0.15 & -4.61 & -2.81 & -0.97 & -0.04 & 0.69 & 4.32 & 1.46 & 0.09 & 3.68 \\
\hline Year & & & & & & M & BV & NI & DIV & \# of Obs. \\
\hline 2008 & & & & & & 2.86 & 2.56 & 0.44 & -0.06 & 65 \\
\hline 2009 & & & & & & 3.11 & 2.62 & 0.22 & -0.22 & 66 \\
\hline 2010 & & & & & & 3.19 & 2.66 & 0.50 & -0.29 & 66 \\
\hline 2011 & & & & & & 3.01 & 2.73 & 0.56 & -0.21 & 66 \\
\hline 2012 & & & & & & 3.03 & 2.70 & 0.29 & -0.16 & 66 \\
\hline 2013 & & & & & & 3.23 & 2.71 & 0.28 & -0.25 & 66 \\
\hline 2014 & & & & & & 3.23 & 2.66 & 0.29 & -0.29 & 67 \\
\hline 2015 & & & & & & 3.37 & 2.63 & 0.56 & -0.18 & 67 \\
\hline 2016 & & & & & & 3.33 & 2.69 & 0.58 & -0.07 & 68 \\
\hline 2017 & & & & & & 3.41 & 2.67 & 0.66 & -0.01 & 70 \\
\hline 2018 & & & & & & 3.26 & 2.70 & 0.52 & 0.04 & 70 \\
\hline
\end{tabular}

This table presents descriptive statistics of variables from companies registered in the European Stock Exchanges excluding United Kingdom over the 2008 to 2018 period. Variables are logs of absolute values. $M$ is market price per share. $B V$ is book value per share. $N I$ is earnings per share. DIV is dividend per share. Yearly values presented are means of the variables. All data have been collected from EIKON Datastream. Both financial and non-financial firms are included. 


\section{Chapter 7}

\section{Discussion of results - Mandatory setting}

\subsection{Introduction}

This chapter discusses the results and findings of the research in the mandatory setting of JSE. The results provide support for Hypothesis 1 and show that sum of market price elasticities of summary accounting information is higher and closer to one after the implementation of IR than it was before in the mandatory setting. The results also show an existence of structural break in the coefficients of summary accounting variables and share values between the before IR and after IR periods which further confirms Hypothesis 1. The findings are discussed in detail below.

\subsection{Main results}

Table 7.1 demonstrates the main regression results in the mandatory setting using the full sample. It can be noticed that the elasticity on book value per share, earnings per share and dividend per share varies over time. However, the key interest of this paper is in the overall value relevance on accounting information and thus the value of interest is the sum of the 
coefficients. The sum of the coefficients demonstrates an increasing pattern and consistent with the hypothesis, they are higher and more closer to one in the after IR period than the before IR period.

[Table 7.1 about here]

To further visualize the results, the value of the coefficients are presented in graph. Figure 7.1 shows the results of the main regression. An increasing pattern in the sum of the coefficients is clearly noticeable and overall value of the coefficients persists around one in the after IR period. There is also an anticipation effect that is noticed from the trend. South African mandated IR in 2010. It has been noted in the academic literature that new regulations elicit an anticipation effect whereby the effect of the regulation begins to manifest before the actual event (Ball and Brown, 1968). The same can possible by the case here. South African had been arguing about the implementation of integrated reporting few years before 2010 and the increasing value relevance before 2010 can be due to the anticipation effect.

[Figure 7.1 about here]

Further look into the yearly adjusted R-squared values also show a steadily increasing explanatory power of the multiplicative model. These results provide support for the idea that value relevance of accounting information increases under an IR approach under mandatory setting.

This provides evidence that in the mandatory setting of JSE, implementation of IR results in increased value relevance of accounting information. The results can be associated with the notion that implementation of IR increases the value of the information to the capital providers and thus increases the value relevance of presented accounting information. This is consistent 
with the Hypothesis 1 of this thesis that implementation of IR in a mandatory setting results in increased value relevance of accounting information.

Research into the economic condition of South Africa around the implementation of IR did not reveal any other significant major events that may have an exogenous effect in the findings of this thesis. South Africa has experienced steady Gross Domestic Product (GDP) growth since 2003 of around 3 percent per year with a relatively constant unemployment rate which has increased in the past few years (IMF, 2020). The country adopted the IFRS in 2005 (Ames, 2013) and since then the only major change in the reporting regime has been the implementation of IR. Analysis of the JSE all share index, which is one of the comprehensive indexes of JSE show that while the index has always experienced volatility, there has been no major unexpected movements around the implementation of IR (Bloomberg, 2020).

The discussion above provides evidence that the findings of this research in unlikely to be effected by other exogenous events. Thus it can be reasonably stated that while it cannot be absolutely discounted that there could be additional events that are effecting the findings of this thesis, the change in value relevance of accounting information as seen in this thesis is primarily due to the implementation of IR and not other factors.

\subsubsection{Variation in type of industry}

Since, financial firms have different reporting regulations from non-financial firms, in order to understand if the results vary across different type of industries, the sample is sub-divided between financial and non-financial firms. Table 7.2 and Figure 7.2 shows the results of the regression on financial firms only. Analysis of the financial firms shows mixed results.

[Table $7.2 \&$ Figure 7.2 about here] 
There is an increasing pattern in the sum of the coefficients however, they are neither as close to one or as stable as the full sample results. Adjusted R-squared values are steady over time but, there are no significant change in the after IR period. The results of the same analysis on nonfinancial firms are shown in Table 7.3 and Figure 7.3. Here, it can be clearly noticed that the sum of coefficients are more close to one in the after IR period and they remain stable. Adjusted R-squared values also remain stable over time and they demonstrate greater explanatory power in the after IR period.

[Table 7.3 \& Figure 7.3 about here]

These results suggest that the findings are more pronounced for non-financial firms than for financial firms. This could be due to the fact that financial firms have their separate reporting regime and thus are not as effected by IR as are non-financial firms.

\subsubsection{Effect of reporting quality}

Existing literature shows that there could be a effect of IR reporting quality in the derived benefit from implementing IR (Barth et al., 2016). To test this, the Ernst \& Young Excellence in Integrated Reporting awards (Ernst and Young, 2012) is used as a proxy for IR quality and the firms included in their award list in 2012 are assumed as firms that have issued high quality IR reports. The regression is run on these sub sample of firms from 2003 to 2017 . The results are reported in Table 7.4 and Figure 7.4.

[Table 7.4 \& Figure 7.4 about here]

The results are mixed until 2013 where the coefficients do not follow any particular discernible pattern. In fact, they seem to decrease between 2011 and 2012 instead of increasing. However, 
from 2013 a sharp increase is observed in the elasticity and as hypothesized, they become closer to one. While the decrease in elasticity in 2011 and 2012 is somewhat puzzling, the sharp increase following 2013 again shows that value relevance of accounting information does indeed increase in the after IR periods.

\subsubsection{Chow Test}

A Chow test using contrast is conducted to determine if there is a structural break within the coefficients of the accounting variables between the before and after IR periods. If there is a significant change in value relevance after implementing IR, the Chow test should show the presence of an structural break at the point where IR was implemented. The results of the Chow test is reported in Table 7.5.

[Table 7.5 about here]

The results show that overall Chow test statistic is highly significant. This provides further evidence to the assertion that value relevance of accounting information is different between before and after IR implementation. While this does not signal to the direction of the relationship, it provides support to the existing results.

\subsubsection{Difference-in-difference analysis}

Additionally, a difference-in-difference analysis is conducted between the before and after IR values to see if the two groups are significantly different from each other. The results are reported in Table 7.6.

[Table 7.6 about here] 
The results show that the interaction terms with the after IR period are highly significant for both earnings per share and book value per share which signifies that implementation of IR is associated with increased value relevance of these accounting variables. The overall model is also found to be highly significant which further provides validity to the results.

\subsection{Sensitivity Analysis}

As a novel statistical method is used in this thesis, in order to compare with the existing methods, a sensitivity analysis is performed where the initial results of the thesis is replicated using the full sample and traditional linear models instead of the multiplicative models. Table 7.7 and Figure 7.5 demonstrates the results using the traditional linear model.

\section{[Table $7.7 \&$ Figure 7.5 about here]}

It can be clearly seen that the coefficient values using the traditional model is highly unstable over time and provides little evidence of predictability. The coefficient values of earnings per share and dividend per share seem to be very close to zero and book value per share coefficient varies significantly with no discernible pattern. This provides very little evidence that can be used for any interpretation. Where as in the multiplicative model, as demonstrated in Figure 7.1, the estimates are more stable over time and thus are easier and more useful to interpret. In order to analyze the difference in explanatory power of both of these models, the adjusted R-squared values from both models are plotted in a comparative chart. The results are shown in Figure 7.6.

[Figure 7.6 about here]

This figure clearly shows that adjusted R-squared values are much higher and steady over time in multiplicative model when compared to traditional model. The traditional linear model 
provides highly variable values over time. This signifies high degree of variability in their explanatory power from one year to the next, which is unlikely and thus is difficult to explain. Whereas, the multiplicative model provides a much more plausible explanation with R-squared values that are more stable and steadily increasing over time. This provides evidence that the use of multiplicative models results in greater explanatory power and more useful interpretation of the results.

\subsection{Summary of findings}

The results discussed above provide confirmatory evidence of Hypothesis 1. The value relevance of accounting information increases in the after IR in the mandatory setting which indicates that capital providers value the effect of IR in the decision usefulness of accounting information. The existence of structural break in the coefficient values before and after IR implementation further confirms the increase in the value relevance of accounting information after implementation of IR in the mandatory setting. The results are robust for industry variations and reporting quality.

The sensitivity analysis demonstrates that the use of the multiplicative model provides estimates that are more consistent and provides greater explanatory power than the traditional linear models. This provides evidence that multiplicative model in the more robust and useful model to use when looking at value relevance as has been done in this thesis. 


\subsection{Appendix for Chapter 7}

Table 7.1 Overall Regression Results. - South Africa

\begin{tabular}{|c|c|c|c|c|c|c|c|c|c|c|}
\hline Year & & NI & BV & DIV & SUM & Intercept & $R^{2}$ & $A d j . R^{2}$ & Prob $>F$ & \# of Obs. \\
\hline 2003 & & 0.11 & 0.63 & 0.07 & 0.81 & -1.15 & 0.74 & 0.74 & 0.00 & 152 \\
\hline 2004 & & 0.18 & 0.62 & 0.04 & 0.84 & -1.37 & 0.77 & 0.76 & 0.00 & 156 \\
\hline 2005 & & 0.20 & 0.49 & 0.05 & 0.74 & -1.39 & 0.74 & 0.74 & 0.00 & 160 \\
\hline 2006 & Before IR & 0.18 & 0.56 & 0.06 & 0.79 & -0.95 & 0.79 & 0.79 & 0.00 & 163 \\
\hline 2007 & & 0.24 & 0.46 & 0.05 & 0.75 & -1.34 & 0.75 & 0.75 & 0.00 & 175 \\
\hline 2008 & & 0.32 & 0.49 & 0.03 & 0.85 & -2.51 & 0.80 & 0.80 & 0.00 & 200 \\
\hline 2009 & & 0.19 & 0.66 & 0.09 & 0.93 & -2.18 & 0.82 & 0.81 & 0.00 & 209 \\
\hline 2010 & & 0.15 & 0.78 & 0.08 & 1.01 & -1.66 & 0.83 & 0.83 & 0.00 & 214 \\
\hline 2011 & & 0.24 & 0.68 & 0.06 & 0.98 & -2.31 & 0.86 & 0.86 & 0.00 & 222 \\
\hline 2012 & & 0.20 & 0.65 & 0.07 & 0.92 & -1.78 & 0.85 & 0.84 & 0.00 & 229 \\
\hline 2013 & After IR & 0.20 & 0.59 & 0.08 & 0.88 & -1.82 & 0.79 & 0.79 & 0.00 & 236 \\
\hline 2014 & & 0.21 & 0.67 & 0.06 & 0.95 & -1.89 & 0.81 & 0.81 & 0.00 & 242 \\
\hline 2015 & & 0.29 & 0.50 & 0.08 & 0.87 & -2.67 & 0.77 & 0.77 & 0.00 & 257 \\
\hline 2016 & & 0.20 & 0.70 & 0.06 & 0.96 & -1.91 & 0.80 & 0.79 & 0.00 & 265 \\
\hline 2017 & & 0.11 & 0.82 & 0.06 & 0.98 & -1.10 & 0.83 & 0.83 & 0.00 & 268 \\
\hline
\end{tabular}

This table reports result of yearly regressions that rely on companies registered in the Johannesburg Exchange over the 2003 to 2017 period using the following model:

$$
\rho_{t}=\beta_{0}+\beta_{1} N I+\beta_{2} B V+\beta_{3} D I V+\varepsilon
$$

$\rho$ is $\log$ of absolute value of market price per share. $B V$ is $\log$ of absolute values of book value per share. $N I$ is log of absolute values of earnings per share. $D I V$ is $\log$ of absolutes values of dividend per share. SUM is the summation of all the coefficients. All data have been collected from EIKON Datastream. Both financial and non-financial firms are included. 
Figure 7.1: Market elasticities using full sample - South Africa

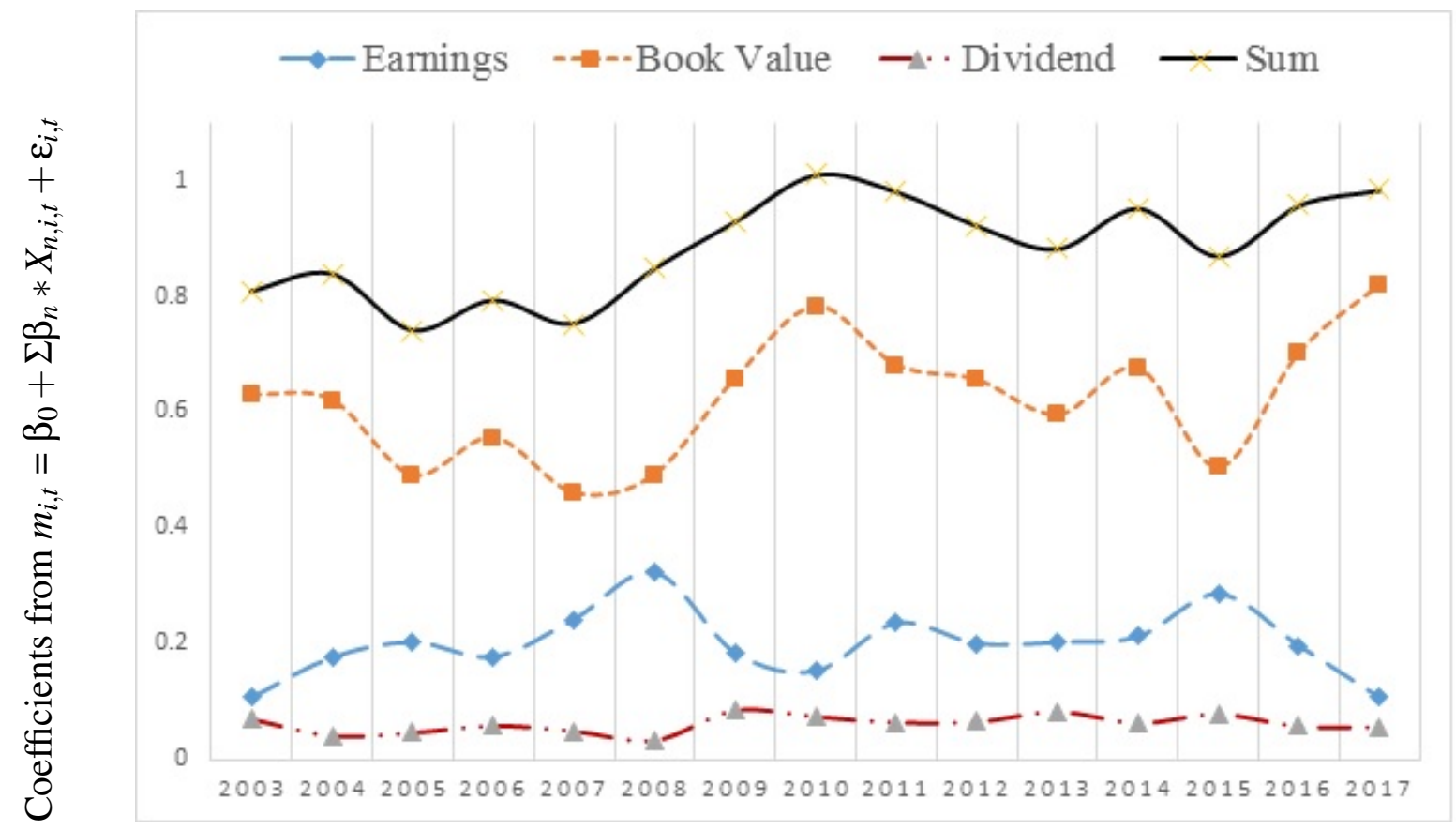

Comparison of market elasticities for $m=f(n i), m=f(b v), m=f(d i v)$, where the variables are logged absolute values of market price $(m)$; earnings per share $(n i)$; book value per share $(b v)$ and dividend per share (div). 
Table 7.2 Regression Results - Financial Firms - South Africa

\begin{tabular}{|c|c|c|c|c|c|c|c|c|c|c|}
\hline Year & & NI & $\mathrm{BV}$ & DIV & SUM & Intercept & $R^{2}$ & $A d j . R^{2}$ & Prob $>F$ & \# of Obs. \\
\hline 2003 & & 0.35 & 0.26 & 0.00 & 0.61 & -2.98 & 0.68 & 0.64 & 0.00 & 33 \\
\hline 2004 & & 0.19 & 0.48 & 0.03 & 0.71 & -1.37 & 0.76 & 0.73 & 0.00 & 35 \\
\hline 2005 & & 0.26 & 0.45 & -0.01 & 0.70 & -1.66 & 0.74 & 0.71 & 0.00 & 37 \\
\hline 2006 & Before IR & 0.09 & 0.52 & 0.07 & 0.68 & -0.05 & 0.75 & 0.73 & 0.00 & 36 \\
\hline 2007 & & 0.05 & 0.48 & 0.09 & 0.62 & 0.41 & 0.75 & 0.72 & 0.00 & 40 \\
\hline 2008 & & 0.19 & 0.48 & 0.04 & 0.71 & -1.12 & 0.74 & 0.72 & 0.00 & 45 \\
\hline 2009 & & 0.06 & 0.73 & 0.07 & 0.86 & -0.68 & 0.78 & 0.76 & 0.00 & 46 \\
\hline 2010 & & -0.03 & 0.72 & 0.14 & 0.83 & -0.03 & 0.83 & 0.82 & 0.00 & $\overline{48}$ \\
\hline 2011 & & 0.18 & 0.63 & 0.06 & 0.87 & -1.53 & 0.82 & 0.81 & 0.00 & 50 \\
\hline 2012 & & 0.19 & 0.65 & 0.04 & 0.88 & -1.51 & 0.77 & 0.75 & 0.00 & 54 \\
\hline 2013 & After IR & 0.16 & 0.42 & 0.08 & 0.67 & -0.94 & 0.62 & 0.60 & 0.00 & 60 \\
\hline 2014 & & 0.26 & 0.43 & 0.05 & 0.74 & -1.98 & 0.71 & 0.70 & 0.00 & 63 \\
\hline 2015 & & 0.17 & 0.59 & 0.06 & 0.83 & -1.27 & 0.82 & 0.81 & 0.00 & 70 \\
\hline 2016 & & 0.02 & 0.80 & 0.06 & 0.88 & 0.09 & 0.79 & 0.78 & 0.00 & 75 \\
\hline 2017 & & 0.10 & 0.89 & 0.03 & 1.02 & -1.02 & 0.85 & 0.84 & 0.00 & 77 \\
\hline
\end{tabular}

This table reports result of yearly regressions that rely on companies registered in the Johannesburg Exchange over the 2003 to 2017 period using the following model:

$$
\rho_{t}=\beta_{0}+\beta_{1} N I+\beta_{2} B V+\beta_{3} D I V+\varepsilon
$$

$\rho$ is log of absolute value of market price per share. $B V$ is log of absolute values of book value per share. $N I$ is log of absolute values of earnings per share. $D I V$ is log of absolutes values of dividend per share. SUM is the summation of all the coefficients. All data have been collected from EIKON Datastream. Only financial firms with SIC codes between 6,000 and 6,799 are included. 
Figure 7.2: Market elasticities for Financial Firms - South Africa

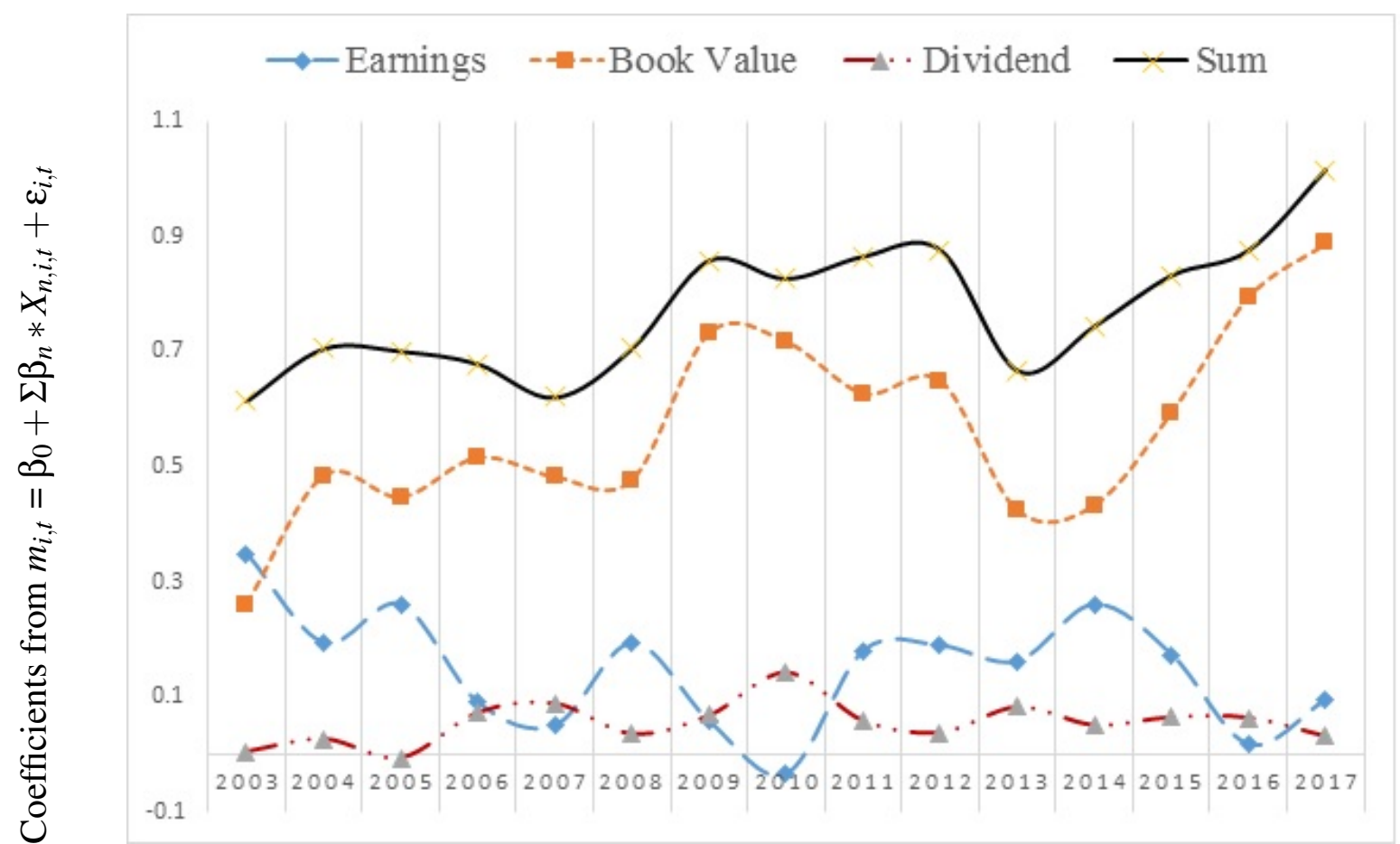

Comparison of market elasticities for $m=f(n i), m=f(b v), m=f(d i v)$, where the variables are logged absolute values of market price $(m)$; earnings per share $(n i)$; book value per share $(b v)$; and dividend per share (div). 
Table 7.3 Regression Results - Non-Financial Firms - South Africa

\begin{tabular}{|c|c|c|c|c|c|c|c|c|c|c|}
\hline Year & & NI & BV & DIV & SUM & Intercept & $R^{2}$ & $A d j . R^{2}$ & Prob $>F$ & \# of Obs. \\
\hline 2003 & & 0.05 & 0.78 & 0.08 & 0.91 & -0.74 & 0.80 & 0.80 & 0.00 & 119 \\
\hline 2004 & & 0.18 & 0.65 & 0.05 & 0.88 & -1.51 & 0.78 & 0.77 & 0.00 & 121 \\
\hline 2005 & & 0.20 & 0.49 & 0.06 & 0.76 & -1.51 & 0.75 & 0.74 & 0.00 & 123 \\
\hline 2006 & Before IR & 0.21 & 0.55 & 0.06 & 0.82 & -1.27 & 0.81 & 0.80 & 0.00 & 127 \\
\hline 2007 & & 0.30 & 0.44 & 0.05 & 0.79 & -1.93 & 0.77 & 0.77 & 0.00 & 135 \\
\hline 2008 & & 0.37 & 0.48 & 0.04 & 0.89 & -2.99 & 0.83 & 0.83 & 0.00 & 155 \\
\hline 2009 & & 0.22 & 0.64 & 0.09 & 0.95 & -2.60 & 0.83 & 0.83 & 0.00 & 163 \\
\hline 2010 & & 0.22 & 0.78 & 0.06 & 1.06 & -2.27 & 0.84 & 0.84 & 0.00 & 166 \\
\hline 2011 & & 0.28 & 0.68 & 0.07 & 1.03 & -2.88 & 0.88 & 0.88 & 0.00 & 172 \\
\hline 2012 & & 0.22 & 0.64 & 0.08 & 0.94 & -2.03 & 0.87 & 0.87 & 0.00 & 175 \\
\hline 2013 & After IR & 0.22 & 0.66 & 0.08 & 0.96 & -2.12 & 0.86 & 0.86 & 0.00 & 176 \\
\hline 2014 & & 0.19 & 0.78 & 0.07 & 1.04 & -1.82 & 0.86 & 0.86 & 0.00 & 179 \\
\hline 2015 & & 0.34 & 0.46 & 0.09 & 0.88 & -3.26 & 0.76 & 0.76 & 0.00 & 187 \\
\hline 2016 & & 0.30 & 0.65 & 0.06 & 1.01 & -3.04 & 0.81 & 0.81 & 0.00 & 190 \\
\hline 2017 & & 0.13 & 0.79 & 0.07 & 0.99 & -1.32 & 0.84 & 0.84 & 0.00 & 191 \\
\hline
\end{tabular}

This table reports result of yearly regressions that rely on companies registered in the Johannesburg Exchange over the 2003 to 2017 period using the following model:

$$
\rho_{t}=\beta_{0}+\beta_{1} N I+\beta_{2} B V+\beta_{3} D I V+\varepsilon
$$

$\rho$ is log of absolute value of market price per share. $B V$ is $\log$ of absolute values of book value per share. $N I$ is log of absolute values of earnings per share. $D I V$ is log of absolutes values of dividend per share. SUM is the summation of all the coefficients. All data have been collected from EIKON Datastream. Only non-financial firms are included. Companies with SIC codes between 6,000 and 6,799 are excluded. 
Figure 7.3: Market elasticities for Non-Financial Firms - South Africa

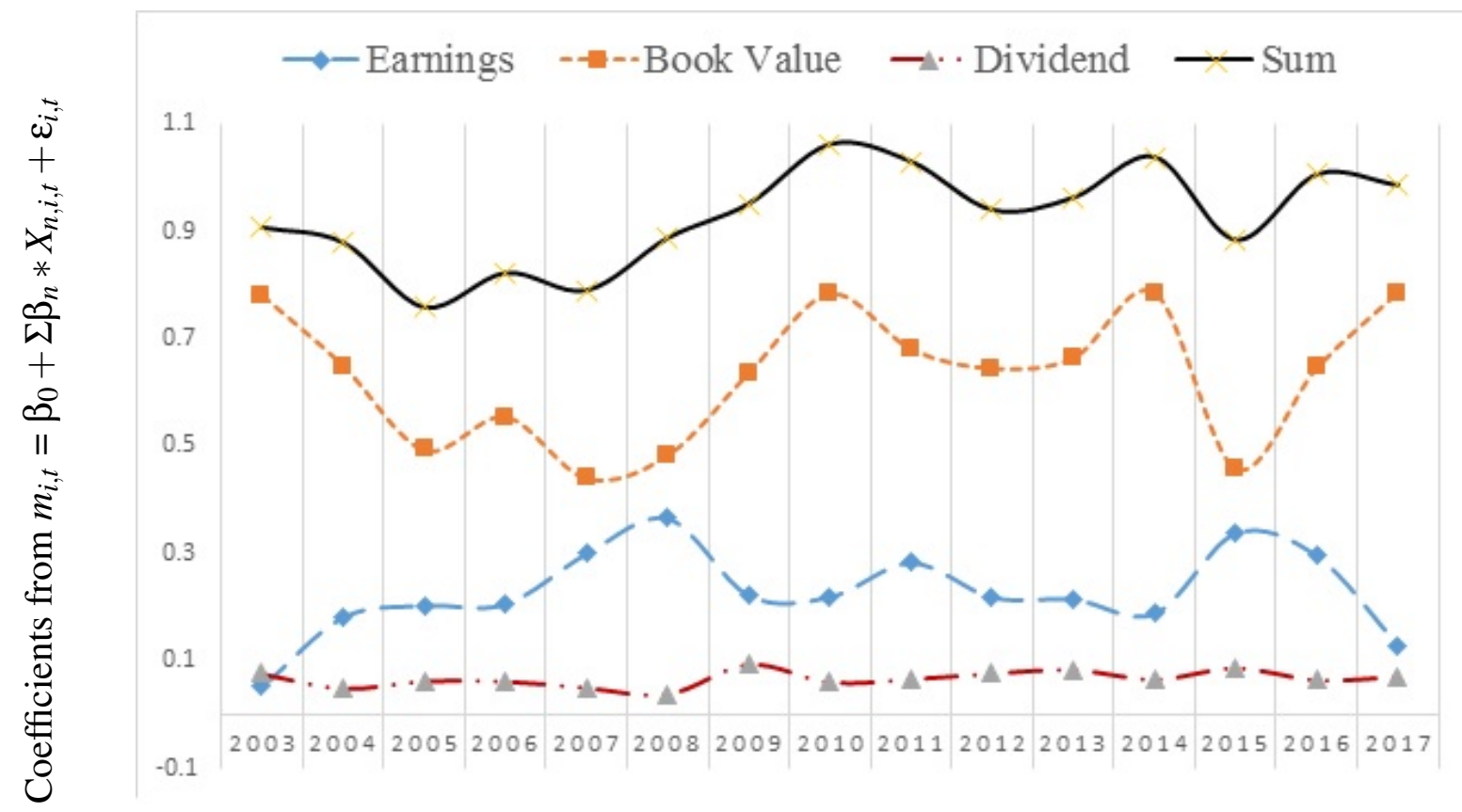

Comparison of market elasticities for $m=f(n i), m=f(b v), m=f(d i v)$, where the variables are logged absolute values of market price $(m)$; earnings per share $(n i)$; book value per share $(b v)$; and dividend per share (div). 
Table 7.4 Regression Results - Top 2012 - South Africa

\begin{tabular}{|c|c|c|c|c|c|c|c|c|c|c|}
\hline Year & & NI & $\mathrm{BV}$ & DIV & SUM & Intercept & $R^{2}$ & $A d j . R^{2}$ & Prob $>F$ & \# of Obs. \\
\hline 2003 & & 0.26 & 0.52 & 0.00 & 0.78 & -1.88 & 0.64 & 0.61 & 0.00 & 38 \\
\hline 2004 & & 0.16 & 0.58 & 0.00 & 0.74 & -0.37 & 0.67 & 0.64 & 0.00 & 38 \\
\hline 2005 & & 0.10 & 0.52 & -0.01 & 0.61 & 0.78 & 0.64 & 0.61 & 0.00 & 39 \\
\hline 2006 & Before IR & 0.04 & 0.53 & 0.04 & 0.61 & 1.51 & 0.61 & 0.57 & 0.00 & 39 \\
\hline 2007 & & 0.19 & 0.45 & 0.03 & 0.67 & -0.09 & 0.61 & 0.58 & 0.00 & 40 \\
\hline 2008 & & 0.31 & 0.39 & 0.05 & 0.76 & -2.16 & 0.63 & 0.60 & 0.00 & 40 \\
\hline 2009 & & 0.13 & 0.51 & -0.03 & 0.60 & 0.90 & 0.50 & 0.46 & 0.00 & 41 \\
\hline 2010 & & 0.15 & 0.58 & 0.00 & 0.73 & 0.32 & 0.61 & 0.57 & 0.00 & $\overline{42}$ \\
\hline 2011 & & 0.09 & 0.63 & 0.05 & 0.77 & 0.27 & 0.68 & 0.65 & 0.00 & 44 \\
\hline 2012 & & 0.23 & 0.51 & 0.02 & 0.76 & -1.01 & 0.64 & 0.62 & 0.00 & 45 \\
\hline 2013 & After IR & -0.04 & 0.37 & 0.04 & 0.37 & 3.21 & 0.41 & 0.37 & 0.00 & 46 \\
\hline 2014 & & 0.07 & 0.36 & 0.04 & 0.47 & 1.67 & 0.46 & 0.42 & 0.00 & 46 \\
\hline 2015 & & 0.14 & 0.70 & 0.08 & 0.93 & -1.27 & 0.58 & 0.55 & 0.00 & 46 \\
\hline 2016 & & 0.12 & 0.76 & 0.04 & 0.92 & -0.78 & 0.57 & 0.54 & 0.00 & 47 \\
\hline 2017 & & 0.10 & 0.77 & 0.04 & 0.91 & -0.55 & 0.65 & 0.63 & 0.00 & 47 \\
\hline
\end{tabular}

This table reports result of yearly regressions that rely on companies registered in the Johannesburg Exchange over the 2003 to 2017 period using the following model:

$$
\rho_{t}=\beta_{0}+\beta_{1} N I+\beta_{2} B V+\beta_{3} D I V+\varepsilon
$$

$\rho$ is log of absolute value of market price per share. $B V$ is log of absolute values of book value per share. $N I$ is log of absolute values of earnings per share. $D I V$ is log of absolutes values of dividend per share. SUM is the summation of all the coefficients. All data have been collected from EIKON Datastream. Only firms whose reports have been recognized by Ernst \& Young for excellence awards have been included. 
Figure 7.4: Market elasticities for Firms with Recognized Reports - South Africa

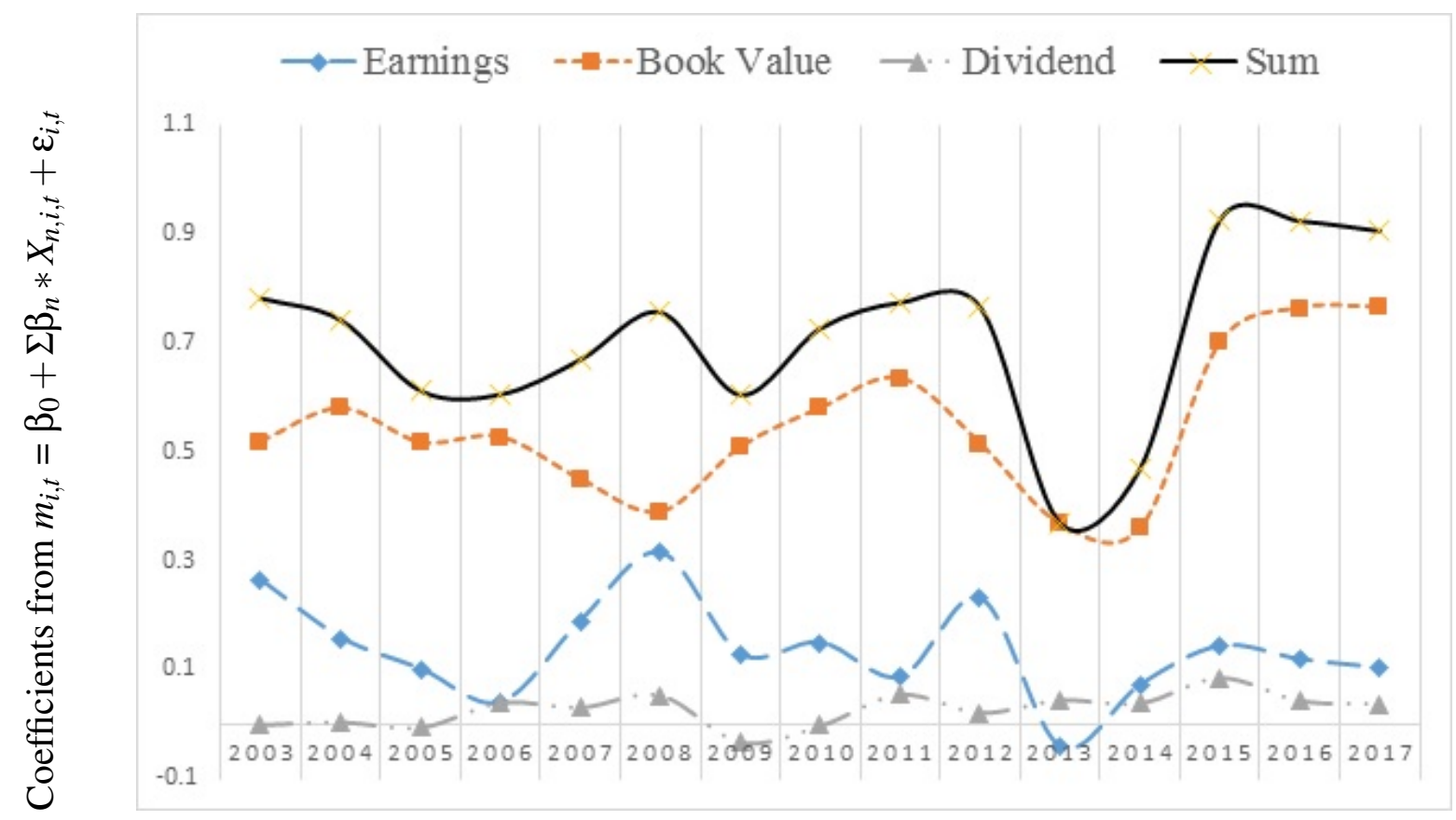

Comparison of market elasticities for $m=f(n i), m=f(b v), m=f(d i v)$, where the variables are logged absolute values of market price $(m)$; earnings per share $(n i)$; book value per share $(b v)$; and dividend per share (div). 
Table 7.5 Chow Test - South Africa

\begin{tabular}{lcc}
\hline Variables & F & Prob $>$ F \\
\hline POST & 43.49 & 0 \\
POST*BV & 13.73 & 0 \\
POST*NI & 271.53 & 0 \\
POST*DIV & 308.12 & 0 \\
OVERALL & $\mathbf{9 7 . 2}$ & $\mathbf{0 . 0 0}$
\end{tabular}

The table reports result of chow test that rely on companies registered in the Johannesburg Exchange over the 2003 to 2017 period using contrasts of marginal linear predictions. The following regression is used::

$$
\rho_{t}=\beta_{0}+\beta_{1} N I+\beta_{2} P O S T+\beta_{3} c . N I * P O S T+\beta_{4} B V+\beta_{5} c . B V * P O S T+\beta_{6} D I V+\beta_{7} c . D I V * P O S T+\varepsilon
$$

$\rho$ is log of absolute value of market price per share. $B V$ is log of absolute values of book value per share. $N I$ is log of absolute values of earnings per share. DIV is log of absolutes values of dividend per share. $c$ refers to contrast function. POST is indicator variable that has the value of 1 in after IR period from 2010 and 0 otherwise. All data have been collected from EIKON Datastream. Both financial and non-financial firms are included. 
Table 7.6 Regression Results - Difference in Difference - South Africa

\begin{tabular}{lrrrrrrrrrrrr}
\hline & Post & NI & Post*NI & BV & Post*BV & DIV & Post*DIV & Intercept & Adj.R $R^{2}$ & Prob $>F$ & Obs \\
\hline$\beta$ & 0.89 & 0.32 & -0.11 & 0.35 & 0.31 & 0.07 & 0.00 & -2.80 & 0.77 & 0.00 & 3,143 \\
$(t)$ & $4.00^{* * *}$ & $19.1 * * *$ & $-5.21 * * *$ & $19.1 * * *$ & $13.0 * * *$ & $10.3 * * *$ & -0.28 & & &
\end{tabular}

This table reports result of regression that rely on companies registered in the Johannesburg Exchange over the 2003 to 2017 period using the following model:

$$
\rho=\beta_{0}+\beta_{1} \text { Post }+\beta_{2} N I+\beta_{3} \text { Post } * N I+\beta_{4} B V+\beta_{5} \text { Post } * B V+\beta_{6} D I V+\beta_{7} \text { Post } * D I V+\varepsilon
$$

$\rho$ is market price per share. Post is an indicator variable that takes value of 1 in the after IR period and 0 in before IR period. NI is earnings per share. BV is book value per share. DIV is dividend per share. All data have been collected from EIKON Datastream. Both financial and non-financial firms are included.

For $t$-stat $* * * * * \& *$ represent significance at $1 \%, 5 \%$ and $10 \%$ respectively. 
Table 7.7 Regression Results - Traditional - South Africa

\begin{tabular}{|c|c|c|c|c|c|c|c|c|c|}
\hline Year & & NI & BV & DIV & Intercept & $R^{2}$ & $A d j . R^{2}$ & Prob $>F$ & \# of Obs. \\
\hline 2003 & & 0.00 & 0.01 & 0.00 & 4.98 & 0.67 & 0.66 & 0.00 & 147 \\
\hline 2004 & & 0.00 & 1.75 & 0.00 & -0.90 & 0.65 & 0.65 & 0.00 & 156 \\
\hline 2005 & & 0.00 & 1.71 & 0.00 & 1.24 & 0.68 & 0.67 & 0.00 & 160 \\
\hline 2006 & Before IR & 0.00 & 2.50 & 0.00 & 0.26 & 0.59 & 0.58 & 0.00 & 163 \\
\hline 2007 & & 0.00 & 1.76 & 0.00 & 5.96 & 0.74 & 0.74 & 0.00 & 175 \\
\hline 2008 & & 0.00 & 1.38 & 0.00 & 0.47 & 0.72 & 0.71 & 0.00 & 200 \\
\hline 2009 & & 0.00 & 0.14 & 0.00 & 14.0 & 0.29 & 0.28 & 0.00 & 209 \\
\hline 2010 & & 0.00 & 0.18 & 0.00 & 24.8 & 0.28 & 0.27 & 0.00 & 214 \\
\hline 2011 & & 0.00 & 0.26 & 0.00 & 18.3 & 0.44 & 0.44 & 0.00 & 222 \\
\hline 2012 & & 0.00 & 0.27 & 0.00 & 23.7 & 0.36 & 0.35 & 0.00 & 230 \\
\hline 2013 & After IR & 0.00 & 0.11 & 0.00 & 30.7 & 0.25 & 0.24 & 0.00 & 238 \\
\hline 2014 & & 0.00 & 0.22 & 0.00 & 32.3 & 0.28 & 0.27 & 0.00 & 243 \\
\hline 2015 & & 0.00 & 0.00 & 0.00 & 40.5 & 0.21 & 0.20 & 0.00 & 257 \\
\hline 2016 & & 0.00 & 0.19 & 0.00 & 27.0 & 0.22 & 0.21 & 0.00 & 265 \\
\hline 2017 & & 0.00 & 0.58 & 0.00 & 24.5 & 0.68 & 0.68 & 0.00 & 268 \\
\hline
\end{tabular}

This table reports result of yearly regressions that rely on companies registered in the Johannesburg Exchange over the 2003 to 2017 period using the following model:

$$
M=\beta_{0}+\beta_{1} N I+\beta_{2} B V+\beta_{3} D I V+\varepsilon
$$

$\mathrm{M}$ is market price per share. BV is book value per share. NI is earnings per share. DIV is dividend per share. All data have been collected from EIKON Datastream. Both financial and non-financial firms are included. . 
Figure 7.5: Regression coefficients using traditional linear model - South Africa

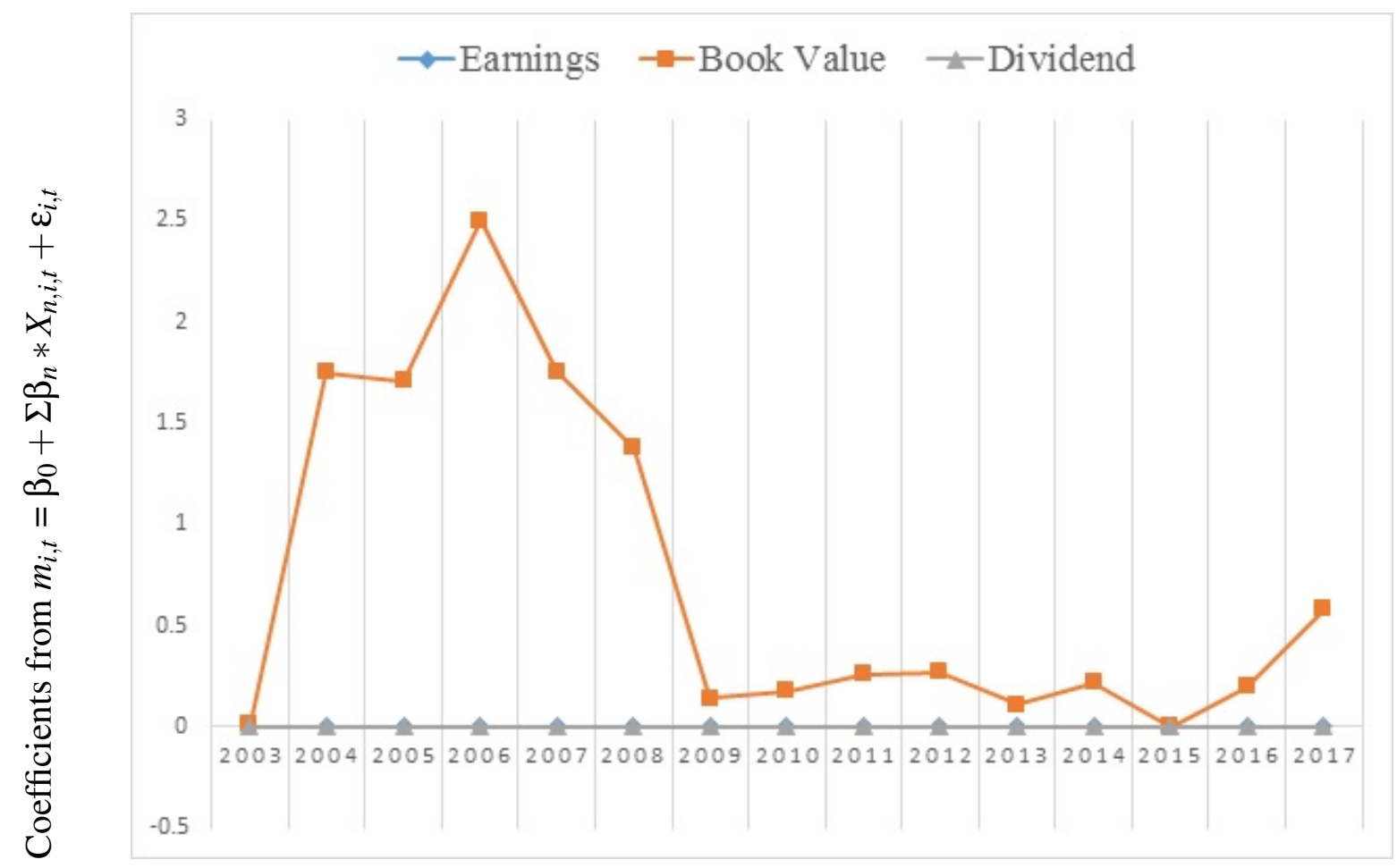

Regression coefficients using traditional linear models for $m=f(n i), m=f(b v), m=f(d i v)$, where the variables are market price $(m)$; earnings per share $(n i)$; book value per share $(b v)$; and dividend per share (div). 
Figure 7.6: Comparison of Adj.R-squared values - South Africa

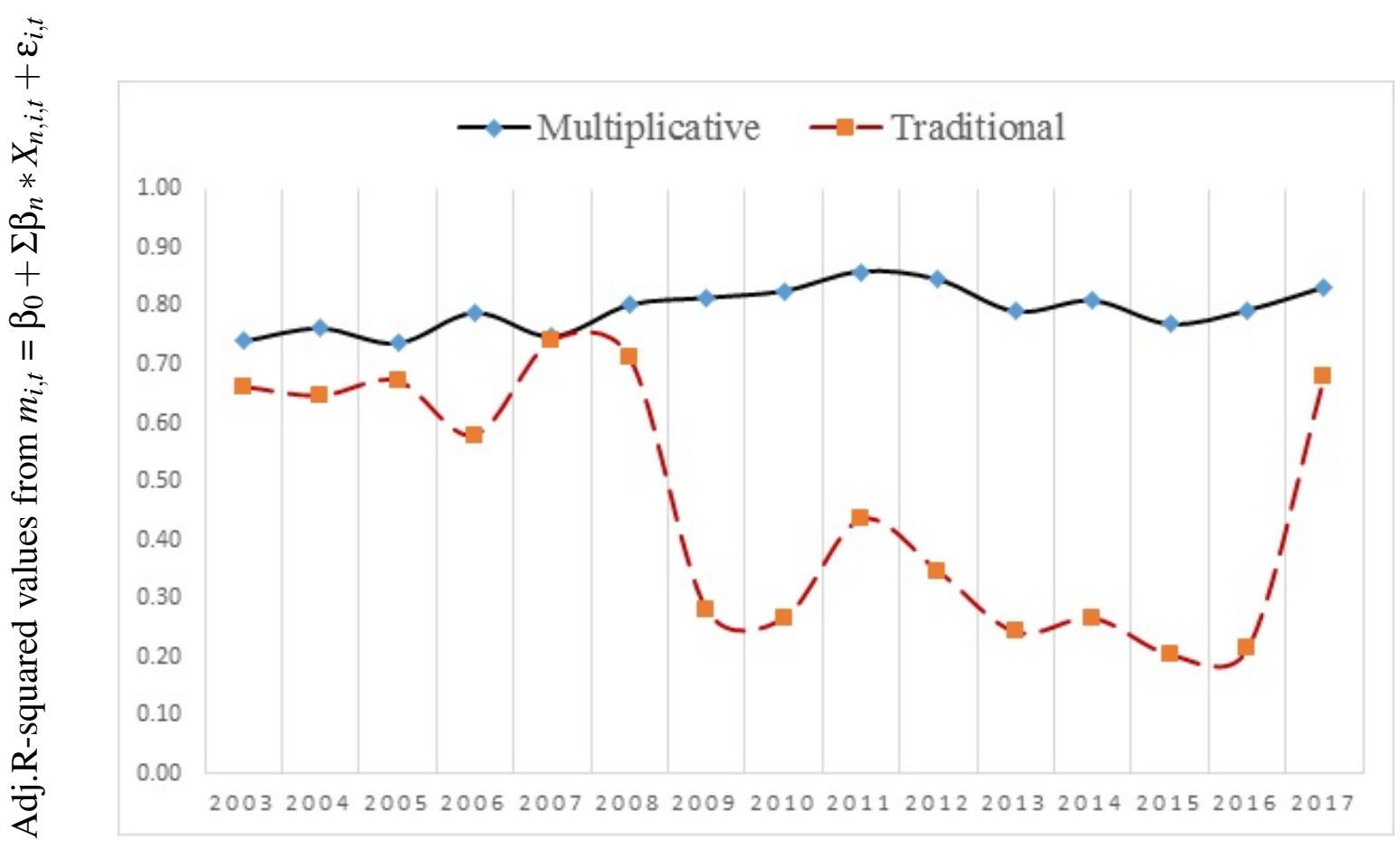

Adj.R-squared values from multiplicative and traditional models 


\section{Chapter 8}

\section{Discussion of results - Voluntary setting}

\subsection{Introduction}

This chapter presents a discussion of the findings in the voluntary setting of TSE and the European markets. The results provide support for Hypothesis 2 and show that in large markets with rigorous reporting environment as is the case of TSE and Europe including UK, voluntary implementation of IR has minimal to no effect in the value relevance of accounting information. However, in the smaller markets, as evidenced by the finding from Europe excluding UK, implementation of IR results in increased value relevance of accounting information. This provides evidence to support Hypothesis 3. The results are discussed in detail below.

\subsection{Main results - Japan}

Table 8.1 shows the overall regression results using the multiplicative model for the firms in Japan. As expected, the sum of the coefficients of the accounting values are closer to one in Japan in both before IR and after IR period. This result is consistent with the theory that in highly regulated and well managed reporting environments, voluntary implementation of IR 
does not result in any additional improvement in the value relevance of accounting information. This can be explained by the concept of information saturation where most of the necessary information needed is already present and any additional information does not add any significant incremental value.

[Table $8.1 \&$ Figure 8.1 about here]

Figure 8.1 provides further confirmation of this as a clear linear and horizontal pattern is seen in the sum of coefficients over the years. This provides evidence that there is no significant change in the value of accounting information under IR in the voluntary setting of TSE.

This finding can be associated with the notion that in a large well developed market such as TSE, voluntary implementation of IR does not improve the quality of the existing information paradigm in the market. Argument can be made that in such a setting, market is information saturated and additional information added by voluntary implementation of IR does not add any additional value to the capital providers. Thus there is no significant change in value relevance of accounting information after the implementation of IR in the TSE of Japan.

\subsubsection{Chow test}

The Chow test as shown in Table 8.2 shows that, while overall there is some evidence of structural break between before and after IR periods, there is no structural break in the individual coefficients of accounting estimates in Japan.

[Table 8.2 about here]

This provides to confirm the hypothesis that in a large regulated market like TSE, voluntary implementation of IR does not result in increased value relevance of accounting information. 


\subsubsection{Difference-in-difference analysis}

The difference in difference analysis demonstrated in Table 8.3 also shows similar evidence as the interaction between after IR indicator and accounting values are not statistically significant. This provides further evidence that implementation of IR did not have a significant effect in change of value relevance of accounting information in Japan.

[Table 8.3 about here]

\subsubsection{Sensitivity analysis}

Table 8.4 shows that regression coefficients of the companies in Japan using the traditional linear model. Compared to the coefficients found using the multiplicative model, the coefficients here are more volatile and shows ambiguous movement patterns. This further demonstrates that using the multiplicative model provides results that are more consistent and explainable over time. A illustration of the results are shown in Figure 8.2

[Table 8.4 \& Figure 8.2 about here]

Figure 8.3 shows the comparative adjusted R-squared values of Japan between the multiplicative and traditional models. The movement in the values are similar for both methods however, the multiplicative model clearly shows higher adjusted R-squared values which indicated greater explanatory power.

[Figure 8.3 about here] 


\subsection{Main results - Europe}

The results from Europe are presented in two parts. First the results are calculated using the Europe sample including UK. Then the UK is excluded from the sample as UK is the outlier as the largest market in Europe and has different reporting environment. This provides a differentiated sample which enables to gather insights about the effect of existing reporting regime characteristics on the effect of IR in the value relevance of accounting information.

\subsubsection{Results for Europe including UK}

As Table 8.5 shows, the sum of coefficients in Europe does not increase in value after the implementation of IR. This shows that value relevance of accounting information does not increase significantly after voluntarily adopting IR in Europe as a whole. This is expected as large part of the data in Europe is coming from the UK, which has a well developed reporting regime and is a large international market. This is consistent with the notion that if existing reporting regime is well developed, then IR has little effect on value relevance of accounting information. This result is further illustrated in Figure 8.4.

[Table $8.5 \&$ Figure 8.4 about here]

\subsubsection{Chow test}

Table 8.6 demonstrates the results of Chow test using the whole Europe as the sample. The results here are insignificant which collaborates the conclusion above that value relevance of accounting information does not increase significantly after voluntarily adopting IR in Europe as a whole. 


\subsubsection{Difference-in-difference analysis}

The difference-in-difference analysis presented in Table 8.7 shows similar findings with no significant results. The interaction terms between after IR indicator and accounting variables are mostly insignificant which further confirms that value relevance of accounting information in the after IR period did not change.

[Table 8.7 about here]

\subsubsection{Sensitivity analysis}

Table 8.8 and Figure 8.5 shows the regression coefficients for Europe using the traditional linear model. Comparing the results with the multiplicative model shows that the traditional model has higher degree of volatility in the results and are thus more difficult to explain. The multiplicative model again provides estimates that are more stable over time.

[Table $8.8 \&$ Figure 8.5 about here]

Comparative adjusted R-squared values in Figure 8.6 further show that adjusted R-squared values using the multiplicative model provides more stable estimates and thus better explanatory power over time.

[Figure 8.6 about here]

\subsubsection{Results for Europe excluding UK}

Table 8.9 and Figure 8.7 shows the results from Europe excluding UK using the multiplicative model. Comparing this to the results of the sample including UK clearly show that market elasticities of accounting variables in the after IR period are higher and more closer to one for 
the excluding UK sample. The trend of the sum of the market elasticities are consistently higher and the results are significant, which provides evidence of higher value relevance of accounting information.

[Table 8.9 \& Figure 8.7 about here]

This supports the hypothesis that market effects and rigorousness of existing reporting environment changes the effect of IR on the value relevance of accounting information. Removing UK, a large market with highly developed reporting regime from the sample, results in increased value relevance of accounting information in the after IR period.

This finding can be associated with the fact that in smaller, less developed reporting regimes, implementation of IR results in better quality of information being provided in the market. This in turn results in increased reliability of presented accounting information to the capital providers, which results in increased value relevance of accounting information after the implementation of IR. This is consistent with the hypothesis that in smaller markets implementation of IR adds information value for the capital providers and results in increased value relevance of accounting information after implementation of IR.

\subsubsection{Chow test}

Table 8.10 shows the Chow test on the excluding UK sample and clearly demonstrates a structural break between the coefficient values of accounting variables between the before and after IR periods. This provides further confirmation that markets effects and existing reporting regime moderates the effect of IR.

[Table 8.10 about here] 


\subsubsection{Difference-in-difference analysis}

The difference-in-difference analysis presented in Table 8.11 also shows similar evidence. The interaction terms between after IR period and accounting variables are mostly significant.

[Table 8.11 about here]

This provides evidence to support the hypothesis that the effect of IR in value relevance of accounting information is moderated by market effects and existing reporting paradigm. In large markets with well developed reporting regimes, voluntary adoption of IR seems to have negligent effect. However, in smaller markets with less developed reporting regimes, IR has a positive effect in the value relevance of accounting information.

\subsubsection{Sensitivity analysis}

Table 8.12 and Figure 8.8 shows the regression coefficients of accounting variables using the Europe excluding UK sample. The coefficients are highly volatile and do not follow any discernible pattern.

[Table $8.12 \&$ Figure 8.8 about here]

Compared to the results from the multiplicative model which are more stable and thus better explainable over time, the results using the traditional model are significantly more difficult to explain. This provides further evidence that using the multiplicative model provides better results. 
The comparative adjusted R-squared values presented in Figure 8.9 also provides evidence of the same. The values are more consistent and less volatile using the multiplicative model as opposed to the traditional model.

[Figure 8.9 about here]

\subsection{Summary of findings}

The findings discussed provide evidence to confirm both Hypothesis 2 and Hypothesis 3 of this research. The results from Japan demonstrates that in large well regulated markets implementation of IR does not result in significant increase in value relevance of accounting information. This is expected as in such reporting environment the market is efficient and IR does not add any significant additional information to make a difference in value relevance of accounting information.

Look into the results from the comparative evidence between Europe including and excluding UK sample shows that market effects and existing reporting environment moderates the effect IR has on the value relevance of reported accounting information. Excluding UK from the sample, which is an outlier by being the largest market in Europe, significantly increases the value relevance of accounting information in the after IR period. The significant coefficients and evidence of structural breaks confirms this effect.

The sensitivity analysis shows that in all cases the multiplicative model provides estimates that are more consistent over time and provide greater explanatory power when compared to the traditional linear models. This provides further evidence that the multiplicative model in the better predictive method for value relevance analysis as is done in this thesis. 


\subsection{Appendix for Chapter 8}

Table 8.1 Overall Regression Results - Japan

\begin{tabular}{|c|c|c|c|c|c|c|c|c|c|c|}
\hline Year & & NI & BV & DIV & SUM & Intercept & $R^{2}$ & $A d j . R^{2}$ & Prob $>F$ & \# of Obs. \\
\hline 2008 & & 0.12 & 0.77 & 0.06 & 0.94 & -0.91 & 0.75 & 0.74 & 0.00 & 124 \\
\hline 2009 & & -0.02 & 0.80 & 0.15 & 0.94 & -0.81 & 0.80 & 0.80 & 0.00 & 125 \\
\hline 2010 & Before IR & 0.06 & 0.88 & 0.04 & 0.98 & -0.67 & 0.77 & 0.76 & 0.00 & 124 \\
\hline 2011 & & 0.11 & 0.83 & 0.01 & 0.94 & -0.67 & 0.73 & 0.72 & 0.00 & 127 \\
\hline 2012 & & 0.02 & 0.79 & 0.08 & 0.90 & -0.24 & 0.66 & 0.65 & 0.00 & 130 \\
\hline 2013 & & 0.07 & 0.74 & 0.04 & 0.85 & 0.34 & 0.58 & 0.57 & 0.00 & 133 \\
\hline 2014 & & 0.00 & 0.76 & 0.12 & 0.88 & 0.05 & 0.63 & 0.62 & 0.00 & 130 \\
\hline 2015 & After IR & 0.07 & 0.77 & 0.07 & 0.90 & -0.19 & 0.63 & 0.62 & 0.00 & 130 \\
\hline 2016 & & 0.12 & 0.74 & -0.01 & 0.85 & 0.05 & 0.50 & 0.49 & 0.00 & 131 \\
\hline 2017 & & 0.02 & 0.79 & 0.08 & 0.89 & 0.34 & 0.58 & 0.57 & 0.00 & 133 \\
\hline 2018 & & 0.01 & 0.79 & 0.09 & 0.89 & 0.36 & 0.57 & 0.56 & 0.00 & 132 \\
\hline
\end{tabular}

This table reports result of yearly regressions that rely on companies registered in the Tokyo Exchange over the 2008 to 2018 period using the following model:

$$
\rho_{t}=\beta_{0}+\beta_{1} N I+\beta_{2} B V+\beta_{3} D I V+\varepsilon
$$

$\rho$ is log of absolute value of market price per share. $B V$ is log of absolute values of book value per share. $N I$ is log of absolute values of earnings per share. $D I V$ is log of absolutes values of dividend per share. SUM is the summation of all the coefficients. All data have been collected from EIKON Datastream. Both financial and non-financial firms are included. 
Figure 8.1: Market elasticities - Japan

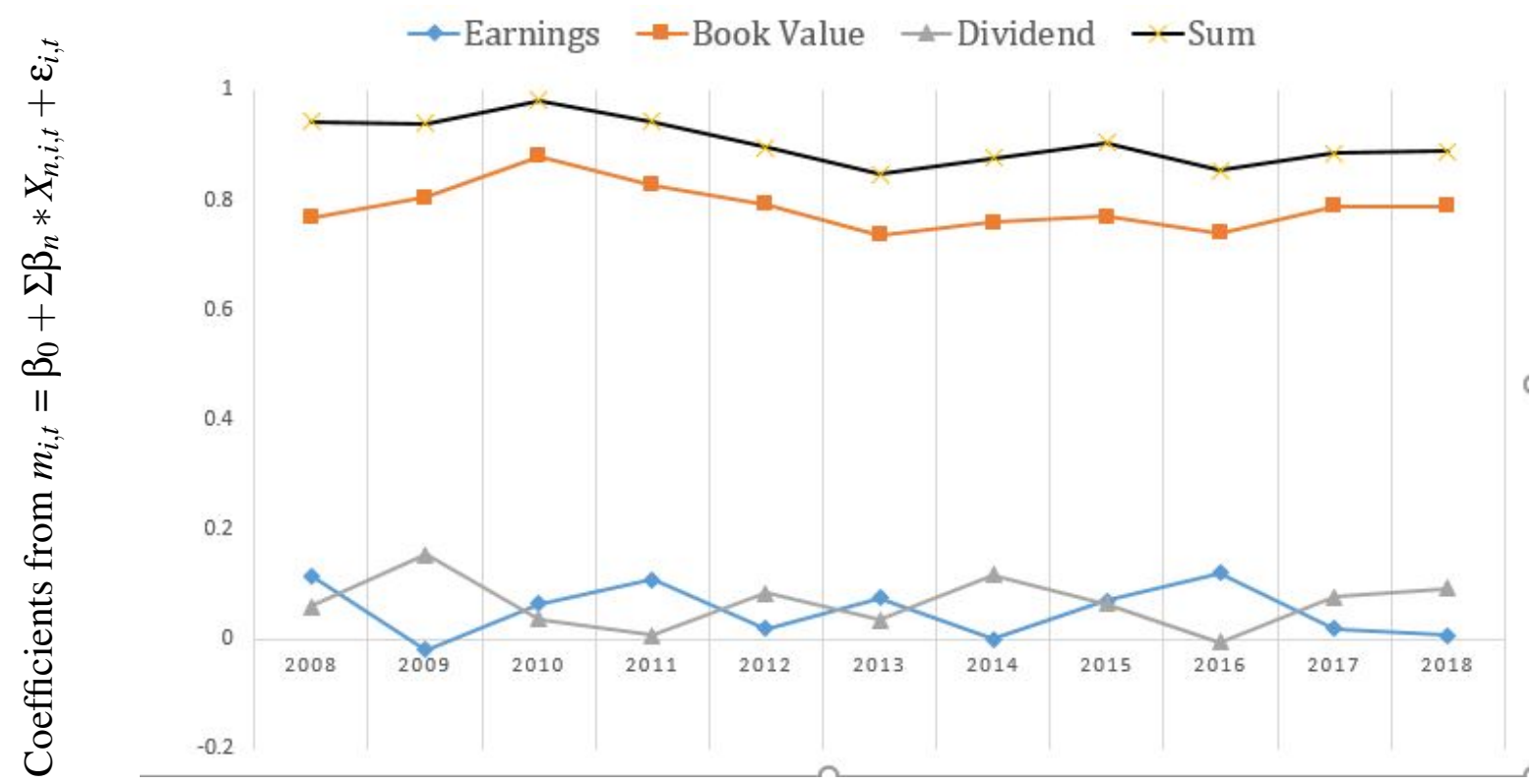

Comparison of market elasticities for $m=f(n i), m=f(b v), m=f($ div $)$, where the variables are logged absolute values of market price $(m)$; earnings per share $(n i)$; book value per share $(b v)$; and dividend per share (div). 
Table 8.2 Chow Test - Japan

\begin{tabular}{lll}
\hline Variables & F & Prob $>$ F \\
\hline POST & 4.55 & 0.03 \\
POST*BV & 1.35 & 0.24 \\
POST*NI & 0.24 & 0.63 \\
POST*DIV & 0.86 & 0.36 \\
OVERALL & $\mathbf{1 9 . 7}$ & $\mathbf{0 . 0 0}$ \\
\hline
\end{tabular}

The table reports result of chow test that rely on companies registered in the Tokyo Exchange over the 2008 to 2018 period using contrasts of marginal linear predictions. The following regression is used::

$$
\rho_{t}=\beta_{0}+\beta_{1} N I+\beta_{2} P O S T+\beta_{3} c . N I * P O S T+\beta_{4} B V+\beta_{5} c . B V * P O S T+\beta_{6} D I V+\beta_{7} c . D I V * P O S T+\varepsilon
$$

$\rho$ is log of absolute value of market price per share. $B V$ is log of absolute values of book value per share. $N I$ is log of absolute values of earnings per share. DIV is $\log$ of absolutes values of dividend per share. $c$ refers to contrast function. POST is indicator variable that has the value of 1 in after IR period from 2010 and 0 otherwise. All data have been collected from EIKON Datastream. Both financial and non-financial firms are included. 
Table 8.3 Regression Results - Difference-in-Difference - Japan

\begin{tabular}{lrrrrrrrrrrrr}
\hline & Post & NI & Post*NI & BV & Post*BV & DIV & Post*DIV & Intercept & Adj.R ${ }^{2}$ & Prob $>F$ & Obs \\
\hline$\beta$ & 0.69 & 0.05 & 0.01 & 0.81 & -0.04 & 0.07 & -0.02 & -0.62 & 0.66 & 0.00 & 1,419 \\
$(t)$ & $2.13^{* *}$ & $3.19^{* * *}$ & 0.49 & $30.7^{* * *}$ & -1.16 & $4.61 * * *$ & -0.92 & & &
\end{tabular}

This table reports result of regression that rely on companies registered in the Tokyo Exchange over the 2008 to 2018 period using the following model:

$$
\rho=\beta_{0}+\beta_{1} \text { Post }+\beta_{2} N I+\beta_{3} \text { Post } * N I+\beta_{4} B V+\beta_{5} \text { Post } * B V+\beta_{6} D I V+\beta_{7} \text { Post } * D I V+\varepsilon
$$

$\rho$ is market price per share. Post is an indicator variable that takes value of 1 in the after IR period and 0 in before IR period. NI is earnings per share. BV is book value per share. DIV is dividend per share. All data have been collected from EIKON Datastream. Both financial and non-financial firms are included.

For $t$-stat $* * * * * \& *$ represent significance at $1 \%, 5 \%$ and $10 \%$ respectively. 
Table 8.4 Regression Results - Traditional - Japan

\begin{tabular}{|c|c|c|c|c|c|c|c|c|c|}
\hline Year & & NI & BV & DIV & Intercept & $R^{2}$ & $A d j \cdot R^{2}$ & Prob $>F$ & \# of Obs. \\
\hline 2008 & & 0.00 & 1.04 & 0.00 & 271 & 0.59 & 0.58 & 0.00 & 126 \\
\hline 2009 & & 0.00 & 0.72 & 0.00 & 163 & 0.68 & 0.67 & 0.00 & 126 \\
\hline 2010 & Before IR & 0.00 & 0.91 & 0.00 & 255 & 0.63 & 0.62 & 0.00 & 130 \\
\hline 2011 & & 0.00 & 0.79 & 0.00 & 308 & 0.53 & 0.52 & 0.00 & 133 \\
\hline 2012 & & 0.00 & 0.62 & 0.00 & 396 & 0.38 & 0.37 & 0.00 & 135 \\
\hline 2013 & & 0.00 & 0.78 & 0.00 & 734 & 0.31 & 0.29 & 0.00 & 135 \\
\hline 2014 & & 0.00 & 0.84 & 0.00 & 500 & 0.41 & 0.40 & 0.00 & 136 \\
\hline 2015 & After IR & 0.00 & 1.12 & 0.00 & 563 & 0.40 & 0.39 & 0.00 & 136 \\
\hline 2016 & & 0.00 & 0.67 & 0.00 & 803 & 0.22 & 0.20 & 0.00 & 135 \\
\hline 2017 & & 0.00 & 1.10 & 0.00 & 678 & 0.35 & 0.34 & 0.00 & 136 \\
\hline 2018 & & 0.00 & 1.07 & 0.00 & 1,033 & 0.31 & 0.30 & 0.00 & 136 \\
\hline
\end{tabular}

This table reports result of yearly regressions that rely on companies registered in the Tokyo Exchange over the 2008 to 2018 period using the following model:

$$
M=\beta_{0}+\beta_{1} N I+\beta_{2} B V+\beta_{3} D I V+\varepsilon
$$

$\mathrm{M}$ is market price per share. BV is book value per share. NI is earnings per share. DIV is dividend per share. All data have been collected from EIKON Datastream. Both financial and non-financial firms are included. . 
Figure 8.2: Regression coefficients using traditional linear model - Japan

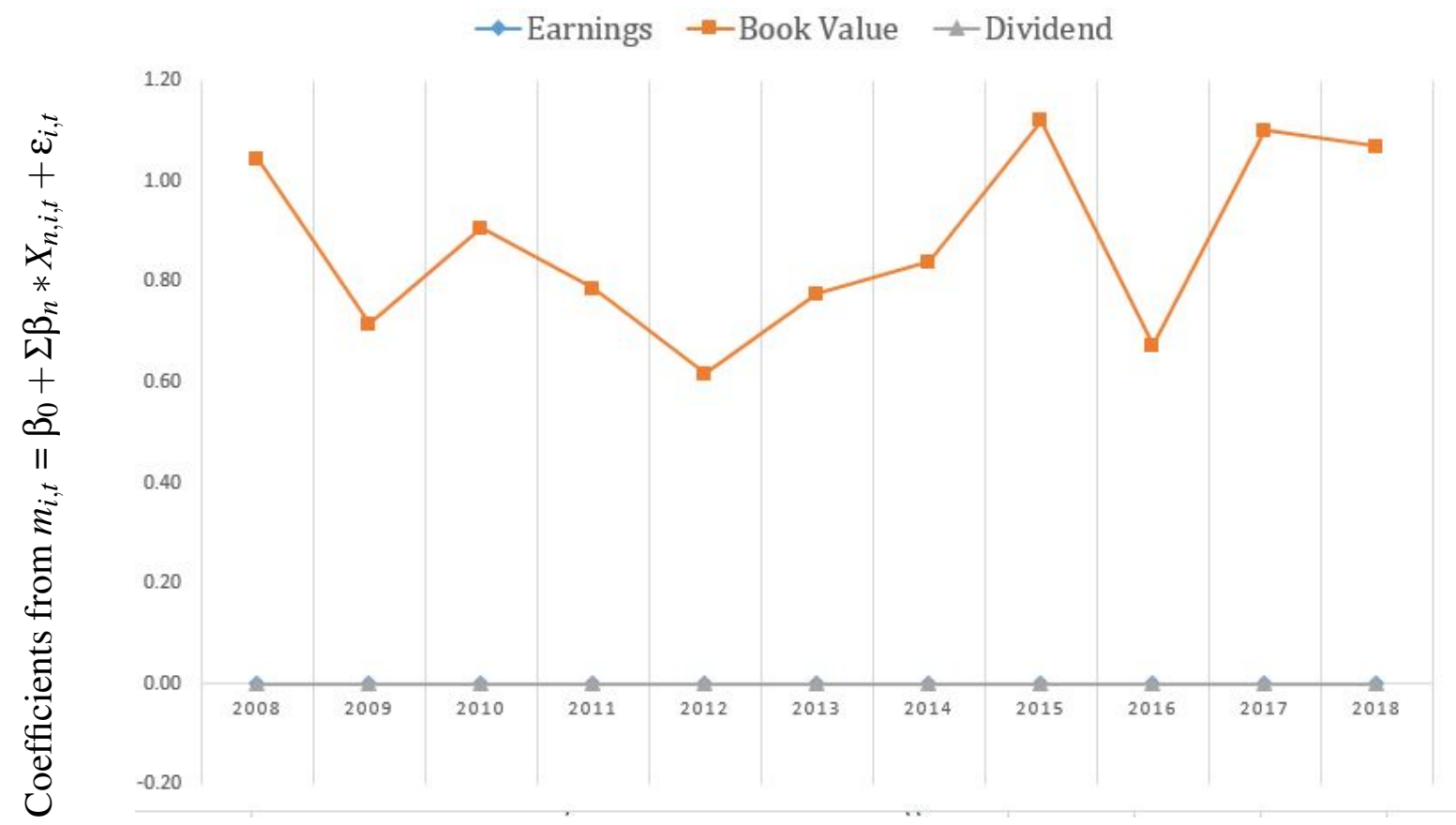

Regression coefficients using traditional linear models for $m=f(n i), m=f(b v), m=f(d i v)$, where the variables are market price $(m)$; earnings per share $(n i)$; book value per share $(b v)$; and dividend per share (div). 
Figure 8.3: Comparison of Adj.R-squared values - Japan

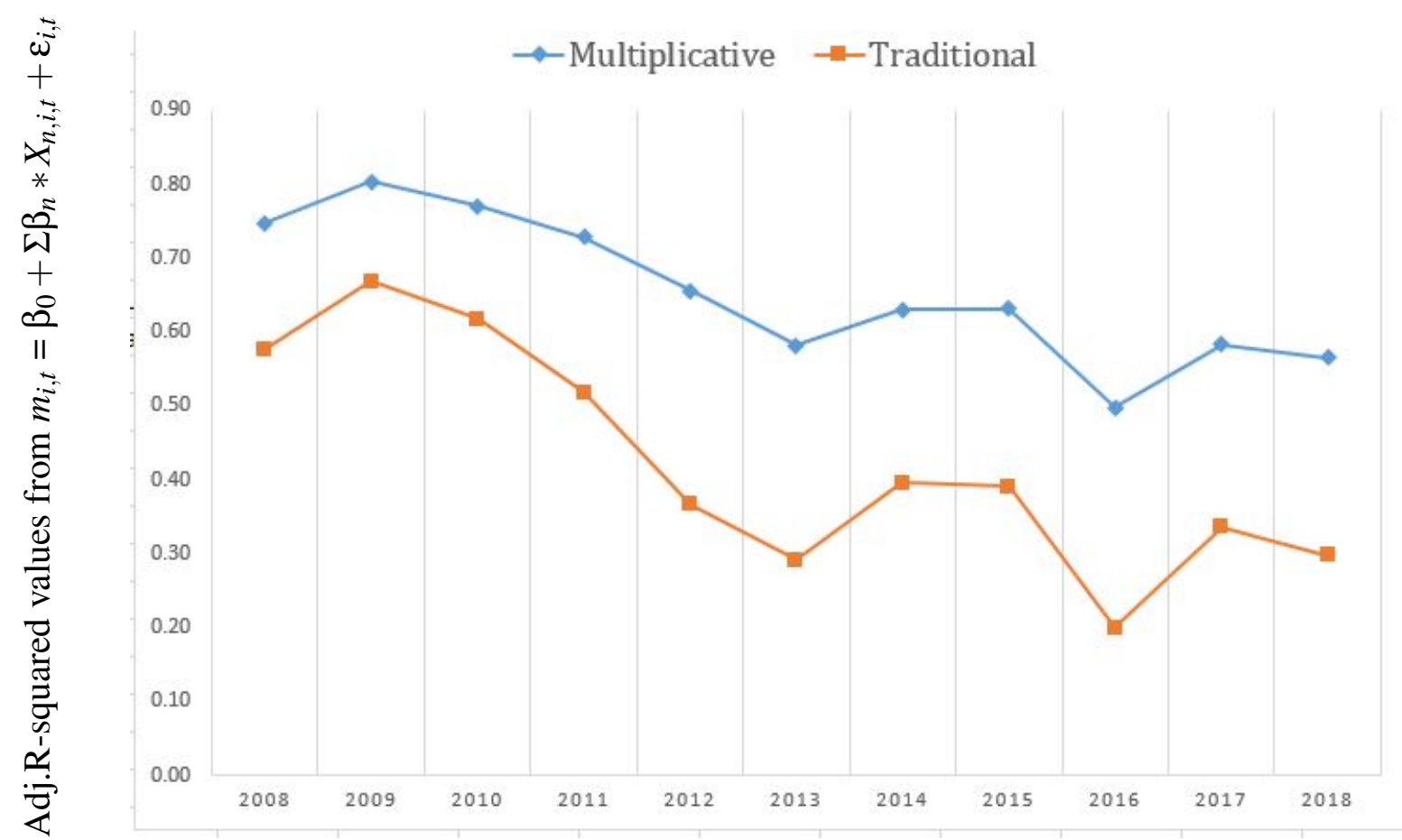

Adj.R-squared values from multiplicative and traditional models 
Table 8.5 Overall Regression Results - Europe Combined

\begin{tabular}{|c|c|c|c|c|c|c|c|c|c|c|}
\hline Year & & NI & BV & DIV & SUM & Intercept & $R^{2}$ & $A d j \cdot R^{2}$ & Prob $>F$ & \# of Obs. \\
\hline 2008 & & 0.06 & -0.09 & 0.89 & 0.87 & 2.56 & 0.77 & 0.76 & 0.00 & 91 \\
\hline 2009 & & -0.01 & 0.03 & 0.85 & 0.87 & 3.69 & 0.71 & 0.70 & 0.00 & 82 \\
\hline 2010 & Before IR & 0.04 & 0.05 & 0.85 & 0.93 & 3.27 & 0.67 & 0.66 & 0.00 & 85 \\
\hline 2011 & & 0.07 & 0.02 & 0.90 & 1.00 & 2.49 & 0.75 & 0.74 & 0.00 & 90 \\
\hline 2012 & & 0.06 & 0.05 & 0.93 & 1.04 & 2.58 & 0.76 & 0.75 & 0.00 & 91 \\
\hline 2013 & & -0.02 & 0.06 & 0.88 & 0.91 & 3.98 & 0.73 & 0.72 & 0.00 & 93 \\
\hline 2014 & & 0.00 & 0.01 & 0.80 & 0.81 & 3.85 & 0.72 & 0.71 & 0.00 & 96 \\
\hline 2015 & After IR & -0.06 & 0.07 & 0.81 & 0.81 & 4.63 & 0.70 & 0.69 & 0.00 & 97 \\
\hline 2016 & & 0.01 & 0.02 & 0.82 & 0.85 & 3.66 & 0.68 & 0.67 & 0.00 & 96 \\
\hline 2017 & & 0.02 & 0.11 & 0.84 & 0.97 & 3.45 & 0.72 & 0.71 & 0.00 & 97 \\
\hline 2018 & & 0.01 & 0.13 & 0.86 & 0.99 & 3.24 & 0.72 & 0.71 & 0.00 & 99 \\
\hline
\end{tabular}

This table reports result of yearly regressions that rely on companies registered in different European Stock Exchanges over the 2008 to 2018 period using the following model:

$$
\rho_{t}=\beta_{0}+\beta_{1} N I+\beta_{2} B V+\beta_{3} D I V+\varepsilon
$$

$\rho$ is log of absolute value of market price per share. $B V$ is $\log$ of absolute values of book value per share. $N I$ is log of absolute values of earnings per share. $D I V$ is log of absolutes values of dividend per share. SUM is the summation of all the coefficients. All data have been collected from EIKON Datastream. Both financial and non-financial firms are included. 
Figure 8.4: Market elasticities - Europe Combined

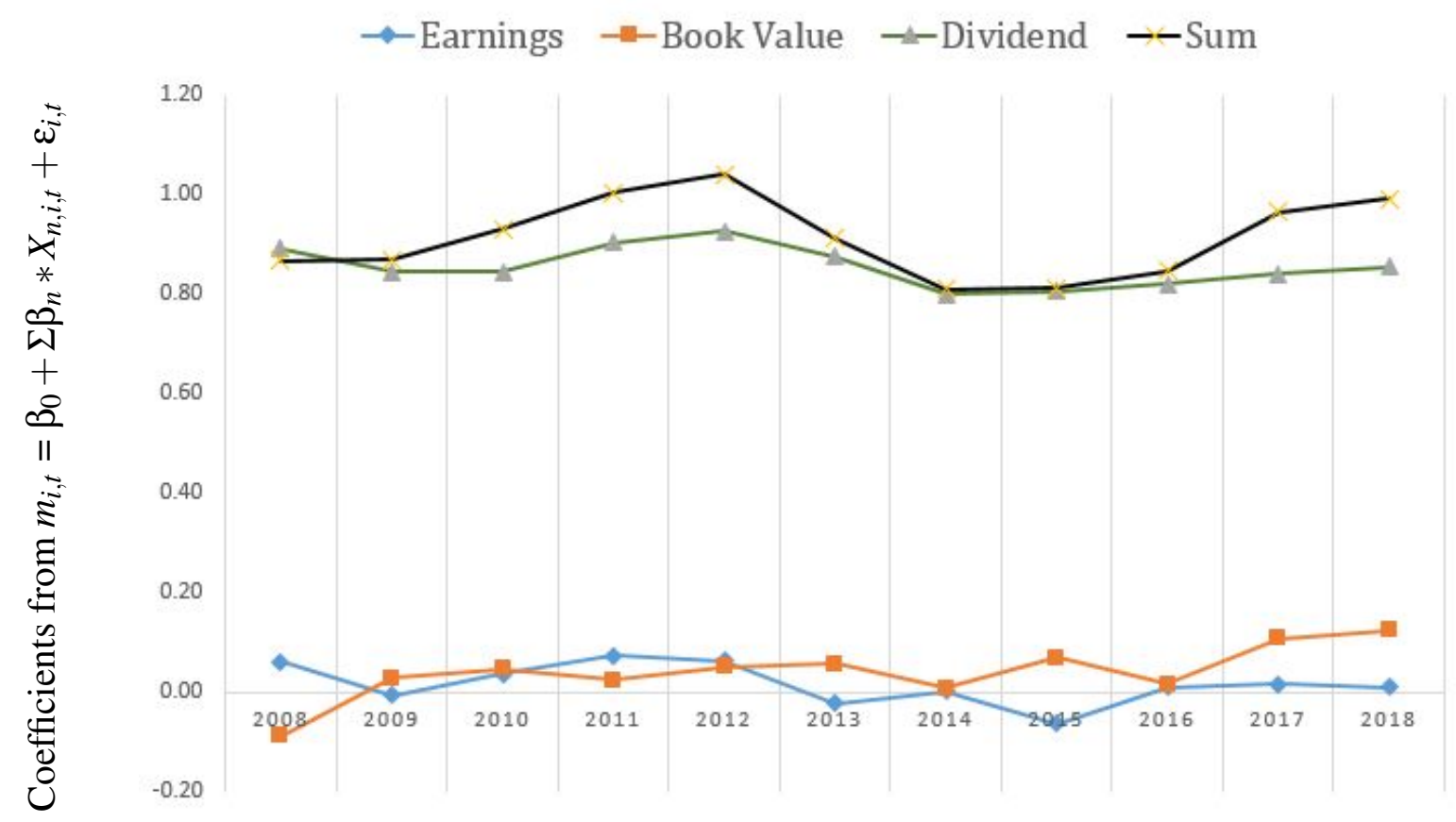

Comparison of market elasticities for $m=f(n i), m=f(b v), m=f(d i v)$, where the variables are logged absolute values of market price $(m)$; earnings per share $(n i)$; book value per share $(b v)$; and dividend per share (div). 
Table 8.6 Chow Test - Europe Combined

\begin{tabular}{lll}
\hline Variables & F & Prob $>$ F \\
\hline POST & 2.79 & 0.10 \\
POST*BV & 1.63 & 0.20 \\
POST*NI & 2.22 & 0.14 \\
POST*DIV & 1.51 & 0.22 \\
OVERALL & $\mathbf{2 . 6 3}$ & $\mathbf{0 . 0 3}$ \\
\hline
\end{tabular}

The table reports result of chow test that rely on companies registered in different European Stock Exchanges over the 2008 to 2018 period using contrasts of marginal linear predictions. The following regression is used::

$$
\rho_{t}=\beta_{0}+\beta_{1} N I+\beta_{2} P O S T+\beta_{3} c . N I * P O S T+\beta_{4} B V+\beta_{5} c . B V * P O S T+\beta_{6} D I V+\beta_{7} c . D I V * P O S T+\varepsilon
$$

$\rho$ is log of absolute value of market price per share. $B V$ is log of absolute values of book value per share. $N I$ is log of absolute values of earnings per share. DIV is $\log$ of absolutes values of dividend per share. $c$ refers to contrast function. POST is indicator variable that has the value of 1 in after IR period from 2010 and 0 otherwise. All data have been collected from EIKON Datastream. Both financial and non-financial firms are included. 
Table 8.7 Regression Results - Difference in Difference - Europe Combined

\begin{tabular}{lrrrrrrrrrrr}
\hline & Post & NI & Post*NI & BV & Post*BV & DIV & Post*DIV & Intercept & Adj.R & Prob $>F$ & Obs \\
\hline$\beta$ & 0.84 & 0.05 & -0.06 & 0.00 & 0.06 & 0.87 & -0.04 & 2.98 & 0.71 & 0.00 & 1,107 \\
$(t)$ & $1.67^{*}$ & $1.85^{*}$ & -1.49 & 1.28 & 1.28 & $35.0^{* * *}$ & -1.23 & &
\end{tabular}

This table reports result of regression that rely on companies registered in different European Stock Exchanges over the 2008 to 2018 period using the following model:

$$
\rho=\beta_{0}+\beta_{1} \text { Post }+\beta_{2} N I+\beta_{3} \text { Post } * N I+\beta_{4} B V+\beta_{5} \text { Post } * B V+\beta_{6} D I V+\beta_{7} \text { Post } * D I V+\varepsilon
$$

$\rho$ is market price per share. Post is an indicator variable that takes value of 1 in the after IR period and 0 in before IR period. NI is earnings per share. BV is book value per share. DIV is dividend per share. All data have been collected from EIKON Datastream. Both financial and non-financial firms are included.

For $t$-stat $* * * * * \& *$ represent significance at $1 \%, 5 \%$ and $10 \%$ respectively. 
Table 8.8 Regression Results - Traditional - Europe Combined

\begin{tabular}{|c|c|c|c|c|c|c|c|c|c|}
\hline Year & & NI & $\mathrm{BV}$ & DIV & Intercept & $R^{2}$ & $\operatorname{Adj} . R^{2}$ & Prob $>F$ & \# of Obs. \\
\hline 2008 & & 0.00 & 0.88 & 21.7 & 11.6 & 0.81 & 0.80 & 0.00 & 97 \\
\hline 2009 & & 0.00 & 0.90 & 22.5 & 100 & 0.59 & 0.58 & 0.00 & 97 \\
\hline 2010 & Before IR & 0.00 & 0.95 & 24.2 & 145 & 0.54 & 0.53 & 0.00 & 98 \\
\hline 2011 & & 0.00 & 0.56 & 22.6 & 123 & 0.65 & 0.64 & 0.00 & 98 \\
\hline 2012 & & 0.00 & 1.10 & 21.7 & 138 & 0.65 & 0.64 & 0.00 & 99 \\
\hline 2013 & & 0.00 & 1.20 & 23.1 & 145 & 0.72 & 0.71 & 0.00 & 101 \\
\hline 2014 & & 0.00 & 0.10 & 25.3 & 104 & 0.84 & 0.83 & 0.00 & 102 \\
\hline 2015 & After IR & 0.00 & 0.39 & 23.4 & 115 & 0.84 & 0.83 & 0.00 & 102 \\
\hline 2016 & & 0.00 & 0.43 & 26.9 & 110 & 0.82 & 0.81 & 0.00 & 103 \\
\hline 2017 & & 0.00 & 0.92 & 26.5 & 125 & 0.78 & 0.77 & 0.00 & 105 \\
\hline 2018 & & 0.00 & 1.27 & 22.2 & 117 & 0.73 & 0.73 & 0.00 & 105 \\
\hline
\end{tabular}

This table reports result of yearly regressions that rely on companies registered in different European Stock Exchanges over the 2008 to 2018 period using the following model:

$$
M=\beta_{0}+\beta_{1} N I+\beta_{2} B V+\beta_{3} D I V+\varepsilon
$$

$\mathrm{M}$ is market price per share. BV is book value per share. NI is earnings per share. DIV is dividend per share. All data have been collected from EIKON Datastream. Both financial and non-financial firms are included. . 
Figure 8.5: Regression coefficients using traditional linear model - Europe Combined

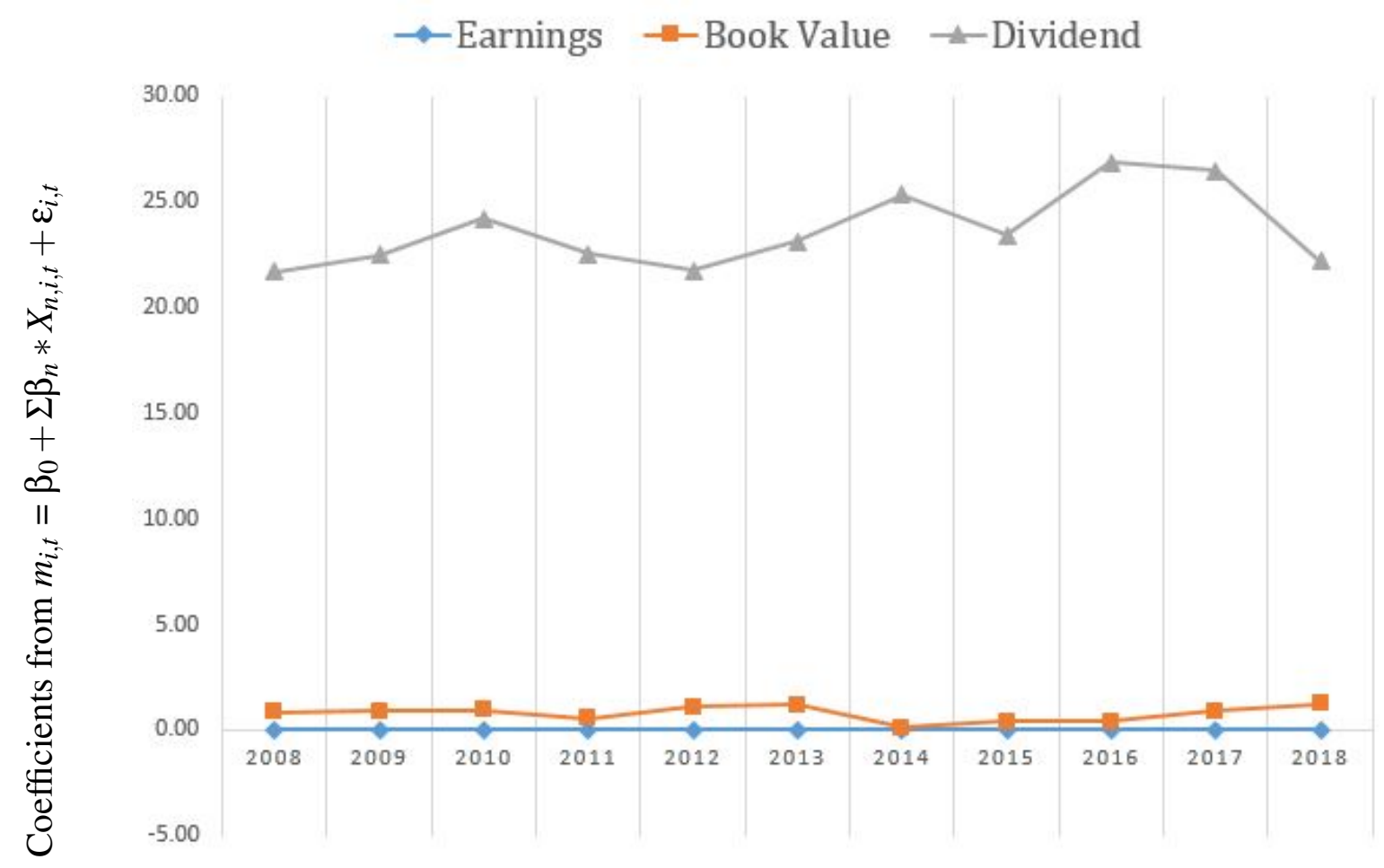

Regression coefficients using traditional linear models for $m=f(n i), m=f(b v), m=f($ div $)$, where the variables are market price $(m)$; earnings per share $(n i)$; book value per share $(b v)$; and dividend per share (div). 
Figure 8.6: Comparison of Adj.R-squared values - Europe Combined

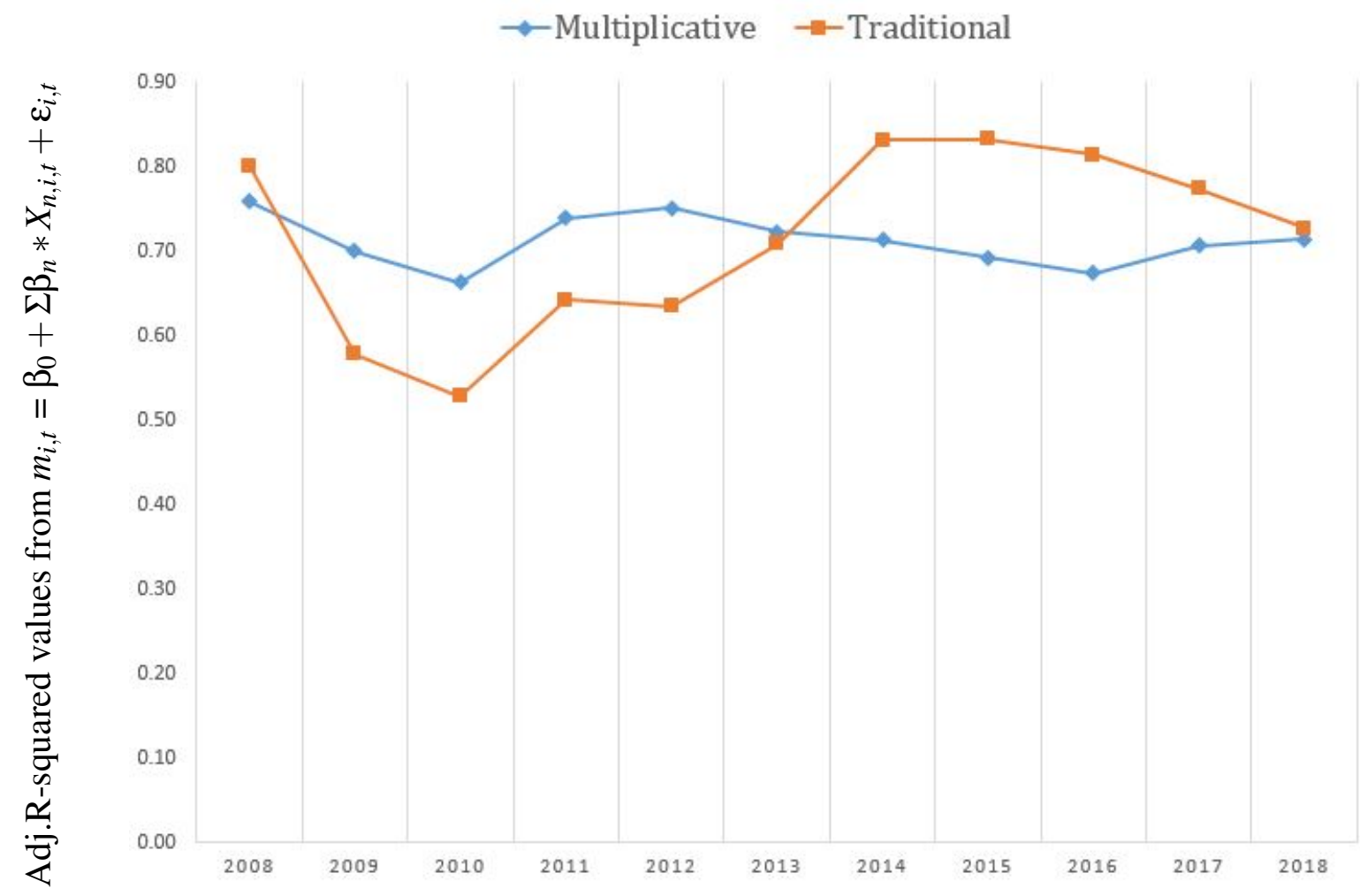

Adj.R-squared values from multiplicative and traditional models 
Table 8.9 Overall Regression Results - Europe excluding UK

\begin{tabular}{|c|c|c|c|c|c|c|c|c|c|c|}
\hline Year & & $\mathrm{NI}$ & $\mathrm{BV}$ & DIV & SUM & Intercept & $R^{2}$ & Adj. $R^{2}$ & Prob $>F$ & \# of Obs. \\
\hline 2008 & & 0.06 & 0.31 & 0.56 & 0.93 & 1.29 & 0.76 & 0.75 & 0.00 & 61 \\
\hline 2009 & & 0.02 & 0.43 & 0.55 & 1.00 & 1.90 & 0.87 & 0.86 & 0.00 & 53 \\
\hline 2010 & Before IR & 0.03 & 0.45 & 0.53 & 1.02 & 1.76 & 0.83 & 0.82 & 0.00 & 55 \\
\hline 2011 & & 0.04 & 0.38 & 0.60 & 1.03 & 1.58 & 0.86 & 0.86 & 0.00 & 60 \\
\hline 2012 & & 0.05 & 0.47 & 0.56 & 1.09 & 1.19 & 0.85 & 0.84 & 0.00 & 61 \\
\hline 2013 & & -0.02 & 0.38 & 0.65 & 1.01 & 2.62 & 0.87 & 0.87 & 0.00 & 61 \\
\hline 2014 & & 0.00 & 0.32 & 0.65 & 0.97 & 2.55 & 0.90 & 0.89 & 0.00 & 62 \\
\hline 2015 & After IR & -0.02 & 0.40 & 0.61 & 1.00 & 2.63 & 0.87 & 0.86 & 0.00 & 63 \\
\hline 2016 & & -0.03 & 0.38 & 0.65 & 1.01 & 2.74 & 0.85 & 0.84 & 0.00 & 63 \\
\hline 2017 & & -0.04 & 0.33 & 0.76 & 1.06 & 3.17 & 0.91 & 0.91 & 0.00 & 63 \\
\hline 2018 & & -0.03 & 0.31 & 0.78 & 1.06 & 2.86 & 0.91 & 0.91 & 0.00 & 65 \\
\hline
\end{tabular}

This table reports result of yearly regressions that rely on companies registered in different European Stock Exchanges excluding United Kingdom over the 2008 to 2018 period using the following model:

$$
\rho_{t}=\beta_{0}+\beta_{1} N I+\beta_{2} B V+\beta_{3} D I V+\varepsilon
$$

$\rho$ is $\log$ of absolute value of market price per share. $B V$ is $\log$ of absolute values of book value per share. $N I$ is log of absolute values of earnings per share. $D I V$ is log of absolutes values of dividend per share. SUM is the summation of all the coefficients. All data have been collected from EIKON Datastream. Both financial and non-financial firms are included. 
Figure 8.7: Market elasticities - Europe excluding UK

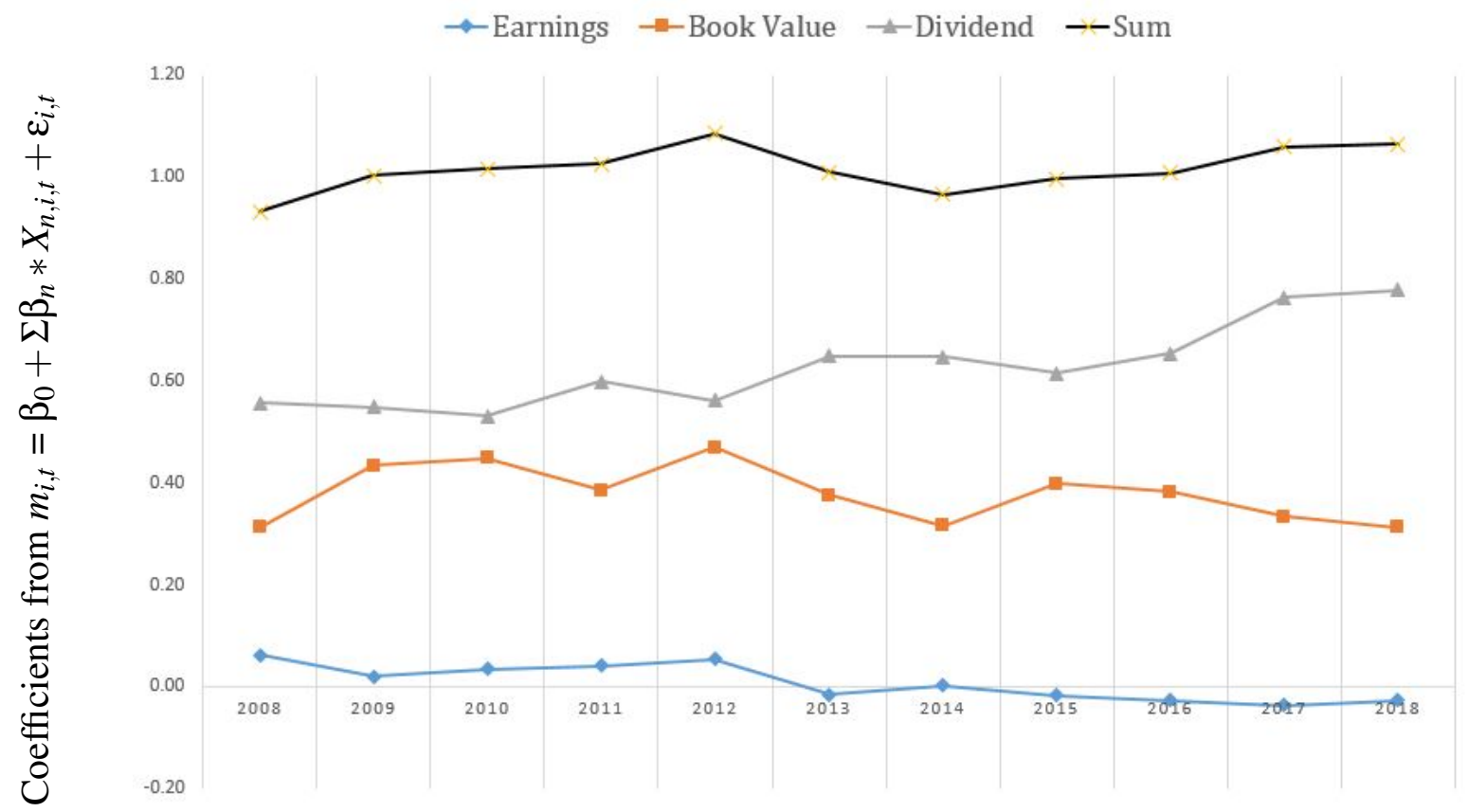

Comparison of market elasticities for $m=f(n i), m=f(b v), m=f($ div $)$, where the variables are logged absolute values of market price $(m)$; earnings per share $(n i)$; book value per share $(b v)$; and dividend per share (div). 
Table 8.10 Chow Test - Europe excluding UK

\begin{tabular}{lcc}
\hline Variables & F & Prob $>$ F \\
\hline POST & 12.5 & 0.00 \\
POST $^{*}$ BV & 0.89 & 0.35 \\
POST*NI & 8.35 & 0.00 \\
POST*DIV & 4.94 & 0.03 \\
OVERALL & $\mathbf{7 . 7 1}$ & $\mathbf{0 . 0 0}$ \\
\hline
\end{tabular}

The table reports result of chow test that rely on companies registered in different European Stock Exchanges excluding UK over the 2008 to 2018 period using contrasts of marginal linear predictions. The following regression is used::

$$
\rho_{t}=\beta_{0}+\beta_{1} N I+\beta_{2} P O S T+\beta_{3} c . N I * P O S T+\beta_{4} B V+\beta_{5} c . B V * P O S T+\beta_{6} D I V+\beta_{7} c . D I V * P O S T+\varepsilon
$$

$\rho$ is log of absolute value of market price per share. $B V$ is log of absolute values of book value per share. NI is log of absolute values of earnings per share. DIV is log of absolutes values of dividend per share. $c$ refers to contrast function. POST is indicator variable that has the value of 1 in after IR period from 2010 and 0 otherwise. All data have been collected from EIKON Datastream. Both financial and non-financial firms are included. 
Table 8.11 Regression Results - Difference in Difference - Europe excluding UK

\begin{tabular}{lrrrrrrrrrrr}
\hline & Post & NI & Post*NI & BV & Post*BV & DIV & Post*DIV & Intercept & Adj.R & Prob $>F$ & Obs \\
\hline$\beta$ & 1.30 & 0.05 & -0.07 & 0.42 & -0.05 & 0.55 & 0.12 & 1.42 & 0.86 & 0.00 & 667 \\
$(t)$ & $3.53^{* * *}$ & $2.92 * * *$ & $-2.89 * * *$ & $10.6 * * *$ & -0.94 & $13.7 * * *$ & $2.22^{* *}$ & & & &
\end{tabular}

This table reports result of regression that rely on companies registered in different European Stock Exchanges excluding UK over the 2008 to 2018 period using the following model:

$$
\rho=\beta_{0}+\beta_{1} \text { Post }+\beta_{2} N I+\beta_{3} \text { Post } * N I+\beta_{4} B V+\beta_{5} \text { Post } * B V+\beta_{6} D I V+\beta_{7} \text { Post } * D I V+\varepsilon
$$

$\rho$ is market price per share. Post is an indicator variable that takes value of 1 in the after IR period and 0 in before IR period. NI is earnings per share. BV is book value per share. DIV is dividend per share. All data have been collected from EIKON Datastream. Both financial and non-financial firms are included.

For $t$-stat $* * * * * \& *$ represent significance at $1 \%, 5 \%$ and $10 \%$ respectively. 
Table 8.12 Regression Results - Traditional - Europe excluding UK

\begin{tabular}{|c|c|c|c|c|c|c|c|c|c|}
\hline Year & & $\mathrm{NI}$ & BV & DIV & Intercept & $R^{2}$ & Adj. $R^{2}$ & Prob $>F$ & \# of Obs. \\
\hline 2008 & & 0.00 & 0.37 & 33.7 & -28.2 & 0.87 & 0.86 & 0.00 & 65 \\
\hline 2009 & & 0.00 & 1.45 & 26.8 & -22.5 & 0.92 & 0.91 & 0.00 & 65 \\
\hline 2010 & Before IR & 0.00 & 0.08 & 49.6 & -9.6 & 0.97 & 0.96 & 0.00 & 66 \\
\hline 2011 & & 0.00 & 0.28 & 36.7 & -18.7 & 0.87 & 0.86 & 0.00 & 66 \\
\hline 2012 & & 0.00 & 1.74 & 24.2 & -31.7 & 0.70 & 0.69 & 0.00 & 66 \\
\hline 2013 & & 0.00 & -1.46 & 62.5 & 4.40 & 0.85 & 0.84 & 0.00 & $\overline{66}$ \\
\hline 2014 & & 0.00 & 0.08 & 30.1 & 7.92 & 0.99 & 0.99 & 0.00 & 67 \\
\hline 2015 & After IR & 0.00 & 0.83 & 25.1 & 1.65 & 0.97 & 0.97 & 0.00 & 67 \\
\hline 2016 & & 0.00 & 0.25 & 31.4 & 4.11 & 0.98 & 0.98 & 0.00 & 68 \\
\hline 2017 & & 0.00 & 0.67 & 32.2 & 1.35 & 0.98 & 0.98 & 0.00 & 70 \\
\hline 2018 & & 0.00 & 1.13 & 28.6 & -16.2 & 0.96 & 0.96 & 0.00 & 70 \\
\hline
\end{tabular}

This table reports result of yearly regressions that rely on companies registered in different European Stock Exchanges excluding UK over the 2008 to 2018 period using the following model:

$$
M=\beta_{0}+\beta_{1} N I+\beta_{2} B V+\beta_{3} D I V+\varepsilon
$$

$\mathrm{M}$ is market price per share. BV is book value per share. NI is earnings per share. DIV is dividend per share. All data have been collected from EIKON Datastream. Both financial and non-financial firms are included. . 
Figure 8.8: Regression coefficients using traditional linear model - Europe excluding UK

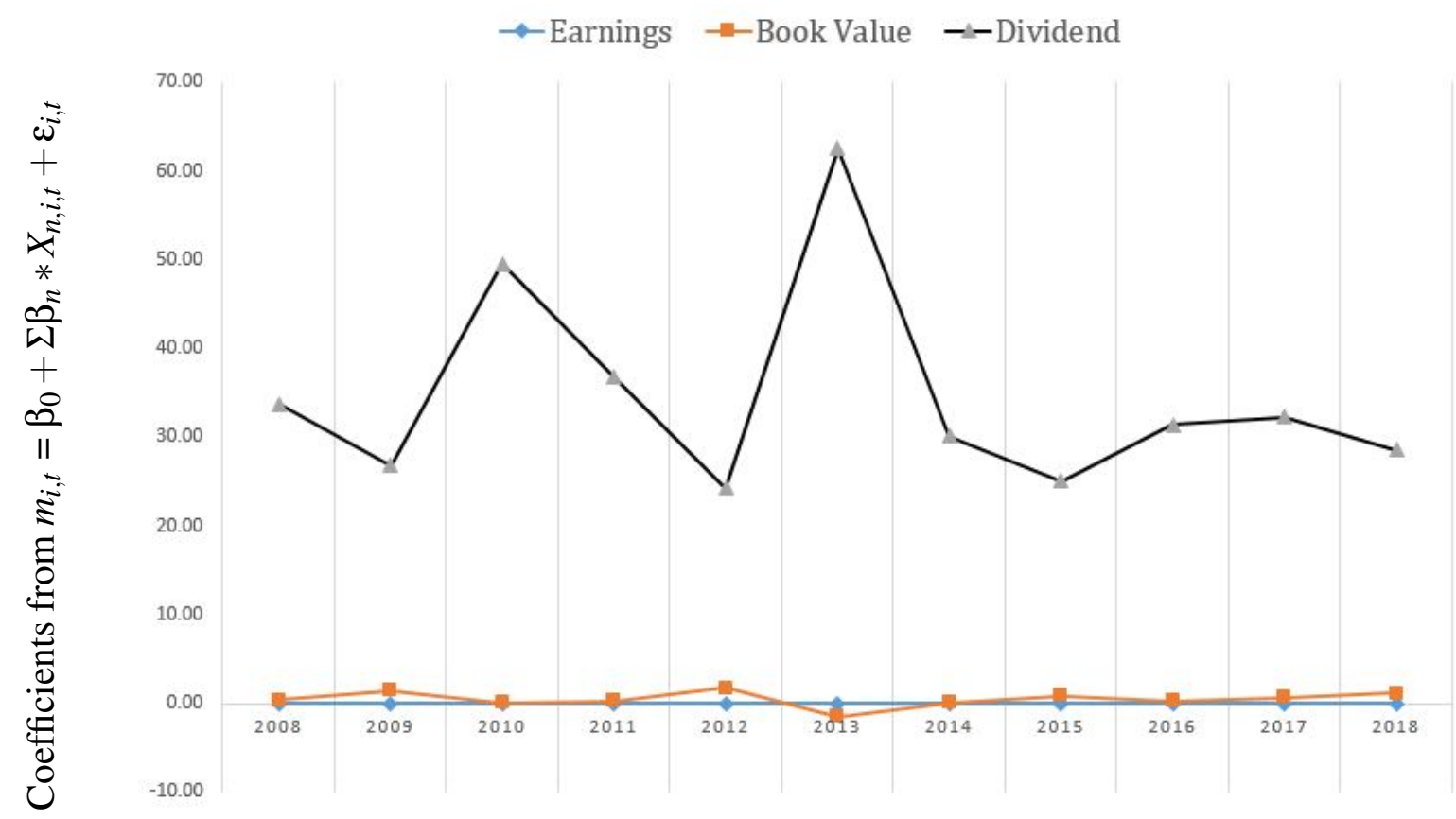

Regression coefficients using traditional linear models for $m=f(n i), m=f(b v), m=f($ div $)$, where the variables are market price $(m)$; earnings per share $(n i)$; book value per share $(b v)$; and dividend per share (div). 
Figure 8.9: Comparison of Adj.R-squared values - Europe excluding UK

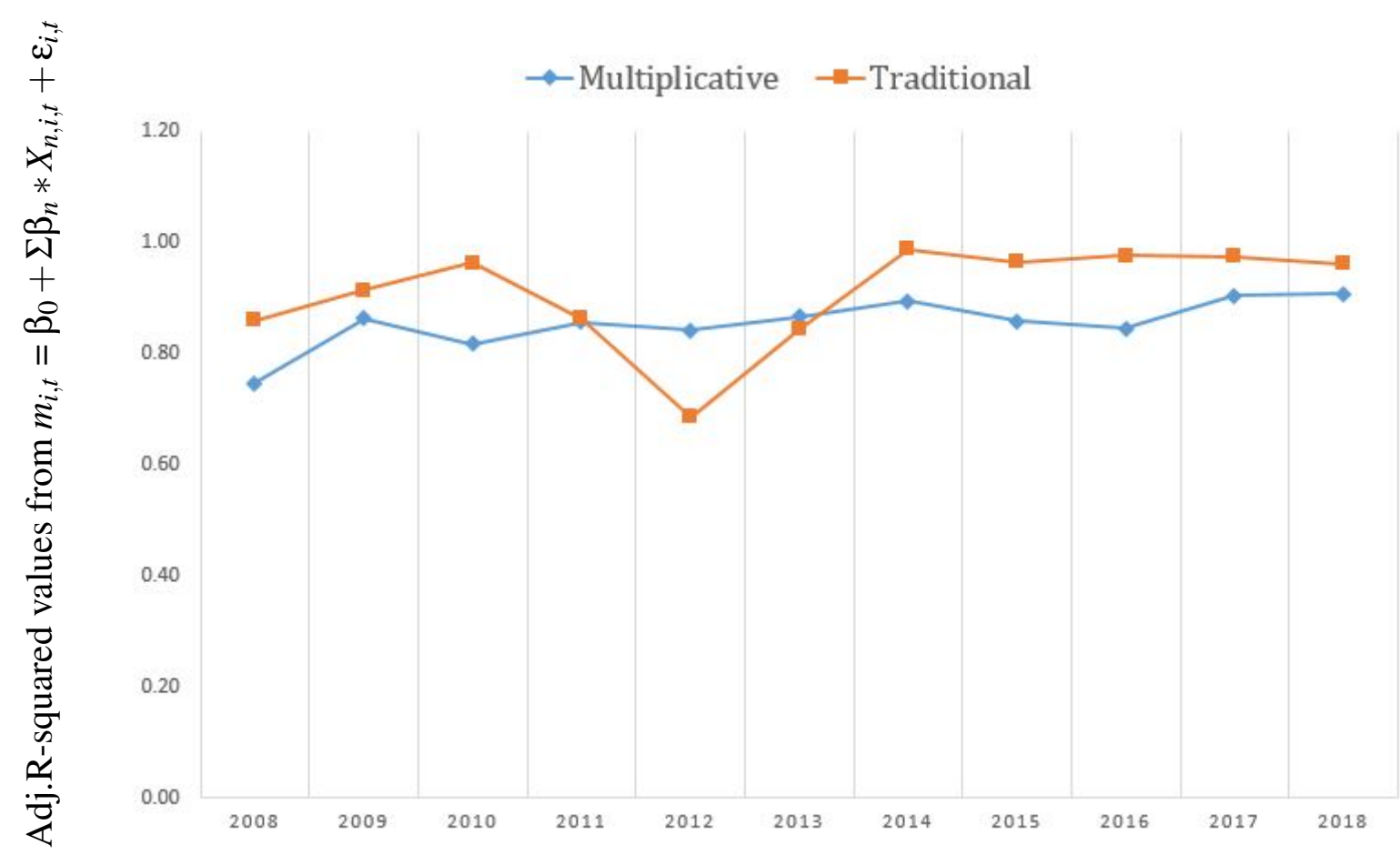

Adj.R-squared values from multiplicative and traditional models 


\section{Chapter 9}

\section{Conclusion of thesis}

\subsection{Introduction}

This thesis examines the value relevance of accounting information under IR in both mandatory and voluntary settings. For the mandatory settings, the JSE in South Africa is used as the sample as it is the only stock exchange to this date to mandate the use of IR. For the voluntary setting, the TSE in Japan and Europe is used as sample as they have a high volume of voluntary adopters of IR.

A novel multiplicative modelling technique is used which relies on multiplicative log linear method that results in a scale free system. This mitigates the shortcomings of traditional linear models and provides significantly better results.

The thesis provides evidence that value relevance of accounting information increases after implementation of IR in the mandatory setting. In the voluntary setting the effect of IR varies and is moderated by market effects and reporting environment. 


\subsection{Summary of findings}

The results for the mandatory setting in JSE of South Africa show that value relevance of accounting information under IR increases after the implementation of IR. Though relevance of individual component of accounting variables may vary, overall relevance of accounting information is higher in all cases in the after IR period. The thesis provides evidence of some anticipation effect, where it can be noticed that accounting information starts becoming more valuable in the period leading up to IR and then the relevance tends to persist.

Further analysis shows that the results are robust for different types of firms and for reporting quality. Better reporting quality results in greater spike in relevance of accounting information under after IR period.

In the voluntary setting mixed results are observed. In large controlled markets with well developed reporting regimes, which is the case of Japan and Europe as a whole, voluntary adoption of IR seems to have negligible effect in the value relevance of accounting information. However, excluding UK, which is the largest and most well developed market in Europe from the sample, shows that voluntary adoption of IR results in significant increase in the value relevance of accounting information of accounting information. This demonstrates that the effect of IR in the value relevance of accounting information in the voluntary setting, is moderated by market effects and existing reporting environment.

When compared to traditional linear methods, this thesis demonstrates that the multiplicative model provides estimates that are more stable and carries significantly greater explanatory power. In all the analysis performed in this thesis in both the mandatory and voluntary setting, 
the multiplicative model provides estimates which are more stable and consistent over time as well as provides better explanatory power compared to the traditional linear models.

Overall, this thesis demonstrates that there is a positive association between shareholder decision making and implementation of IR under specific circumstances. Additionally, the thesis also show that multiplicative log linear models are better at providing more consistent estimates and greater explanatory power than traditional linear models.

\subsection{Research contributions}

This thesis enhances the existing value relevance literature by showing a comprehensive comparative cross country evidence of the effect of the IR in the value relevance of accounting information. Research of IR is a relatively new field and this thesis augments the literature pertaining to IR.

The thesis uses a novel multiplicative modelling technique and demonstrates its efficacy in a practical setting. This enhances the value relevance research field by providing an alternative and arguably better method for modelling. Existing value relevance models are all linear but, as thesis demonstrates, the use of multiplicative model can be a better alternative, which is a novel inclusion to the literature.

By demonstrating the effect of implementation of IR in mandatory and voluntary settings, this thesis provides input to standard setters and decision makers of IR. Implementation of IR is a resource demanding procedure and it is important to understand its effect on the organizations before setting new rules or improving the existing ones. IIRC and other standard setters may find the findings of this thesis useful in deciding possible improvements to the framework by understanding where IR is adding value and where it is not. Policy makers and regulators on 
different national or international jurisdictions may use the findings of this thesis to decide whether or not to implement IR in their respective jurisdictions.

On a jurisdictional level, the finding of thesis can be useful in determining whether or not to mandate IR. While this thesis does not argue about overall value of IR as it may have possible secondary benefits which are outside the scope of this thesis, it provides evidence of the value IR adds to the decision making of the capital providers. As capital providers bear the risk of the organization, it is important to understand the effect of IR on their interest before any decision regarding mandating IR is taken.

\subsection{Research limitations}

IR is still in its early stages of implementation and as is true for any emerging field, research in this area is constrained by the availability of data. Due the lack of available data robustness checks in this research had to be limited. As more data pertaining to implementation of IR becomes available in the future, the breadth of this research can be widened to create more robust insights.

This thesis uses a novel multiplicative modelling technique which has not been used extensively in the literature to analyze value relevance. While the model due to its novelty has not been widely implemented in the literature, this thesis provides evidence to support the efficacy of the multiplicative modelling technique for the purpose of value relevance research. The evidence from this thesis indicates that the multiplicative modelling technique provides superior explanatory power when compared to traditional linear models and provides estimates that are more consistent and thus are better explained. 
Value relevance research are association studies and even with the limitation of data availability, this thesis demonstrates the association between market values and summary accounting information under different settings of implementing IR.

\subsection{Future research opportunities}

The meta review of IR literature presented in this thesis show that existing IR literature predominantly focused on external reporting and not enough attention have been paid to important areas such as auditing, assurance and performance measurement. Since IR is a developing form of reporting system, it is important to look in to the issues of auditing, assurance and performance measurement. This provides a good opportunity to future researchers to look into these areas of IR.

The existing literature in IR have focused more on qualitative discussion based work with sparse emphasis given to empirical research. As IR is being implemented more around the globe, more empirical data will continue to become available. This provides an opportunity to use data and analytical techniques to get novel insights about IR, as demonstrated by this thesis.

Similar to Dumay et al., this thesis also show that to this date, IR research have primarily been the domain of academics with very little professional collaboration or contribution. If IR research is to be relevant in the practical setting, it is important to include the practitioners in this field. This provides an opportunity create academic-practitioner collaboration and further enhance the existing IR literature. 


\section{Bibliography}

A4S (2020). Accounting for Sustainability Project. https://www.accountingforsustainability. org/en/index.html [Accessed: 1 March 2020].

A4S-GRI (2010). Formation of the International Integrated Reporting Committee (IIRC). http: //integratedreporting.org/wp-content/uploads/2011/03/Press-Release1.pdf [Accessed: 6 October 2017].

Abeysekera, I. (2013). A template for integrated reporting. Journal of Intellectual Capital.

Aboody, D. and B. Lev (1998). The value relevance of intangibles: The case of software capitalization. Journal of Accounting research 36, 161-191.

Adams, C. A. (2015). The international integrated reporting council: a call to action. Critical Perspectives on Accounting 27, 23-28.

Adams, C. A., B. Potter, P. J. Singh, and J. York (2016). Exploring the implications of integrated reporting for social investment (disclosures). The British Accounting Review 48(3), 283-296.

Adams, S. and R. Simnett (2011). Integrated reporting: An opportunity for australia's not-forprofit sector. Australian Accounting Review 21(3), 292-301.

Ali, A. and L.-S. Hwang (2000). Country-specific factors related to financial reporting and the value relevance of accounting data. Journal of accounting research 38(1), 1-21.

Ames, D. (2013). Ifrs adoption and accounting quality: The case of south africa. Journal of Applied Economics and Business Research 3(3), 154-165.

Amir, E. and B. Lev (1996). Value-relevance of nonfinancial information: The wireless communications industry. Journal of accounting and economics 22(1-3), 3-30.

Baboukardos, D. and G. Rimmel (2016). Value relevance of accounting information under an integrated reporting approach: A research note. Journal of Accounting and Public Policy 35(4), 437-452.

Baiman, S. and R. E. Verrecchia (1996). The relation among capital markets, financial disclosure, production efficiency, and insider trading. Journal of accounting research 34(1), $1-22$.

Ball, R. and P. Brown (1968). An empirical evaluation of accounting income numbers. Journal of accounting research, 159-178.

Barth, M. E. (1994). Fair value accounting: Evidence from investment securities and the market valuation of banks. Accounting review, 1-25.

Barth, M. E., W. H. Beaver, and W. R. Landsman (1996). Value-relevance of banks' fair value disclosures under sfas no. 107. Accounting Review, 513-537.

Barth, M. E., W. H. Beaver, and W. R. Landsman (2001). The relevance of the value relevance literature for financial accounting standard setting: another view. Journal of Accounting and Economics 31(1-3), 77-104.

Barth, M. E., S. F. Cahan, L. Chen, and E. R. Venter (2016). The economic consequences associated with integrated report quality: Capital market and real effects. SSRN: https://ssrn.com/abstract $=2699409$.

Barth, M. E., W. R. Landsman, and M. H. Lang (2008). International accounting standards and accounting quality. Journal of Accounting Research 46(3), 467-498.

Barth, M. E., K. Li, and C. G. McClure (2017). Evolution in value relevance of accounting information. Stanford University Graduate School of Business Research Paper 17-24.

Beck, C., J. Dumay, and G. Frost (2017). In pursuit of a 'single source of truth': from threatened legitimacy to integrated reporting. Journal of Business Ethics 141(1), 191-205. 
Beisland, L. A. (2009). A review of the value relevance literature. The Open Business Journal 2(1).

Bernardi, C. and A. W. Stark (2018). Environmental, social and governance disclosure, integrated reporting, and the accuracy of analyst forecasts. The British Accounting Review 50(1), $16-31$.

Bloomberg (2020).

Briem, C. R. and A. Wald (2018). Implementing third-party assurance in integrated reporting. Accounting, Auditing \& Accountability Journal.

Brown, J. and J. Dillard (2014). Integrated reporting: On the need for broadening out and opening up. Accounting, Auditing \& Accountability Journal 27(7), 1120-1156.

Buhr, N. (2007). Histories of and rationales for sustainability reporting. Sustainability accounting and accountability 57, 59-62.

Byard, D., Y. Li, and Y. Yu (2011). The effect of mandatory ifrs adoption on financial analysts' information environment. Journal of Accounting Research 49(1), 69-96.

Cauchy, A. L. (1821). Cours d'analyse de l'Ecole royale polytechnique; par m. Augustin-Louis Cauchy... 1. re partie. Analyse algébrique. de l'Imprimerie royale.

Cheng, M., W. Green, P. Conradie, N. Konishi, and A. Romi (2014). The international integrated reporting framework: Key issues and future research opportunities. Journal of International Financial Management \& Accounting 25(1), 90-119.

Chow, G. C. (1960). Tests of equality between sets of coefficients in two linear regressions. Econometrica 28(3), 591-605.

Churet, C. and R. G. Eccles (2014). Integrated reporting, quality of management, and financial performance. Journal of Applied Corporate Finance 26(1), 56-64.

Clatworthy, M. A. and M. J. Jones (2006). Differential patterns of textual characteristics and company performance in the chairman's statement. Accounting, Auditing \& Accountability Journal.

Collins, D. W., E. L. Maydew, and I. S. Weiss (1997). Changes in the value-relevance of earnings and book values over the past forty years. Journal of accounting and economics 24(1), 39-67.

Core, J. E., W. R. Guay, and A. Van Buskirk (2003). Market valuations in the new economy: An investigation of what has changed. Journal of Accounting and Economics 34(1-3), $43-67$.

Cortesi, A. and L. Vena (2019). Disclosure quality under integrated reporting: a value relevance approach. Journal of cleaner production 220, 745-755.

Daske, H., L. Hail, C. Leuz, and R. Verdi (2008). Mandatory ifrs reporting around the world: Early evidence on the economic consequences. Journal of Accounting Research 46(5), 10851142.

De Villiers, C., L. Rinaldi, and J. Unerman (2014). Integrated reporting: Insights, gaps and an agenda for future research. Accounting, Auditing \& Accountability Journal 27(7), 10421067.

de Villiers, C., J. Unerman, L. Rinaldi, A. Haller, and C. van Staden (2014). The value added statement-an appropriate instrument for integrated reporting. Accounting, Auditing \& Accountability Journal.

Del Baldo, M. (2015). Is it time for integrated reporting in small and medium-sized enterprises? reflections on an italian experience. In Corporate Social Responsibility and Governance, pp. 183-209. Springer.

Dumay, J., C. Bernardi, J. Guthrie, and P. Demartini (2016). Integrated reporting: A structured literature review. In Accounting Forum, Volume 40, pp. 166-185. Taylor \& Francis. 
Dumay, J. and T. Dai (2017). Integrated thinking as a cultural control? Meditari Accountancy Research.

Eccles, R. G. and D. Saltzman (2011). Achieving sustainability through integrated reporting. Stanford Social Innovation Review 9(3), 56-61.

Eccles, R. G. and G. Serafeim (2011). Accelerating the adoption of integrated reporting. CSR INDEX. Available at https://ssrn.com/abstract $=1910965$.

Elkington, J. (1997). Cannibals with Forks: The Triple Bottom Line of 21 st Century Business. Oxford: Capstone Publishing.

Elkington, J. (2009). The holy grail of integrated reporting.

Ernst and Young (2012). Ernst and young's excellence in integrated reporting awards 2012.

Fama, E. F. and J. D. MacBeth (1973). Risk, return, and equilibrium: Empirical tests. Journal of political economy 81(3), 607-636.

Fasan, M. and C. Mio (2017). Fostering stakeholder engagement: The role of materiality disclosure in integrated reporting. Business Strategy and the Environment 26(3), 288-305.

Feng, T., L. Cummings, and D. Tweedie (2017). Exploring integrated thinking in integrated reporting-an exploratory study in australia. Journal of Intellectual Capital.

Flower, J. (2015). The international integrated reporting council: A story of failure. Critical Perspectives on Accounting 27(Supplement C), 1-17.

Francis, J. and K. Schipper (1999). Have financial statements lost their relevance? Journal of accounting Research 37(2), 319-352.

Frias-Aceituno, J. V., L. Rodríguez-Ariza, and I. M. García-Sánchez (2013). Is integrated reporting determined by a country's legal system? an exploratory study. Journal of cleaner production 44, 45-55.

Frias-Aceituno, J. V., L. Rodriguez-Ariza, and I. M. Garcia-Sanchez (2013). The role of the board in the dissemination of integrated corporate social reporting. Corporate social responsibility and environmental management 20(4), 219-233.

Frias-Aceituno, J. V., L. Rodríguez-Ariza, and I. M. Garcia-Sánchez (2014). Explanatory factors of integrated sustainability and financial reporting. Business strategy and the environment 23(1), 56-72.

Fries, J., K. McCulloch, and W. Webster (2010). The prince's accounting for sustainability project: creating 21st-century decision-making and reporting systems to respond to 21 stcentury challenges and opportunities. In Accounting for Sustainability, pp. 53-69. Routledge.

Gibassier, D., M. Rodrigue, and D.-L. Arjaliès (2018). Integrated reporting is like god: no one has met him, but everybody talks about him. Accounting, Auditing \& Accountability Journal.

Gibrat, R. (1931). Les Inegalites economiq. Recueil Sirey.

Giovannoni, E. and M. P. Maraghini (2013). The challenges of integrated performance measurement systems. Accounting, Auditing \& Accountability Journal.

Green, W. J. and M. M. Cheng (2019). Materiality judgments in an integrated reporting setting: The effect of strategic relevance and strategy map. Accounting, Organizations and Society 73, 1-14.

GRI (2017). About gri.

Guthrie, J., J. Dumay, S. Veltri, and A. Silvestri (2015). The free state university integrated reporting: a critical consideration. Journal of Intellectual Capital.

Guthrie, J., F. Manes-Rossi, and R. L. Orelli (2017). Integrated reporting and integrated thinking in italian public sector organisations. Meditari Accountancy Research. 
Guthrie, J. and L. D. Parker (1989). Corporate social reporting: a rebuttal of legitimacy theory. Accounting and business research 19(76), 343-352.

Guthrie, J. and L. D. Parker (2012). Reflections and projections. Accounting, Auditing \& Accountability Journal.

Haji, A. A. and M. Anifowose (2016). The trend of integrated reporting practice in south africa: ceremonial or substantive? Sustainability Accounting, Management and Policy Journal.

Hassel, L., H. Nilsson, and S. Nyquist (2005). The value relevance of environmental performance. European Accounting Review 14(1), 41-61.

Holthausen, R. W. and R. L. Watts (2001). The relevance of the value-relevance literature for financial accounting standard setting. Journal of Accounting and Economics 31(1), 3-75.

Hopwood, A. G., J. Unerman, and J. Fries (2010). Accounting for sustainability: Practical insights. Earthscan.

Horton, J., G. Serafeim, and I. Serafeim (2013). Does mandatory ifrs adoption improve the information environment?*. Contemporary Accounting Research 30(1), 388-423.

IASPLUS (2017). International Integrated Reporting Council (IIRC). https://www.iasplus. com/en/resources/sustainability/iirc\#ir-history [Accessed: 27 October 2017].

IIRC (2013). The international ir framework. retrieved from: http://integratedreporting.org/wp-content/uploads/2013/12/13-12-08-THEINTERNATIONAL-IR-FRAMEWORK-2-1.pdf.

IIRC (2014). Strategy: The Breakthrough Phase 2014-17. http://integratedreporting.org/ wp-content/uploads/2015/02/IIRC-Strategy-Summary-2015.pdf [Accessed: 15 September 2017].

IIRC (2017). IIRC Website. http://integratedreporting.org/the-iirc-2/ [Accessed: 15 September 2017].

IIRC (2020). IIRC Database. https://integratedreporting.org/integrated-reporting-database/ [Accessed: 6 October 2017].

IMF (2020). World economic outlook databases.

Jensen, J. C. and N. Berg (2012). Determinants of traditional sustainability reporting versus integrated reporting. an institutionalist approach. Business Strategy and the Environment 21(5), 299-316.

Kannenberg, L. and P. Schreck (2019). Integrated reporting: boon or bane? a review of empirical research on its determinants and implications. Journal of Business Economics 89(5), 515-567.

Kaplan, R. S. and D. P. Norton (1996). Using the balanced scorecard as a strategic management system.

Kaplan, R. S. and D. P. Norton (2001). Transforming the balanced scorecard from performance measurement to strategic management: Part i. Accounting horizons 15(1), 87-104.

Kılıç, M. and C. Kuzey (2018). Determinants of forward-looking disclosures in integrated reporting. Managerial Auditing Journal.

Lai, A., G. Melloni, and R. Stacchezzini (2016). Corporate sustainable development: is 'integrated reporting'a legitimation strategy? Business Strategy and the Environment 25(3), $165-177$.

Laine, M. (2014). Towards a legitimate compromise? an exploration of integrated reporting in the netherlands. Social and Environmental Accountability Journal 34(3), 188-189.

Landau, A., J. Rochell, C. Klein, and B. Zwergel (2020). Integrated reporting of environmental, social, and governance and financial data: Does the market value integrated reports? Business Strategy and the Environment 29(4), 1750-1763. 
Lang, M., J. S. Raedy, and M. H. Yetman (2003). How representative are firms that are crosslisted in the united states? an analysis of accounting quality. Journal of Accounting Research 41(2), 363-386.

Lang, M., J. Smith Raedy, and W. Wilson (2006). Earnings management and cross listing: Are reconciled earnings comparable to us earnings? Journal of Accounting and Economics 42(1-2), 255-283.

Leary, M. R. and R. M. Kowalski (1990). Impression management: A literature review and two-component model. Psychological bulletin 107(1), 34.

Lee, K.-W. and G. H.-H. Yeo (2016). The association between integrated reporting and firm valuation. Review of Quantitative Finance and Accounting 47(4), 1221-1250.

Lev, B. and T. Sougiannis (1996). The capitalization, amortization, and value-relevance of r\&d. Journal of accounting and economics 21(1), 107-138.

Lodhia, S. (2015). Exploring the transition to integrated reporting through a practice lens: an australian customer owned bank perspective. Journal of Business Ethics 129(3), 585-598.

Lubberink, M. J. P. and R. J. Willett (2017). The value relevance of regulatory capital components. SSRN: https://ssrn.com/abstract $=2826359$.

Lubberink, M. J. P. and R. J. Willett (2020). The fundamental relation between firm market and accounting values is a multiplicative power law. Available at SSRN 3531319.

Maniora, J. (2017). Is integrated reporting really the superior mechanism for the integration of ethics into the core business model? an empirical analysis. Journal of Business Ethics 140(4), 755-786.

Massaro, M., J. Dumay, and J. Guthrie (2016). On the shoulders of giants: undertaking a structured literature review in accounting. Accounting, Auditing \& Accountability Journal.

Meckling, W. H. and M. C. Jensen (1976). Theory of the firm: Managerial behavior, agency costs and ownership structure. Journal of financial economics 3(4), 305-360.

Milne, M. J. and R. Gray (2013). W(h)ither ecology? the triple bottom line, the global reporting initiative, and corporate sustainability reporting. Journal of Business Ethics 118(1), 13-29.

Milne, M. J., H. Tregidga, and S. Walton (2009). Words not actions! the ideological role of sustainable development reporting. Accounting, Auditing \& Accountability Journal 22(8), 1211-1257.

Moses, O., F. Mohaimen, and M. Emmanuel (2020). A meta-review of seaj: The past and projections for 2020 and beyond. Social and Environmental Accountability Journal, 1-18.

Ohlson, J. A. (1995). Earnings, book values, and dividends in equity valuation. Contemporary accounting research 11(2), 661-687.

Owen, G. (2013). Integrated reporting: A review of developments and their implications for the accounting curriculum. Accounting Education 22(4), 340-356.

Penman, S. H. (1992). Return to fundamentals. Journal of Accounting, Auditing \& Finance 7(4), 465-483.

Reimsbach, D., R. Hahn, and A. Gürtürk (2018). Integrated reporting and assurance of sustainability information: An experimental study on professional investors' information processing. European Accounting Review 27(3), 559-581.

Rensburg, R. and E. Botha (2014). Is integrated reporting the silver bullet of financial communication? a stakeholder perspective from south africa. Public Relations Review 40(2), 144-152.

Sofian, I. and M. Dumitru (2017). The compliance of the integrated reports issued by european financial companies with the international integrated reporting framework. Sustainability 9(8), 1319. 
Song, C. J., W. B. Thomas, and H. Yi (2010). Value relevance of fas no. 157 fair value hierarchy information and the impact of corporate governance mechanisms. The Accounting Review 85(4), 1375-1410.

Stent, W. and T. Dowler (2015). Early assessments of the gap between integrated reporting and current corporate reporting. Meditari Accountancy Research.

STOXX (2020). STOXX Index. https://www.stoxx.com/ [Accessed: 6 May 2020].

Stubbs, W. and C. Higgins (2014). Integrated reporting and internal mechanisms of change. Accounting, Auditing and Accountability Journal 27(7), 1068-1089.

Stubbs, W. and C. Higgins (2018). Stakeholders' perspectives on the role of regulatory reform in integrated reporting. Journal of Business Ethics 147(3), 489-508.

Wang, R., S. Zhou, and T. Wang (2019). Corporate governance, integrated reporting and the use of credibility-enhancing mechanisms on integrated reports. European Accounting Review, $1-33$.

Zeng, Y., E. Lee, and J. Zhang (2016). Value relevance of alleged corporate bribery expenditures implied by accounting information. Journal of Accounting and Public Policy 35(6), 592-608.

Zhou, S., R. Simnett, and W. Green (2017). Does integrated reporting matter to the capital market? Abacus 53(94-132). 


\section{Appendices}




\section{Reference of papers used in meta review}

Abeysekera, I. (2013). A template for integrated reporting. Journal of Intellectual Capital.

Abhayawansa, S., E. Elijido-Ten, and J. Dumay (2019). A practice theoretical analysis of the irrelevance of integrated reporting to mainstream sell-side analysts. Accounting \& Finance 59(3), 1615-1647.

Adams, C. A. (2015). The international integrated reporting council: a call to action. Critical Perspectives on Accounting 27, 23-28.

Adams, C. A., B. Potter, P. J. Singh, and J. York (2016). Exploring the implications of integrated reporting for social investment (disclosures). The British Accounting Review 48(3), 283-296.

Adams, S. and R. Simnett (2011). Integrated reporting: An opportunity for australia's not-forprofit sector. Australian Accounting Review 21(3), 292-301.

Adhariani, D. and C. De Villiers (2019). Integrated reporting: perspectives of corporate report preparers and other stakeholders. Sustainability Accounting, Management and Policy Journal.

Al-Htaybat, K. and L. von Alberti-Alhtaybat (2018). Integrated thinking leading to integrated reporting: case study insights from a global player. Accounting, Auditing \& Accountability Journal.

Albertini, E. (2019). Integrated reporting: an exploratory study of french companies. Journal of Management and Governance 23(2), 513-535.

Albetairi, H. T. A., G. Kukreja, and A. Hamdan (2018). Integrated reporting and financial performance: Empirical evidences from bahraini listed insurance companies. Accounting and Finance Research 7(3), 102-110.

Alexander, D. and V. Blum (2016). Ecological economics: A luhmannian analysis of integrated reporting. Ecological Economics 129, 241-251.

Aluchna, M. and M. Roszkowska-Menkes (2019). Early adopters of integrated reporting: The practical evidence from warsaw stock exchange companies. In Integrated Reporting, pp. 319-340. Springer.

Argento, D., F. Culasso, and E. Truant (2019). From sustainability to integrated reporting: The legitimizing role of the csr manager. Organization \& Environment 32(4), 484-507.

Atkins, J. and W. Maroun (2015). Integrated reporting in south africa in 2012. Meditari Accountancy Research.

Baboukardos, D. and G. Rimmel (2016). Value relevance of accounting information under an integrated reporting approach: A research note. Journal of Accounting and Public Policy 35(4), 437-452.

Badia, F., G. Dicuonzo, S. Petruzzelli, and V. Dell'Atti (2019). Integrated reporting in action: mobilizing intellectual capital to improve management and governance practices. Journal of Management and Governance 23(2), 299-320.

Baldarelli, M.-G. (2019). Integrated reporting, integrated thinking and gaming companies: Myths and paradoxes. In Integrated Reporting, pp. 185-197. Springer.

Bananuka, J., Z. Tumwebaze, and L. Orobia (2019). The adoption of integrated reporting: a developing country perspective. Journal of Financial Reporting and Accounting.

Barth, M. E., S. F. Cahan, L. Chen, and E. R. Venter (2017). The economic consequences associated with integrated report quality: Capital market and real effects. Accounting, Organizations and Society 62, 43-64. 
Beattie, V. and S. J. Smith (2013). Value creation and business models: refocusing the intellectual capital debate. The British Accounting Review 45(4), 243-254.

Beck, C., J. Dumay, and G. Frost (2017). In pursuit of a 'single source of truth': from threatened legitimacy to integrated reporting. Journal of Business Ethics 141(1), 191-205.

Beretta, V., C. Demartini, and S. Trucco (2019). Does environmental, social and governance performance influence intellectual capital disclosure tone in integrated reporting? Journal of Intellectual Capital.

Bernardi, C. and A. W. Stark (2018). Environmental, social and governance disclosure, integrated reporting, and the accuracy of analyst forecasts. The British Accounting Review 50(1), $16-31$.

Biondi, L. and E. Bracci (2018). Sustainability, popular and integrated reporting in the public sector: a fad and fashion perspective. Sustainability 10(9), 3112.

Bommel, K. V. (2014). Towards a legitimate compromise?: An exploration of integrated reporting in the netherlands. Accounting, Auditing \& Accountability Journal 27(7), 1157-1189.

Briem, C. R. and A. Wald (2018). Implementing third-party assurance in integrated reporting. Accounting, Auditing \& Accountability Journal.

Brown, D., J. F. Dillard, and S. Marshall (2006). Triple bottom line: a business metaphor for a social construct.

Brusca, I., M. Labrador, and M. Larran (2018). The challenge of sustainability and integrated reporting at universities: A case study. Journal of Cleaner Production 188, 347-354.

Buitendag, N., G. S. Fortuin, and A. De Laan (2017). Firm characteristics and excellence in integrated reporting. South African Journal of Economic and Management Sciences 20(1), $1-8$.

Burcă, V., D. Mateş, and O. C. Bunget (2018). Empirical research on identifying main drivers leading to integrated reporting framework implementation. the case of european region. Romanian Economic Journal (70).

Burke, J. J. and C. E. Clark (2016). The business case for integrated reporting: Insights from leading practitioners, regulators, and academics. Business Horizons 59(3), 273-283.

Burlea, A. S. (2019). The impact of triple bottom dispersal of actions on integrated reporting: A critical perspective. In Integrated Reporting, pp. 141-152. Springer.

Camilleri, M. A. (2017). The integrated reporting of financial, social and sustainability capitals: a critical review and appraisal. International Journal of Sustainable Society 9(4), 311-326.

Camilleri, M. A. (2018). Theoretical insights on integrated reporting. Corporate Communications: An International Journal.

Camilleri, M. A. (2019). Theoretical insights on integrated reporting: Valuing the financial, social and sustainability disclosures. In Integrated Reporting, pp. 61-76. Springer.

Camodeca, R. and A. Almici (2017). Implementing integrated reporting: case studies from the italian listed companies. Accounting and Finance Research 6(2), 121-135.

Camodeca, R., A. Almici, and U. Sagliaschi (2018). Sustainability disclosure in integrated reporting: Does it matter to investors? a cheap talk approach. Sustainability 10(12), 4393.

Camodeca, R., A. Almici, and U. Sagliaschi (2019). Strategic information disclosure, integrated reporting and the role of intellectual capital. Journal of Intellectual Capital.

Casonato, F., F. Farneti, and J. Dumay (2019a). From sustainability to integrated reporting: How the iirc framework affected disclosures by a financial institution in australia. In Integrated Reporting, pp. 125-140. Springer. 
Casonato, F., F. Farneti, and J. Dumay (2019b). Social capital and integrated reporting: Losing legitimacy when reporting talk is not supported by actions. Journal of Intellectual Capital 20(1), 144-164.

Chaidali, P. P. and M. J. Jones (2017). It'sa matter of trust: Exploring the perceptions of integrated reporting preparers. Critical Perspectives on Accounting 48, 1-20.

Cheng, M., W. Green, P. Conradie, N. Konishi, and A. Romi (2014). The international integrated reporting framework: key issues and future research opportunities. Journal of International Financial Management \& Accounting 25(1), 90-119.

CHERSAN, I.-C. (2015). Study on practices and tendencies in integrated reporting. Audit Financiar 13(129).

Chiucchi, M. S., M. Montemari, and M. Gatti (2018). The influence of integrated reporting on management control systems: A case study. International Journal of Business and Management 13(7), 19-32.

Churet, C. and R. G. Eccles (2014). Integrated reporting, quality of management, and financial performance. Journal of Applied Corporate Finance 26(1), 56-64.

Clayton, A. F., J. M. Rogerson, and I. Rampedi (2015). Integrated reporting vs. sustainability reporting for corporate responsibility in south africa. Bulletin of Geography. Socio-economic series 29(29), 7-17.

Corbella, S., C. Florio, A. F. Sproviero, and R. Stacchezzini (2019). Integrated reporting and the performativity of intellectual capital. Journal of Management and Governance 23(2), 459-483.

Corrado, M., P. Demartini, and J. Dumay (2019). Assurance on integrated reporting: a critical perspective. In Integrated Reporting, pp. 199-217. Springer.

Cortesi, A. and L. Vena (2019). Disclosure quality under integrated reporting: a value relevance approach. Journal of cleaner production 220, 745-755.

de Graaff, B., B. Steens, and K. Camfferman (2019). Integrated reporting: Much ado about nothing? Available at SSRN 3382322.

De Villiers, C., P.-C. K. Hsiao, and W. Maroun (2017). Developing a conceptual model of influences around integrated reporting, new insights and directions for future research. Meditari Accountancy Research.

De Villiers, C. and U. Sharma (2017). A critical reflection on the future of financial, intellectual capital, sustainability and integrated reporting. Critical Perspectives on Accounting, 101999.

De Villiers, C., J. Unerman, and L. Rinaldi (2014). Integrated reporting: Insights, gaps and an agenda for future research. Accounting, Auditing \& Accountability Journal.

de Villiers, C., J. Unerman, L. Rinaldi, A. Haller, and C. van Staden (2014). The value added statement-an appropriate instrument for integrated reporting. Accounting, Auditing \& Accountability Journal.

De Villiers, C., E. R. Venter, and P.-C. K. Hsiao (2017). Integrated reporting: background, measurement issues, approaches and an agenda for future research. Accounting \& Finance 57(4), 937-959.

Del Baldo, M. (2015). Is it time for integrated reporting in small and medium-sized enterprises? reflections on an italian experience. In Corporate Social Responsibility and Governance, pp. 183-209. Springer.

Del Baldo, M. (2017). The implementation of integrating reporting $; \mathrm{ir}_{\boldsymbol{i}}$ in smes. Meditari Accountancy Research.

Del Baldo, M. (2019). Small and medium-sized organisations: Why and how do they implement integrated reporting? In Integrated Reporting, pp. 95-121. Springer. 
Doni, F., M. Larsen, S. B. Martini, and A. Corvino (2019). Exploring integrated reporting in the banking industry: the multiple capitals approach. Journal of Intellectual Capital.

Dragu, I. (2019). The evolution of corporate sustainability and corporate social responsibility towards the common goal of integrated reporting. In Integrated Reporting, pp. 77-93. Springer.

Dragu, I.-M. and A. Tiron-Tudor (2013). The integrated reporting initiative from an institutional perspective: emergent factors. Procedia-Social and Behavioral Sciences 92, 275-279.

Du Toit, E. (2017). The readability of integrated reports. Meditari Accountancy Research.

Du Toit, E., R. Van Zyl, and G. Schütte (2017). Integrated reporting by south african companies: a case study. Meditari Accountancy Research.

Dumay, J., C. Bernardi, J. Guthrie, and P. Demartini (2016). Integrated reporting: A structured literature review. In Accounting Forum, Volume 40, pp. 166-185. Taylor \& Francis.

Dumay, J., C. Bernardi, J. Guthrie, and M. La Torre (2017). Barriers to implementing the international integrated reporting framework: A contemporary academic perspective. Meditari Accountancy Research 25(4), 461-480.

Dumay, J. and T. Dai (2017). Integrated thinking as a cultural control? Meditari Accountancy Research.

Eccles, R. G., M. P. Krzus, and S. Ribot (2015a). Meaning and momentum in the integrated reporting movement. Journal of Applied Corporate Finance 27(2), 8-17.

Eccles, R. G., M. P. Krzus, and S. Ribot (2015b). Models of best practice in integrated reporting 2015. Journal of Applied Corporate Finance 27(2), 103-115.

Eccles, R. G. and D. Saltzman (2011). Achieving sustainability through integrated reporting. Stanford Social Innovation Review 9(3), 56-61.

Engelbrecht, L., Y. Yasseen, and I. Omarjee (2018). The role of the internal audit function in integrated reporting: A developing economy perspective. Meditari Accountancy Research.

Esch, M., B. Schnellbächer, and A. Wald (2019). Does integrated reporting information influence internal decision making? an experimental study of investment behavior. Business Strategy and the Environment 28(4), 599-610.

Fasan, M. and C. Mio (2017). Fostering stakeholder engagement: The role of materiality disclosure in integrated reporting. Business Strategy and the Environment 26(3), 288-305.

Feng, T., L. Cummings, and D. Tweedie (2017). Exploring integrated thinking in integrated reporting-an exploratory study in australia. Journal of Intellectual Capital.

Flower, J. (2015). The international integrated reporting council: a story of failure. Critical Perspectives on Accounting 27, 1-17.

Frias-Aceituno, J. V., L. Rodríguez-Ariza, and I. M. García-Sánchez (2013). Is integrated reporting determined by a country's legal system? an exploratory study. Journal of cleaner production 44, 45-55.

Frias-Aceituno, J. V., L. Rodriguez-Ariza, and I. M. Garcia-Sanchez (2013). The role of the board in the dissemination of integrated corporate social reporting. Corporate social responsibility and environmental management 20(4), 219-233.

Frias-Aceituno, J. V., L. Rodríguez-Ariza, and I. M. Garcia-Sánchez (2014). Explanatory factors of integrated sustainability and financial reporting. Business strategy and the environment 23(1), 56-72.

García-Sánchez, I.-M., J. Martínez-Ferrero, and M.-A. Garcia-Benau (2019). Integrated reporting: The mediating role of the board of directors and investor protection on managerial discretion in munificent environments. Corporate Social Responsibility and Environmental Management 26(1), 29-45. 
García-Sánchez, I.-M. and L. Noguera-Gámez (2017). Integrated reporting and stakeholder engagement: The effect on information asymmetry. Corporate Social Responsibility and Environmental Management 24(5), 395-413.

García-Sánchez, I.-M. and L. Noguera-Gámez (2018). Institutional investor protection pressures versus firm incentives in the disclosure of integrated reporting. Australian Accounting Review 28(2), 199-219.

García-Sánchez, I.-M., L. Rodríguez-Ariza, and J.-V. Frías-Aceituno (2013). The cultural system and integrated reporting. International business review 22(5), 828-838.

Gatti, M., M. S. Chiucchi, and M. Montemari (2018). Management control systems and integrated reporting: Which relationships? the case of the azienda ospedaliero universitaria ospedali riuniti ancona. International Journal of Business and Management 13(9), 169-181.

Gelmini, L. (2017). Islamic banks: Sustainability, integrated reporting and religion. Corporate Governance and Sustainability Review, 1 (2), 35-42.

Gerwanski, J., O. Kordsachia, and P. Velte (2019). Determinants of materiality disclosure quality in integrated reporting: Empirical evidence from an international setting. Business Strategy and the Environment 28(5), 750-770.

Ghani, E. K., J. Jamal, E. Puspitasari, and A. Gunardi (2018). Factors influencing integrated reporting practices among malaysian public listed real property companies: a sustainable development effort. International Journal of Managerial and Financial Accounting 10(2), 144-162.

Ghosh, S. (2019). Integrated reporting in india: Research findings and insights. In Integrated Reporting, pp. 365-386. Springer.

Gianfelici, C., A. Casadei, and F. Cembali (2018). The relevance of nationality and industry for stakeholder salience: An investigation through integrated reports. Journal of Business Ethics 150(2), 541-558.

Gibassier, D., M. Rodrigue, and D.-L. Arjaliès (2018). Integrated reporting is like god: no one has met him, but everybody talks about him. Accounting, Auditing \& Accountability Journal.

Girella, L., P. Rossi, and S. Zambon (2019). Exploring the firm and country determinants of the voluntary adoption of integrated reporting. Business Strategy and the Environment 28(7), 1323-1340.

Goicoechea, E., F. Gómez-Bezares, and J. V. Ugarte (2019). Integrated reporting assurance: Perceptions of auditors and users in spain. Sustainability 11(3), 713.

Green, W. J. and M. M. Cheng (2019). Materiality judgments in an integrated reporting setting: The effect of strategic relevance and strategy map. Accounting, Organizations and Society 73, 1-14.

Gunarathne, A. N. and S. Senaratne (2018). Country readiness in adopting integrated reporting: a diamond theory approach from an asian pacific economy. In Accounting for Sustainability: Asia Pacific Perspectives, pp. 39-66. Springer.

Gunarathne, N. and S. Senaratne (2017). Diffusion of integrated reporting in an emerging south asian (saarc) nation. Managerial Auditing Journal.

Guthrie, J., J. Dumay, S. Veltri, and A. Silvestri (2015). The free state university integrated reporting: a critical consideration. Journal of Intellectual Capital.

Guthrie, J., F. Manes-Rossi, and R. L. Orelli (2017). Integrated reporting and integrated thinking in italian public sector organisations. Meditari Accountancy Research.

Haji, A. A. and M. Anifowose (2016a). Audit committee and integrated reporting practice: does internal assurance matter? Managerial Auditing Journal. 
Haji, A. A. and M. Anifowose (2016b). The trend of integrated reporting practice in south africa: ceremonial or substantive? Sustainability Accounting, Management and Policy Journal.

Haji, A. A. and M. Anifowose (2017). Initial trends in corporate disclosures following the introduction of integrated reporting practice in south africa. Journal of Intellectual Capital.

Haji, A. A. and D. M. Hossain (2016). Exploring the implications of integrated reporting on organisational reporting practice. Qualitative Research in Accounting \& Management.

Hassan, A., M. Adhikariparajuli, M. Fletcher, and A. Elamer (2019). Integrated reporting in uk higher education institutions. Sustainability Accounting, Management and Policy Journal.

Havlová, K. (2015). What integrated reporting changed: the case study of early adopters. Procedia Economics and Finance 34, 231-237.

Higgins, C., W. Stubbs, and T. Love (2014). Walking the talk (s): Organisational narratives of integrated reporting. Accounting, Auditing \& Accountability Journal 27(7), 1090-1119.

Higgins, C., W. Stubbs, D. Tweedie, and G. McCallum (2019). Journey or toolbox? integrated reporting and processes of organisational change. Accounting, Auditing \& Accountability Journal.

Hsiao, P.-C. K. and M. Kelly (2018). Investment considerations and impressions of integrated reporting. Sustainability Accounting, Management and Policy Journal.

Ioana, D. and T.-T. Adriana (2014). Research agenda on integrated reporting: new emergent theory and practice. Procedia Economics and Finance 15(14), 221-227.

Islam, R. and M. R. Islam (2018). Insights the practice of integrated reporting: A study on mncs in bangladesh on the degree of adherence to the reporting framework. Open Journal of Business and Management 6(3), 733-748.

Jensen, J. C. and N. Berg (2012). Determinants of traditional sustainability reporting versus integrated reporting. an institutionalist approach. Business Strategy and the Environment 21(5), 299-316.

Kannenberg, L. and P. Schreck (2019). Integrated reporting: boon or bane? a review of empirical research on its determinants and implications. Journal of Business Economics 89(5), $515-567$.

Kilıç, M. and C. Kuzey (2018a). Assessing current company reports according to the iirc integrated reporting framework. Meditari Accountancy Research.

Kılıç, M. and C. Kuzey (2018b). Determinants of forward-looking disclosures in integrated reporting. Managerial Auditing Journal.

Kim, S.-I., H. Shin, H. Shin, and S. Park (2019). Organizational slack, corporate social responsibility, sustainability, and integrated reporting: Evidence from korea. Sustainability 11(16), 4445.

La Torre, M., C. Bernardi, J. Guthrie, and J. Dumay (2019). Integrated reporting and integrating thinking: Practical challenges. In Challenges in Managing Sustainable Business, pp. 25-54. Springer.

Lai, A., G. Melloni, and R. Stacchezzini (2016). Corporate sustainable development: is 'integrated reporting'a legitimation strategy? Business Strategy and the Environment 25(3), $165-177$.

Lai, A., G. Melloni, and R. Stacchezzini (2017). What does materiality mean to integrated reporting preparers? an empirical exploration. Meditari Accountancy Research.

Lai, A., G. Melloni, and R. Stacchezzini (2018). Integrated reporting and narrative accountability: The role of preparers. Accounting, Auditing \& Accountability Journal. 
Lee, K.-W. and G. H.-H. Yeo (2016). The association between integrated reporting and firm valuation. Review of Quantitative Finance and Accounting 47(4), 1221-1250.

Lipunga, A. M. (2015). Integrated reporting in developing countries: Evidence from malawi. Journal of Management Research 7(3), 130-156.

Liu, Z., C. Jubb, and S. Abhayawansa (2019). Analysing and evaluating integrated reporting. Journal of Intellectual Capital.

Lodhia, S. (2015). Exploring the transition to integrated reporting through a practice lens: an australian customer owned bank perspective. Journal of Business Ethics 129(3), 585-598.

Lodhia, S. and G. Stone (2017). Integrated reporting in an internet and social media communication environment: conceptual insights. Australian Accounting Review 27(1), 17-33.

Lopes, A. I. and A. M. Coelho (2018). Engaged in integrated reporting? evidence across multiple organizations. European Business Review.

Loprevite, S., B. Ricca, and D. Rupo (2018). Performance sustainability and integrated reporting: Empirical evidence from mandatory and voluntary adoption contexts. Sustainability 10(5), 1351.

Loprevite, S., D. Rupo, and B. Ricca (2018). Integrated reporting practices in europe and value relevance of accounting information under the framework of iirc. International Journal of Business and Management 13(5), 1-12.

Lueg, K., R. Lueg, K. Andersen, and V. Dancianu (2016). Integrated reporting with csr practices. Corporate Communications: An International Journal.

Macias, H. A. and A. Farfan-Lievano (2017). Integrated reporting as a strategy for firm growth: multiple case study in colombia. Meditari Accountancy Research.

Makiwane, T. S. and N. Padia (2013). Evaluation of corporate integrated reporting in south africa post king iii release south africa-an exploratory enquiry. Journal of Economic and Financial Sciences 6(2), 421-438.

Malola, A. and W. Maroun (2019). The measurement and potential drivers of integrated report quality: Evidence from a pioneer in integrated reporting. South African Journal of Accounting Research 33(2), 114-144.

Manes-Rossi, F. (2018). Is integrated reporting a new challenge for public sector entities. African Journal of Business Management 12(7), 172-187.

Maniora, J. (2017). Is integrated reporting really the superior mechanism for the integration of ethics into the core business model? an empirical analysis. Journal of Business Ethics 140(4), $755-786$.

Maroun, W. (2018). Modifying assurance practices to meet the needs of integrated reporting. Accounting, Auditing \& Accountability Journal.

Massingham, R., P. R. Massingham, and J. Dumay (2019). Improving integrated reporting. Journal of Intellectual Capital.

Matemane, R. and R. Wentzel (2019). Integrated reporting and financial performance of south african listed banks. Banks and Bank Systems 14(2), 128-139.

McNally, M.-A., D. Cerbone, and W. Maroun (2017). Exploring the challenges of preparing an integrated report. Meditari Accountancy Research.

Melloni, G., A. Caglio, and P. Perego (2017). Saying more with less? disclosure conciseness, completeness and balance in integrated reports. Journal of Accounting and Public Policy 36(3), 220-238.

Menicucci, E. (2018). Exploring forward-looking information in integrated reporting. Journal of Applied Accounting Research. 
Mervelskemper, L. and D. Streit (2017). Enhancing market valuation of esg performance: Is integrated reporting keeping its promise? Business Strategy and the Environment 26(4), 536-549.

Mio, C., F. Marco, and R. Pauluzzo (2016). Internal application of ir principles: Generali's internal integrated reporting. Journal of Cleaner Production 139, 204-218.

Montecalvo, M., F. Farneti, and C. De Villiers (2018). The potential of integrated reporting to enhance sustainability reporting in the public sector. Public Money \& Management 38(5), $365-374$.

Morros, J. (2016). The integrated reporting: A presentation of the current state of art and aspects of integrated reporting that need further development. Intangible Capital 12(1), 336-356.

Nakib, M., P. K. Dey, et al. (2018). The journey towards integrated reporting in bangladesh. Asian Economic and Financial Review 8(7), 894-913.

Naynar, N. R., A. J. Ram, and W. Maroun (2018). Expectation gap between preparers and stakeholders in integrated reporting. Meditari Accountancy Research.

Ofoegbu, G. N., N. Odoemelam, and R. G. Okafor (2018). Corporate board characteristics and environmental disclosure quantity: Evidence from south africa (integrated reporting) and nigeria (traditional reporting). Cogent Business \& Management 5(1), 1551510.

Oll, J. and S. Rommerskirchen (2018). What's wrong with integrated reporting? a systematic review. In NachhaltigkeitsManagementForum - Sustainability Management Forum, Volume 26, pp. 19-34. Springer.

Oshika, T. and C. Saka (2017). Sustainability kpis for integrated reporting. Social Responsibility Journal.

Owen, G. (2013). Integrated reporting: A review of developments and their implications for the accounting curriculum. Accounting Education 22(4), 340-356.

Parrot, K. W. and B. X. Tierney (2012). Integrated reporting, stakeholder engagement, and balanced investing at american electric power. Journal of Applied Corporate Finance 24(2), 27-37.

Pavlopoulos, A., C. Magnis, and G. E. Iatridis (2017). Integrated reporting: Is it the last piece of the accounting disclosure puzzle? Journal of Multinational Financial Management 41, 23-46.

Pavlopoulos, A., C. Magnis, and G. E. Iatridis (2019). Integrated reporting: An accounting disclosure tool for high quality financial reporting. Research in International Business and Finance 49, 13-40.

Perego, P., S. Kennedy, and G. Whiteman (2016). A lot of icing but little cake? taking integrated reporting forward. Journal of cleaner production 136, 53-64.

Pistoni, A., L. Songini, and F. Bavagnoli (2018). Integrated reporting quality: An empirical analysis. Corporate Social Responsibility and Environmental Management 25(4), 489-507.

Rambaud, A. and J. Richard (2015). The "triple depreciation line" instead of the "triple bottom line": towards a genuine integrated reporting. Critical Perspectives on Accounting 33, 92116.

Reimsbach, D., R. Hahn, and A. Gürtürk (2018). Integrated reporting and assurance of sustainability information: An experimental study on professional investors' information processing. European Accounting Review 27(3), 559-581.

Rensburg, R. and E. Botha (2014). Is integrated reporting the silver bullet of financial communication? a stakeholder perspective from south africa. Public Relations Review 40(2), $144-152$. 
Reuter, M. and M. Messner (2015). Lobbying on the integrated reporting framework. Accounting, Auditing \& Accountability Journal.

Rinaldi, L., J. Unerman, and C. De Villiers (2018). Evaluating the integrated reporting journey: insights, gaps and agendas for future research. Accounting, Auditing \& Accountability Journal.

Rivera-Arrubla, Y. A. and A. Zorio-Grima (2016). Integrated reporting, connectivity, and social media. Psychology \& Marketing 33(12), 1159-1165.

Robertson, F. A. and M. Samy (2015). Factors affecting the diffusion of integrated reporting-a uk ftse 100 perspective. Sustainability Accounting, Management and Policy Journal.

Ruiz-Lozano, M. and P. Tirado-Valencia (2016). Do industrial companies respond to the guiding principles of the integrated reporting framework? a preliminary study on the first companies joined to the initiative. Revista de Contabilidad 19(2), 252-260.

Rupley, K. H., D. Brown, and S. Marshall (2017). Evolution of corporate reporting: From stand-alone corporate social responsibility reporting to integrated reporting. Research in Accounting Regulation 29(2), 172-176.

Santis, S., M. Bianchi, A. Incollingo, and M. Bisogno (2019). Disclosure of intellectual capital components in integrated reporting: An empirical analysis. Sustainability 11(1), 62.

Shoaf, V., E. K. Jermakowicz, and B. J. Epstein (2018). Toward sustainability and integrated reporting. Review of Business 38(1).

Silvestri, A., S. Veltri, A. Venturelli, and S. Petruzzelli (2017). A research template to evaluate the degree of accountability of integrated reporting: a case study. Meditari Accountancy Research.

Simnett, R. and A. L. Huggins (2015). Integrated reporting and assurance: where can research add value? Sustainability Accounting, Management and Policy Journal.

Slack, R. and I. Tsalavoutas (2018). Integrated reporting decision usefulness: Mainstream equity market views. In Accounting forum, Volume 42, pp. 184-198. Taylor \& Francis.

Sofian, I. and M. Dumitru (2017). The compliance of the integrated reports issued by european financial companies with the international integrated reporting framework. Sustainability 9(8), 1319.

Soyka, P. A. (2013). The international integrated reporting council (iirc) integrated reporting framework: Toward better sustainability reporting and (way) beyond. Environmental Quality Management 23(2), 1-14.

Speziale, M.-T. (2019). Theoretical perspectives on purposes and users of integrated reporting: A literature review. In Integrated Reporting, pp. 13-60. Springer.

Stacchezzini, R., C. Florio, A. F. Sproviero, and S. Corbella (2019). An intellectual capital ontology in an integrated reporting context. Journal of Intellectual Capital.

Stacchezzini, R., G. Melloni, and A. Lai (2016). Sustainability management and reporting: the role of integrated reporting for communicating corporate sustainability management. Journal of Cleaner Production 136, 102-110.

Stent, W. and T. Dowler (2015). Early assessments of the gap between integrated reporting and current corporate reporting. Meditari Accountancy Research.

Steyn, M. (2014). Organisational benefits and implementation challenges of mandatory integrated reporting. Sustainability Accounting, Management and Policy Journal.

Strong, P. T. (2015). Is integrated reporting a matter of public concern? evidence from australia. Journal of Corporate Citizenship (60), 81-100.

Stubbs, W. and C. Higgins (2014). Integrated reporting and internal mechanisms of change. Accounting, Auditing \& Accountability Journal 27(7), 1068-1089. 
Stubbs, W. and C. Higgins (2018). Stakeholders' perspectives on the role of regulatory reform in integrated reporting. Journal of Business Ethics 147(3), 489-508.

Sukhari, A. and C. De Villiers (2019). The influence of integrated reporting on business model and strategy disclosures. Australian Accounting Review 29(4), 708-725.

Surty, M., Y. Yasseen, and N. Padia (2018). Trends in integrated reporting: a state-owned company analysis. Southern African Business Review 22(1).

Terblanche, W. and C. De Villiers (2019). The influence of integrated reporting and internationalisation on intellectual capital disclosures. Journal of Intellectual Capital.

Thomson, I. (2015). 'but does sustainability need capitalism or an integrated report'a commentary on 'the international integrated reporting council: A story of failure' by flower, $\mathrm{j}$. Critical Perspectives on Accounting 27, 18-22.

Tiron-Tudor, A., T. Oprisor, and G. Zanellato (2019). The mimicry of integrated reporting: An analysis of the principles-based approach. In Integrated Reporting, pp. 153-168. Springer.

Trébucq, S. and E. Magnaghi (2017). Using the efqm excellence model for integrated reporting: A qualitative exploration and evaluation. Research in International Business and Finance 42, 522-531.

Tweedie, D. and N. Martinov-Bennie (2015). Entitlements and time: integrated reporting's double-edged agenda. Social and Environmental Accountability Journal 35(1), 49-61.

Tweedie, D., C. Nielsen, and N. Martinov-Bennie (2018). The business model in integrated reporting: Evaluating concept and application. Australian Accounting Review 28(3), 405420.

Umoren, A. O., E. J. Udo, and B. S. George (2015). Environmental, social and governance disclosures: A call for integrated reporting in nigeria. Journal of Finance and Accounting 3(6), 227-233.

Vaz, N., B. Fernandez-Feijoo, and S. Ruiz (2016). Integrated reporting: an international overview. Business Ethics: A European Review 25(4), 577-591.

Velte, P. and M. Stawinoga (2017). Integrated reporting: The current state of empirical research, limitations and future research implications. Journal of Management Control 28(3), 275320.

Vesty, G., C. Ren, and S. Ji (2018). Integrated reporting as a test of worth: A conversation with the chairman of an integrated reporting pilot organisation. Accounting, Auditing and Accountability Journal 31(5), 1406-1434.

Vitolla, F. and N. Raimo (2018). Adoption of integrated reporting: Reasons and benefits-a case study analysis. International Journal of Business and Management 13(12), 244-250.

Vitolla, F., N. Raimo, and E. De Nuccio (2018). Integrated reporting: Development and state of art-the italian case in the international context. International Journal of Business and Management 13(11), 233-240.

Vitolla, F., N. Raimo, and M. Rubino (2019). Appreciations, criticisms, determinants, and effects of integrated reporting: A systematic literature review. Corporate Social Responsibility and Environmental Management 26(2), 518-528.

Vitolla, F., N. Raimo, M. Rubino, and A. Garzoni (2019a). How pressure from stakeholders affects integrated reporting quality. Corporate Social Responsibility and Environmental Management 26(6), 1591-1606.

Vitolla, F., N. Raimo, M. Rubino, and A. Garzoni (2019b). The impact of national culture on integrated reporting quality. a stakeholder theory approach. Business Strategy and the Environment 28(8), 1558-1571. 
Vitolla, F., A. Salvi, N. Raimo, F. Petruzzella, and M. Rubino (2020). The impact on the cost of equity capital in the effects of integrated reporting quality. Business Strategy and the Environment 29(2), 519-529.

Wachira, M. M., T. Berndt, and C. M. Romero (2019). The adoption of international sustainability and integrated reporting guidelines within a mandatory reporting framework: lessons from south africa. Social Responsibility Journal.

Wang, R., S. Zhou, and T. Wang (2019). Corporate governance, integrated reporting and the use of credibility-enhancing mechanisms on integrated reports. European Accounting Review, $1-33$.

Warren, S., J. Davison, C. H. Cho, J. R. Phillips, A. M. Hageman, and D. M. Patten (2009). Media richness, user trust, and perceptions of corporate social responsibility. Accounting, Auditing \& Accountability Journal.

Zappettini, F. and J. Unerman (2016). 'mixing' and 'bending': The recontextualisation of discourses of sustainability in integrated reporting. Discourse \& Communication 10(5), 521542.

Zhou, S., R. Simnett, and W. Green (2017). Does integrated reporting matter to the capital market? Abacus 53(1), 94-132. 


\section{Link to published IR reports}

IIRC Database: https://integratedreporting.org/resource/emerging-integrated-reporting-database/ 